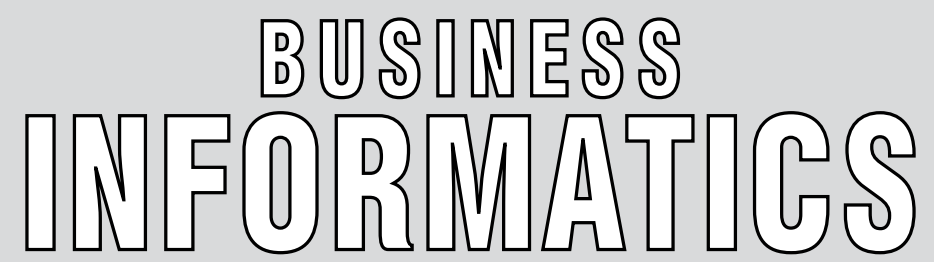

HSE SCIENTIFIC JOURNAL

\section{O N T E N T S}

\section{Data analysis and intelligence systems}

\section{E.I. Gribkov, Yu.P. Yekhlakov}

Neural network model for user request analysis during software operations and maintenance phase

\section{E.S. Prokofyeva, R.D. Zaytsev}

Clinical pathways analysis of patients in medical institutions based on hard and fuzzy clustering methods

\section{Information systems and technologies in business}

D.V. Pervoukhin, E.A. Isaev, G.O. Rytikov, E.K. Filyugina,D.A. Hayrapetyan

Theoretical comparative analysis of cascading, iterative, and hybrid approaches to IT project

life cycle management

\section{E. Agbozo, A.N. Medvedev}

Towards a Multi-Channel Service Delivery model in the data-driven public sector

\section{R.D. Gutgarts}

Practical aspects of project-based learning in the study of the discipline "Developing information systems"

\section{Modeling of social and economic systems}

\section{E.D. Kopnova, L.A. Rodionova}

Modeling globalization processes taking into account structural changes, using Algeria as an example

\section{M.B. Zuev, B.P. Zuev, I.N. Bulgakova}

The formation and development of the performance assessment method in the conception of operational management.

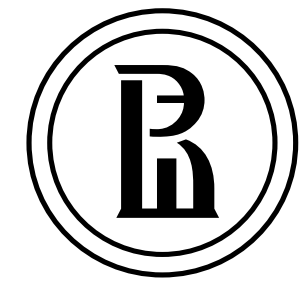

Publisher:

National Research University Higher School of Economics

Subscription index in the Rospechat catalog 80870

The journal is published quarterly

The journal is included into the list of peer reviewed scientific editions established by the Supreme Certification Commission of the Russian Federation

Editor-in-Chief: A. Golosov

Deputy Editor-in-Chief

S. Maltseva

Y. Koucheryavy

Computer Making-up:

O. Bogdanovich

Website Administration:

I. Khrustaleva

Address:

28/11, build. 4, Shablovka Street Moscow 119049, Russia

Tel./fax: +7 (495) 772-9590*26311

http://bijournal.hse.ru

E-mail: bijournal@hse.ru

\section{Circulation:}

English version - 300 copies,

Russian version -300 copies, online versions in English and Russian open access

Printed in HSE Printing House

3, Kochnovsky Proezd, Moscow, Russia

(C) National Research University Higher School of Economics 


\section{ABOUT \\ THE JOURNAL}

B usiness Informatics is a peer reviewed interdisciplinary academic journal published since 2007 by National Research University Higher School of Economics (HSE), Moscow, Russian Federation. The journal is administered by School of Business Informatics. The journal is published quarterly.

The mission of the journal is to develop business informatics as a new field within both information technologies and management. It provides dissemination of latest technical and methodological developments, promotes new competences and provides a framework for discussion in the field of application of modern IT solutions in business, management and economics.

The journal publishes papers in the areas of, but not limited to:

$\downarrow$ data analysis and intelligence systems

$\uparrow$ information systems and technologies in business

$\downarrow$ mathematical methods and algorithms of business informatics

$\downarrow$ software engineering

$\checkmark$ internet technologies

$\downarrow$ business processes modeling and analysis

$\downarrow$ standardization, certification, quality, innovations

$\uparrow$ legal aspects of business informatics

$\downarrow$ decision making and business intelligence

$\downarrow$ modeling of social and economic systems

$\checkmark$ information security.

The journal is included into the list of peer reviewed scientific editions established by the Supreme Certification Commission of the Russian Federation.

The journal is included into Web of Science Emerging Sources Citation Index (WoS ESCI) and Russian Science Citation Index on the Web of Science platform (RSCI).

International Standard Serial Number (ISSN): 2587-814X (in English), 1998-0663 (in Russian).

Editor-in-Chief: Dr. Alexey Golosov - President of FORS Development Center, Moscow, Russian Federation. 


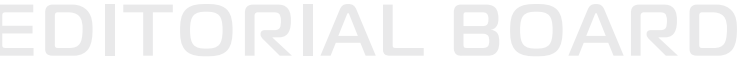

EDITOR-IN-CHIEF

Alexey O. Golosov

FORS Development Center, Moscow, Russia

\section{DEPUTY EDITOR-IN-CHIEF}

\section{Svetlana V. Maltseva}

National Research University Higher School of Economics, Moscow, Russia

Yevgeni A. Koucheryavy

Tampere University of Technology, Tampere, Finland

\section{EDITORIAL BOARD}

\section{Habib Abdulrab}

National Institute of Applied Sciences, Rouen, France

Sergey M. Avdoshin

National Research University Higher School of Economics, Moscow, Russia

Andranik S. Akopov

National Research University Higher School of Economics, Moscow, Russia

\section{Fuad T. Aleskerov}

National Research University Higher School of Economics, Moscow, Russia

\section{Alexander P. Afanasyev}

Institute for Information Transmission Problems (Kharkevich Institute), Russian Academy of Sciences, Moscow, Russia

Anton A. Afanasyev

Central Economics and Mathematics Institute, Russian Academy of Sciences, Moscow, Russia

Eduard A. Babkin

National Research University Higher School of Economics,

Nizhny Novgorod, Russia

\section{Sergey I. Balandin}

Finnish-Russian University Cooperation in Telecommunications (FRUCT), Helsinki, Finland

\section{Vladimir B. Barakhnin}

Institute of Computational Technologies, Siberian Branch of Russian Academy of Sciences, Novosibirsk, Russia

Alexander P. Baranov

Federal Tax Service, Moscow, Russia

Jorg Becker

University of Munster, Munster, Germany

Vladimir V. Belov

Ryazan State Radio Engineering University, Ryazan, Russia

Alexander G. Chkhartishvili

V.A. Trapeznikov Institute of Control Sciences, Russian Academy of Sciences, Moscow, Russia

\section{Vladimir A. Efimushkin}

Central Research Institute of Communications, Moscow, Russia

Tatiana A. Gavrilova

Saint-Petersburg University, St. Petersburg, Russia

Hervé Glotin

University of Toulon, La Garde, France

Andrey Yu. Gribov

CyberPlat Company, Moscow, Russia

Alexander I. Gromoff

National Research University Higher School of Economics,

Moscow, Russia

Vladimir A. Gurvich

Rutgers, The State University of New Jersey, Rutgers, USA

Laurence Jacobs

University of Zurich, Zurich, Switzerland

Liliya A. Demidova

Ryazan State Radio Engineering University, Ryazan, Russia

Iosif E. Diskin

Russian Public Opinion Research Center, Moscow, Russia
Nikolay I. Ilyin

Federal Security Guard of the Russian Federation,

Moscow, Russia

Dmitry V. Isaev

National Research University Higher School of Economics,

Moscow, Russia

Alexander D. Ivannikov

Institute for Design Problems in Microelectronics, Russian Academy of Sciences, Moscow, Russia

\section{Valery A. Kalyagin}

National Research University Higher School of Economics, Nizhny Novgorod, Russia

\section{Tatiana K. Kravchenko}

National Research University Higher School of Economics, Moscow, Russia

\section{Sergei O. Kuznetsov}

National Research University Higher School of Economics,

Moscow, Russia

Kwei-Jay Lin

Nagoya Institute of Technology, Nagoya, Japan

Mikhail I. Lugachev

Lomonosov Moscow State University, Moscow, Russia

Peter Major

UN Commission on Science and Technology for Development, Geneva, Switzerland

\section{Boris G. Mirkin}

National Research University Higher School of Economics, Moscow, Russia

\section{Vadim V. Mottl}

Tula State University, Tula, Russia

Dmitry M. Nazarov

Ural State University of Economics, Ekaterinburg, Russia

Dmitry E. Palchunov

Novosibirsk State University, Novosibirsk, Russia

Panagote (Panos) M. Pardalos

University of Florida, Gainesville, USA

Óscar Pastor

Polytechnic University of Valencia, Valencia, Spain

Joachim Posegga

University of Passau, Passau, Germany

Konstantin E. Samouylov

Peoples' Friendship University, Moscow, Russia

Kurt Sandkuhl

University of Rostock, Rostock, Germany

Yuriy D. Shmidt

Far Eastern Federal University, Vladivostok, Russia

Christine Strauss

University of Vienna, Vienna, Austria

Ali R. Sunyaev

Karlsruhe Institute of Technology, Karlsruhe, Germany

Victor V. Taratukhin

University of Munster, Munster, Germany

José M. Tribolet

Universidade de Lisboa, Lisbon, Portugal

Olga A. Tsukanova

Saint-Petersburg National Research University of Information

Technologies, Mechanics and Optics, St. Petersburg, Russia

Mikhail V. Ulyanov

V.A. Trapeznikov Institute of Control Sciences, Russian Academy of Sciences, Moscow, Russia

\section{Raissa K. Uskenbayeva}

International Information Technology University, Almaty, Kazakhstan

Markus Westner

Regensburg University of Applied Sciences, Regensburg, Germany 


\section{ABOUT THE HIGHER SCHOOL OF ECONOMICS}

Consistently ranked as one of Russia's top universities, the Higher School of Economics (HSE) is a leader in Russian education and one of the preeminent economics and social sciences universities in Eastern Europe and Eurasia. Having rapidly grown into a well-renowned research university over two decades, HSE sets itself apart with its international presence and cooperation.

Our faculty, researchers, and students represent over 50 countries, and are dedicated to maintaining the highest academic standards. Our newly adopted structural reforms support both HSE's drive to internationalize and the groundbreaking research of our faculty, researchers, and students.

Now a dynamic university with four campuses, HSE is a leader in combining Russian educational traditions with the best international teaching and research practices. HSE offers outstanding educational programs from secondary school to doctoral studies, with top departments and research centers in a number of international fields.

Since 2013, HSE has been a member of the 5-100 Russian Academic Excellence Project, a highly selective government program aimed at boosting the international competitiveness of Russian universities. 


\section{ABOUT THE SCHOOL OF BUSINESS INFORMATICS}

The School of Business Informatics is one of the leading divisions of HSE's Faculty of Business and Management. The School offers students diverse courses taught by full-time HSE instructors and invited business practitioners. Students are also given the opportunity to carry out fundamental and applied projects at various academic centers and laboratories.

Within the undergraduate program, students participate each year in different casecompetitions (PWC, E\&Y, Deloitte, Cisco, Google, CIMA, Microsoft Imagine CUP, IBM Smarter Planet, GMC etc.) and some of them are usually as being best students by IBM, Microsoft, SAP, etc. Students also have an opportunity to participate in exchange programs with the University of Passau, the University of Munster, the University of Business and Economics in Vienna, the Seoul National University of Science and Technology, the Radbound University Nijmegen and various summer schools (Hong Kong, Israel etc.). Graduates successfully continue their studies in Russia and abroad, start their own businesses and are employed in high-skilled positions in IT companies.

There are four graduate programs provided by the School:

$\downarrow$ Business Informatics

$\downarrow$ E-Business;

$\downarrow$ Information Security Management;

$\downarrow$ Big Data Systems.

The School's activities are aimed at achieving greater integration into the global education and research community. A member of the European Research Center for Information Systems (ERCIS), the School cooperates with leading universities and research institutions around the world through academic exchange programs and participation in international educational and research projects. 



\title{
Neural network model for user request analysis during software operations and maintenance phase
}

Egor I. Gribkova,b

E-mail: drnemor@gmail.com

\section{Yuri P. Yekhlakov ${ }^{\mathrm{a}}$}

E-mail: upe@tusur.ru

a Tomsk State University of Control Systems and Radioelectronics

Address: 40, Prospect Lenina, Tomsk 634050

${ }^{\mathrm{b}}$ TomskSoft LLC

Address: 8, Nahimova Street, Tomsk 634034

\begin{abstract}
This article offers a transition-based neural network model for extracting informative expressions from user request texts. The configuration and transition system that turns the process of informative expression extraction into the execution of a sequence of transitions is described. Prediction of transition sequence is done using a neural network that uses features derived from the configuration. To train and evaluate a proposed model, a corpus of annotated Android mobile application reviews from the Google Play store was created. The training procedure of the model for informative expressions extraction and selected model's hyperparameters are described. An experiment was conducted comparing the proposed model and an alternative model based on a hybrid of convolutional and recurrent neural networks. To compare quality of these two models, the F1 score that aggregates recall and precision of extracted informative expressions was used. The experiment shows that the proposed model extracts expressions of interest better than the alternative: the F1 score for spans extraction increased by $2.9 \%$ and the $\mathrm{F} 1$ for link extraction increased by $36.2 \%$. A qualitive analysis of extracted expressions indicates that the proposed model is applicable for the task of user request analysis during operation and the maintenance phase of software products.
\end{abstract}

Key words: natural language processing; software maintenance; machine learning; deep learning; transition-based model.

Citation: Gribkov E.I., Yekhlakov Yu.P. (2020) Neural network model for user request analysis during software operations and maintenance phase. Business Informatics, vol. 14, no 1, pp. 7-18.

DOI: $10.17323 / 2587-814 X .2020 .1 .7 .18$ 


\section{Introduction}

7 he competitiveness of a software product on the market largely depends on the speed and quality of the developer's response to end user requests on issues associated with software bugs, errors in technical documentation, insufficient qualification of end users, etc. These problems are usually resolved at the software operation and maintenance stages [1]. According to [2], these account for $67 \%$ of the whole software life cycle.

To handle user requests that usually are presented as unstructured text (emails, messages on forums and support chats) and make appropriate corrective actions, IT companies create specialized structures called technical support services. Modern helpdesk software systems like HappyFox, Service Desk Plus, Zendesk have a large set of functions for the acceptance and storage of user requests, linking related requests, request status monitoring, storage of communication between support staff and users. Despite that, the understanding and interpretation of a request text, as well as assignment of a support specialist to resolve the request is still done by human beings. Unexpected growth of the user base can lead to problems with support service scalability and increase costs of non-core structures within the company.

In addition to processing "explicit" user requests related to the software features, "implicit" requests made by users in channels that are rarely the focus of support services can be of great interest to companies: forums, blogs, and social network pages made at the initiative of the community of software users. "Implicit" requests, presented in the form of opinions or reviews, can be just as useful to the software developer as "explicit" ones, and at the same time they are much more numerous. Since analysis of a large amount of text is a time consuming task, this kind of feedback is either not reviewed systematically or not reviewed at all.
To handle the problems mentioned above, methods of automatic text analysis can be applied to the requests in order to identify statements about problems that users encountered while using the software. There is a body of research devoted to the problem of applying automatic text analysis methods to user requests in order to identify and extract knowledge useful for development and maintenance of software products. In [3], the authors propose to use decision trees, a naive Bayes classifier and logistic regression to identify user complaints about bugs among other kinds of requests in open source software bug trackers. The study [4] is devoted to the analysis of various aspects of the review texts about mobile applications published in the Apple AppStore. It is noted that although some of the reviews are not informative to application developers, others contain information about bugs, user experience, and feature requests. The method for discovery of feature requests in review texts from the Google Store is considered in [5]. The authors use a set of linguistic rules to classify sentences into classes "contains / does not contain a request," and then use a Latent Dirichlet Allocation to determine the main topics in requests. In [6], the authors propose a corpus of mobile application reviews in German from the Google Play Store, in which they annotate application features - aspects, and user opinions about them - descriptions.

Analysis showed that most of the existing models can do only coarse-grained analysis on the level of whole request text or a sentence that is unable to identify and extract the set of phrases that express the essence of request. Furthermore, each of the described models can identify only a kind of request which does not correspond to the real needs of the support service. In this paper, we propose a solution that can extract many kinds of user requests within a single model and at the same time can extract key phrases in the texts. This model is a development of the ideas described earlier in [7]. 


\section{The problem of processing user requests during software operations and maintenance phase}

In this work, the task of user request analysis during software operations and maintenance is reduced to extraction of informative expressions (IE) with specific questions, wishes and requirements of users, from request texts. The structure of an IE is defined as an "object description" pair, where an object is the mention of the software itself, its functions or graphic user interface elements in the text, and a description is a phrase in which the user eval- uates the object or talks about its current state.

To separate IEs into semantically similar subgroups, an original classifier based on the elements of the universal activity model [8] is proposed: the subject of activity, the target object of the activity, the tools used in the process, the relationships between the elements of activity. In this specific task, the subject of activity is the software product user, the object is a software product itself, the tools are hardware and side software that ensure the functioning of the software product. A hierarchical classifier of IE types based on this model is presented in Figure 1. The classifier consists of the following elements:

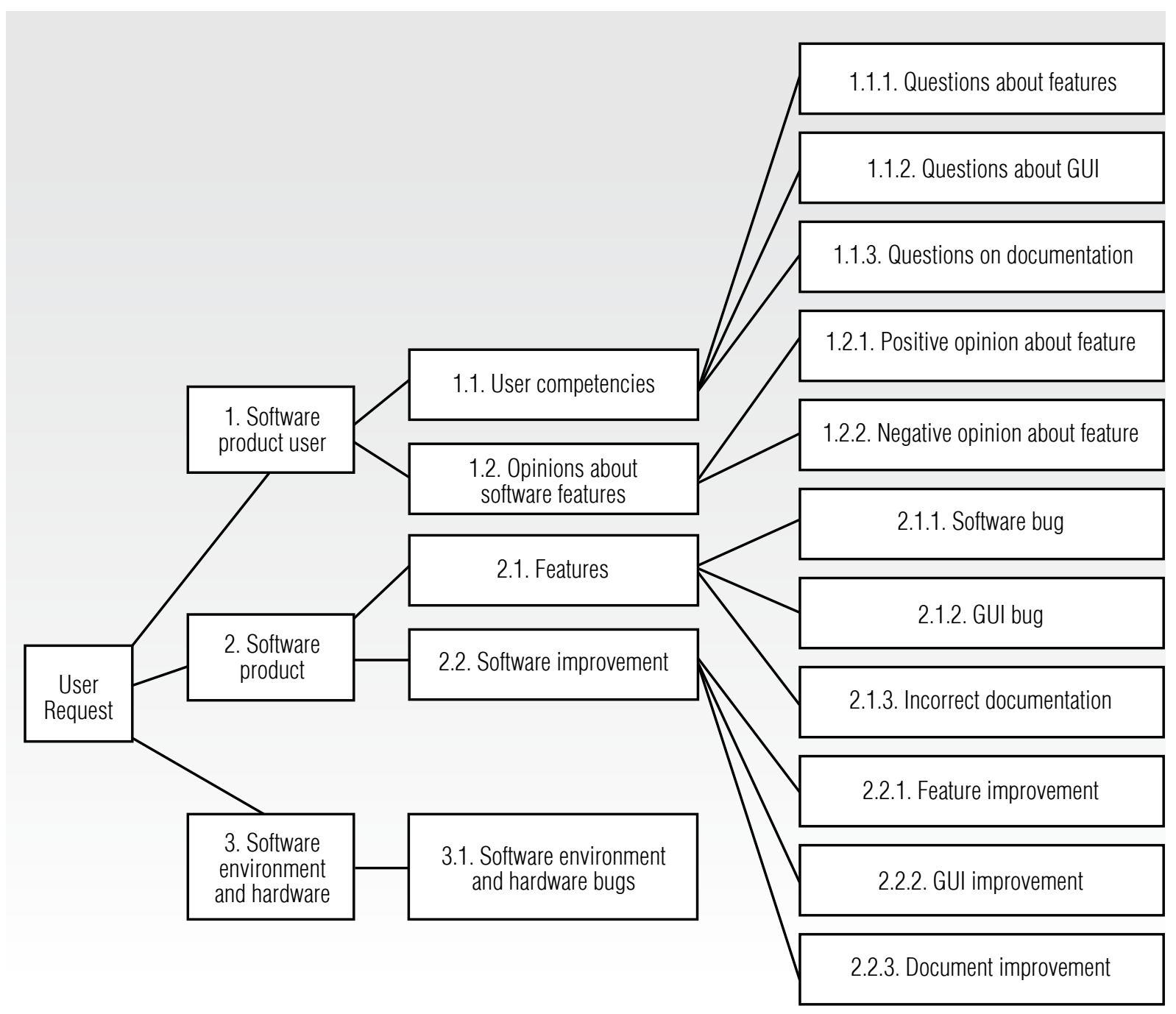

Fig. 1. Classifier of informative expressions 
User competencies - user questions about the features of the software, its graphical user interface and documentation;

Opinions about software features - positive and negative user opinions about the software features;

Software features - phrases in which users report incorrect operation of software features, its graphical user interface, factual errors in the documentation;

Features - requests for new features in software and improvements in documentation and GUI;

Software environment and hardware bugs user complaints about failures in the operation of software environment and hardware.

The authors do not claim that the proposed classifier of informative expressions is complete and general enough to be applied in any domain. In this work, the authors analyzed review texts from the Google Play store and selected 4 classes of IE from the classifier frequently mentioned by users in their reviews: bug ("software and hardware bugs"), feature request ("improvement of the software"), positive feature, negative feature. Here are some examples of IEs from the Google Play Marker review texts (translated from Russian):

Bug: "player does not appear on the lock screen", "playlist does not update when swipe down";

Feature request: "add shuffle button", "allow to edit tags";

Positive feature: "many possibilities for manipulating sound", "quickly cancel the reception";

Negative feature: "record archive is not stored", "duplicates features of the Gosuslugi application".

Thus, given the user request text as a sequence of words $\mathbf{w}=w_{1}, \ldots, w_{N}$ and classifier structure, we should extract the set of IEs from this text. Formally, IE is a triple $(o, d, l)$ where $o$ is an object, $d$ is a description and $l$ is a class of IE from the set Labels $=\{$ Bug, Feature request,
Positive, Negative\}. Objects and descriptions in the text are defined as spans: $o=\left(w_{i}, \ldots, w_{j}\right)$, $d=\left(w_{p}, \ldots, w_{q}\right)$. The IE class is determined by the class label assigned to description. Examples of the IE structure are presented at Figure 2.

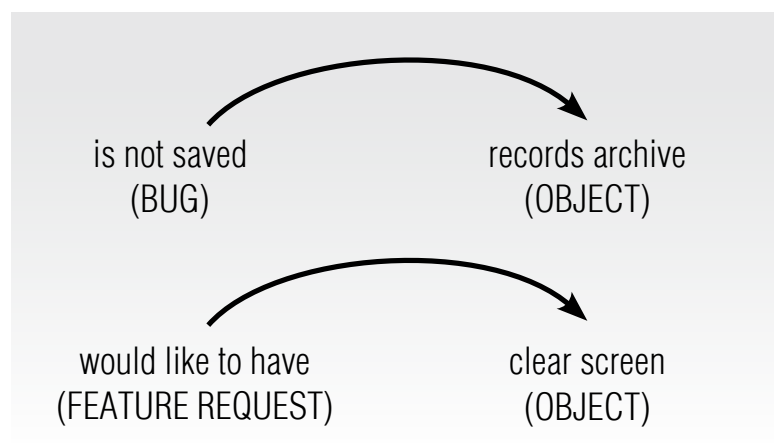

Fig. 2. Examples of informative
expression structure

\section{Transition-based neural network model}

In order to extract IEs from user request text, an original transition-based neural network model is proposed. This kind of model is widely used in tasks where the target variable is an object with a complex structure: prediction of sentence phrase structure [9], dependency parsing [10] and named entity recognition [11]. This kind of model is attractive since it is fast at prediction time and can use complex non-local features. A transition-based model requires the definition of abstract automata that accept text as input and transform it into set of IEs. The state of the abstract automata is determined by configuration $C$, which changes when automata execute transition. Initial configuration $C_{0}$ constructed from the input text. After completion of the transition sequence $\mathbf{y}=y_{1}, \ldots, y_{T}$, $y_{t} \in Y$, the automata reach final configuration $C_{T}$ which contains all the IEs from analyzed text. The next transition at step $t$ is selected by probabilistic classifier that maps current configuration $C_{t}$ to probability distribution over possible transitions: 


$$
\hat{y}_{t}=\underset{y \in A\left(C_{t}\right)}{\operatorname{argmax}} P\left(y \mid C_{t}\right) .
$$

We define configuration as tuple $(B, S, L$, $H$ ). Buffer $B$ holds words from the input text. Stack $S$ contains object and description spans in the order they are found in the text. As spans that consist of several words are built incrementally, the entity on the top of the stack can be extended with additional words during prediction. Buffer $L$ holds links between elements of stack $S$. List $H$ holds the history of taken transitions that led initial configuration to the current $C_{t}$.

Let us describe in detail the meaning of the elements of the set of transitions $Y=\{$ Shift, $\operatorname{Start}(e), \operatorname{Add}(e), \operatorname{Link}\left(n_{1}, n_{2}\right)$, End $\}$. Shift discards the first element of $B$. Start $(e)$ creates a new span of the class $e \in$ Labels $\cup\{$ Object $\}$, puts it on the top of $S$ and moves a word from the beginning of $B$ to created span. $A d d(e)$ moves the item from the beginning of $B$ in the span on the top of $S$. $\operatorname{Link}\left(n_{1}, n_{2}\right)$ links elements of $S$ at positions $n_{1}$ and $n_{2}$; the created link is placed in the end of $L$. By defining set $Y$ in this way, we limit the maximum depth at which a connection between elements of $S$ can be created. We estimate this depth as the maximum depth between linked spans in the training set because further increase in depth will not be supported by appropriate training samples. End transition ends the prediction process.

There are configurations from which some transition can be executed only if the configuration satisfies certain restrictions: for example, if $B$ is empty, no transition can be performed except End and $\operatorname{Link}\left(n_{1}, n_{2}\right)$. These restrictions are expressed with function $A\left(C_{t}\right): C \rightarrow Y^{\prime} \subseteq Y$ that returns the subset of available transitions for current configuration $C_{t}$. The necessary conditions for each transition are shown in Table 1.

Conditional probability distribution on possible transitions from expression (1) is defined as a probabilistic model of the following form:
Table 1.

\section{Transition preconditions}

\begin{tabular}{l|c}
\multicolumn{1}{c|}{ Transition } & Precondition \\
Shift & $B \neq \varnothing$ \\
\hline Start $(e)$ & $B \neq \varnothing$ \\
\hline $\operatorname{Add}(e)$ & $B \neq \varnothing \wedge S \neq \varnothing \wedge \operatorname{class}\left(S_{1}\right)=e$ \\
\hline $\operatorname{Link}\left(n_{1}, n_{2}\right)$ & $\exists S_{n_{1}} \wedge \exists S_{n_{2}} \wedge\left(n_{1}, n_{2}\right) \notin L$ \\
\hline End & $B \neq \varnothing$ \\
\hline
\end{tabular}

$$
\begin{gathered}
P(y \mid C)=\operatorname{softmax}\left(\mathbf{W} \cdot \varphi\left(C_{t}\right)+\mathbf{b}\right)_{y}, \\
\operatorname{softmax}\left(\mathbf{v}_{c}\right)=\frac{\exp \left(\mathbf{v}_{c}\right)}{\sum_{i} \exp \left(\mathbf{v}_{i}\right)},
\end{gathered}
$$

where $\mathbf{W}, \mathbf{b}$ - classifier weights;

$\varphi\left(C_{t}\right)$ - feature vector derived from the current configuration.

Feature vector $\varphi\left(C_{t}\right)$ is formed by a concatenation of feature vectors for individual parts of the configuration:

$$
\varphi(C),=(\varphi(B) ; \varphi(S) ; \varphi(H)) .
$$

To construct feature vectors of configuration elements, we use contextual vector representations of input text that are obtained from function $F$ :

$$
\varphi\left(B_{1}\right), \ldots, \varphi\left(B_{n}\right)=F\left(E\left(w_{1}\right), \ldots, E\left(w_{N}\right)\right)
$$

where $E$ - function that maps words into vector space.

$F$ can be any mapping from one vector sequence to another. This work considers two options that have been used in natural language processing problems: one-dimensional convolutional $(\mathrm{CNN})$ [12-14] and recurrent (RNN) [15-17] neural networks.

In the case of $\mathrm{CNN}$, each vector in the input sequence at position $n$ is built from input 
sequence vectors in the window of size $k$ centered at $n$ by the following equation:

$\mathbf{h}_{n}=\sigma\left(\mathbf{W}\left(E\left(w_{n-(k-1) / 2}\right) ; \ldots ; E\left(w_{n+(k-1) / 2}\right)\right)+\mathbf{b}, \quad(5)\right.$

where $\mathbf{W}, \mathbf{b}$ - weights of convolution;

$\sigma-$ non-linear activation function.

So, $\mathbf{h}_{n}$ can be thought of as a contextual representation of the original word in position $n$. We use MaxOut activation [18] as $\sigma$ because it showed the best accuracy during preliminary experiments. To improve the training process of the neural network, we applied the residual learning approach from [19], when the output of layer is summed with unmodified layer input. In such a case, the output of the layer $i$ is defined as:

$$
\mathbf{h}_{n}^{i}=\sigma\left(\mathbf{W} \mathbf{h}_{n}^{i-1}+\mathbf{b}\right),+\mathbf{h}_{n}^{i-1} .
$$

Contextual representations of sequence elements can be obtained with recurrent neural networks (RNNs) by the following recurrent formula:

$$
\mathbf{h}_{n}=\sigma\left(\mathbf{U} E\left(w_{n}\right)+\mathbf{W h}_{n-1}+\mathbf{b}\right) .
$$

In this case, the contextual information is transmitted in such a way that the element at position $n$ carries information about previous $(n-1)$ elements. To get context information about future context. bidirectional RNNs [20] can be used. The resulting contextual representations are formed as a concatenation of vector representations $\overrightarrow{\mathbf{h}}_{n}$ and $\overleftarrow{\mathbf{h}}_{n}$ from forward (from left to right) and reverse (from right to left) RNNs:

$$
\begin{gathered}
\overrightarrow{\mathbf{h}}_{n}=\sigma\left(\overrightarrow{\mathbf{U}} E\left(w_{n}\right)+\overrightarrow{\mathbf{W}}_{n-1}+\overrightarrow{\mathbf{b}}\right), \\
\overline{\mathbf{h}}_{n}=\sigma\left(\overline{\mathbf{U}} E\left(w_{n}\right)+\overline{\mathbf{W}}_{n+1}+\overline{\mathbf{b}}\right), \\
\mathbf{h}_{n}=\left(\overrightarrow{\mathbf{h}}_{n} ; \overleftarrow{\mathbf{h}}_{n}\right) .
\end{gathered}
$$

One of the most used types of RNNs are Long Short-Term Memory (LSTM) networks [21] which show good performance in many natural language processing tasks [22-24]. In this work, we use a multilayer bidirectional LSTM. Figure 3 shows how contextual representations of sequence elements are obtained with CNN and Bi-LSTM networks.

Vector $\varphi(B)$ is a concatenation of feature vectors for the first three elements of the buffer $B$ :

$$
\varphi(B)=\left[\varphi\left(B_{1}\right) ; \varphi\left(\mathrm{B}_{2}\right), \varphi\left(B_{3}\right)\right] .
$$

To obtain feature vector $\varphi(S)$, the feature vectors for elements of stack $S$ are calculated according to the following formula: a)

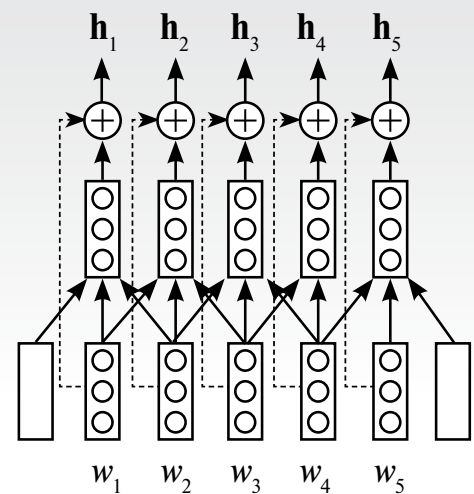

b)

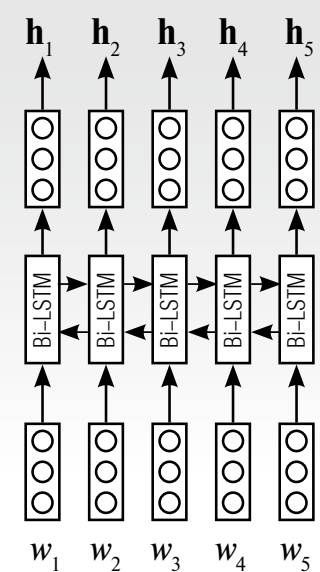

Fig. 3. Diagrams of using CNN and LSTM networks for building contextual representations of input sequence elements: $a-C N N ; b-B i-L S T M$ 


$$
\varphi\left(S_{i}\right)=\left(\frac{1}{e(i)-b(i)} \sum_{j=e(i)}^{b(i)} \varphi\left(B_{j}\right) ; E(\text { type }(i))\right)
$$

where $b(i), e(i)$ - indices of the first and last words in the $i$-th text span;

E(type $(i))$ - embedding of the span type.

Since in the training set the maximum distance between any two fragments joined by a link is 4 , the depth of the search for a link can be limited by the first five elements of $S$. Thus, to get the feature vector for $S$, we concatenate the first five feature vectors for $S$ elements:

$$
\varphi(S)=\left(\varphi\left(S_{1}\right) ; \ldots ; \varphi\left(S_{5}\right)\right)
$$

Features for the history of the taken transitions $H$ at step $t$ are obtained from the last step of LSTM network that processes the sequence of history element embeddings:

$$
\varphi(H)=\operatorname{LSTM}\left(E\left(H_{1}\right) ; \ldots ; E\left(H_{t}\right)\right)_{t}
$$

Proposed model (1-11) shares feature extraction components that are used for span extraction and span linking tasks. This reduces the total number of model parameters that should be estimated during training and prevents overfitting. Furthermore, this kind of model structure enables multitask learning $[25,26]$ when using one model to learn several related tasks can speed up learning or improve accuracy. During training, we maximize the likelihood of true transition sequences that are constructed from the training samples my minimizing cross-entropy loss between predicted distribution on possible transitions and true transition:

$$
L(\hat{\mathbf{y}}, \mathbf{y})=\sum_{t}\left(-\sum_{i \in Y} \log \left(P\left(\hat{\mathbf{y}}_{t} \mid C_{t}\right)\right)_{i}\left(\mathbf{y}_{t}\right)_{i}\right)
$$

Model parameters $\theta$ include the parameters of the classifier, context representation network (BiLSTM or CNN), history representation LSTM and vector representation matrices for $E(H)$ and E(type $(i))$. To optimize the parameters set, any gradient optimization algorithm can be used. The final neural network architecture is shown in Figure 4.

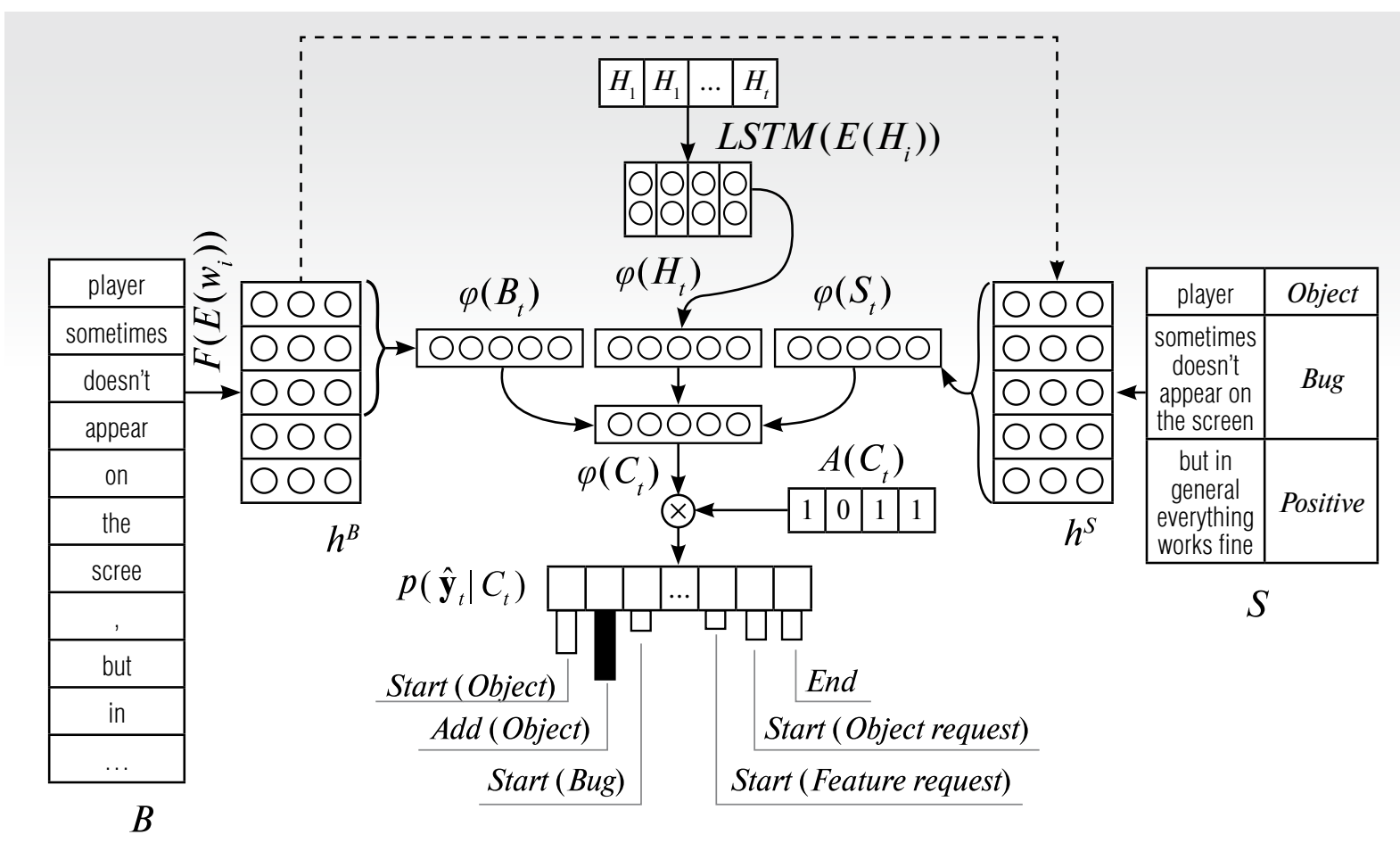

Fig 4. Neural network architecture 


\section{Experimental study of the model and analysis of the results}

Validation of the neural network model was conducted on the annotated user request corpus in Russian that was obtained from the Google Play application store and consists of nine categories of mobile applications: "Auto and vehicles," "Maps and navigation," "Medicine," "Music and audio," "Personalization," "Finance," "Shopping," "Education," "Video players." Five applications were selected in each category and 20 requests were randomly selected per application. Each request was split into sentences.

Annotation of the corpus was carried out by the authors for 3 weeks, after which the annotated corpus was given to a third-party specialist for audit. Then the corpus was corrected based on the feedback received. Quantitative statistics on the collected corpus are given in Table 2.

Table 2.

Quantitative statistics

on the collected corpus

from the Google Play Store

\begin{tabular}{c|c}
\hline Total request count & 900 \\
\hline The average number of words in a query & 52.3 \\
\hline Number of IEs & 2391 \\
\hline The average number of IEs per request & 2.65 \\
\hline Number of objects & 2273 \\
\hline Number of positive features & 999 \\
\hline Number of negative features & 851 \\
\hline Number of feature requests & 200 \\
\hline Number of bugs & 677 \\
\hline
\end{tabular}

During the experiments, two versions of the proposed model were tested, using a convolu- tional neural network (6) and a bi-directional LSTM (8) as a mechanism for obtaining contextual representations, which will be called Trans-CNN and Trans-LSTM. The following hyper-parameter values were set for Trans$\mathrm{CNN}$ : convolution window size -3 , number of convolutional layers -3 , number of filters 150. In the case of Trans-LSTM: the number of BiLSTM layers is 2, the size of the hidden state BiLSTM layer is 200. Other model hyperparameters: the size of the hidden layer $\operatorname{LSTM}_{\mathrm{H}}$ is 30 , the representation $E\left(H_{t}\right)$ is $30, E(\operatorname{class}(i))$ is 30 .

We use a pretrained fast Text [27] Russian model of size 300 for obtaining vector representations of words. FastText was chosen for its ability to handle typos in words and strong performance on different tasks with morphologically rich languages such as Russian. Optimization of model parameters is carried out by Adam with a learning rate of $10^{-3}$. To prevent overfitting, we employed various regularization techniques: $20 \%$ dropout, $L_{2}$ regularization $1,2 \cdot 10^{-6}$. As baseline, a hybrid CNN-RNN model from [28] was used.

To evaluate the quality of IEs extraction, the $k$-fold cross-validation procedure was used. During cross-validation, the sample is divided into $k$ disjoint equally sized parts called folds, then $k$ iterations when model training on $k-1$ folds and testing on the fold that was not used during training are performed. Each fold of the divided sample is used at test time only ones. The set of $k$ quality estimates is then averaged. In our case, the folds were formed from requests from the same application category. Thus, for training and verification, 9 parts were formed. As a result, this method gives a "pessimistic" estimation of model quality: during training the model does not have access to category specific lexicon, which increases the requirements for the generalization ability of the model. 
The results of comparing two versions of the transition-based model and the baseline are shown in Table 3. F-measure for spans was calculated by averaging F-measures for each of the five span classes. Trans-LSTM has the best accuracy both in IF span extraction with $67 \% \mathrm{~F} 1$ and span linking with $64.8 \% \mathrm{~F} 1$. The improvement in extraction quality relative to the baseline model is $2.9 \%$ for span extraction and $36.2 \%$ for span linking.
A detailed comparison of Trans-LSTM and baseline model accuracies for each fold is shown in Table 4, where the first number is a F1 score of Trans-LSTM and the second number in brackets is a F1 score of baseline, best F1 shown in bold.

Testing results suggest that the model showed good results on the IEs extracting task and can be used to solve practical problems.

\section{Models quality comparison}

Table 3.

\begin{tabular}{c|c|c} 
Model & Spans F1 & Links F1 \\
Baseline & 0.651 & 0.476 \\
\hline Trans-CNN & 0.641 & 0.598 \\
\hline Trans-LSTM & $\mathbf{0 . 6 7 0}$ & $\mathbf{0 . 6 4 8}$ \\
\hline
\end{tabular}

Comparison of Trans-LSTM and baseline models

Table 4.

\begin{tabular}{|c|c|c|c|c|c|c|}
\hline Category & Object & Positive & Negative & Bug & Feat. Request & Link \\
\hline $\begin{array}{l}\text { Auto } \\
\text { and vehicles }\end{array}$ & $\mathbf{0 . 7 4 7}(0.730)$ & $\mathbf{0 . 7 2 4}(0.639)$ & $0.548(\mathbf{0 . 6 7 2})$ & $0.646(\mathbf{0 . 6 7 8})$ & $\mathbf{0 . 6 9 1}(0.633)$ & $\mathbf{0 . 6 7 6}(0.493)$ \\
\hline Personalization & $0.721(0.684)$ & $\mathbf{0 . 6 8 5}(0.677)$ & $\mathbf{0 . 6 0 2}(0.559)$ & $0.598(\mathbf{0 . 6 2 5})$ & $0.602(\mathbf{0 . 6 5 8})$ & $\mathbf{0 . 6 3 3}(0.459)$ \\
\hline Music and audio & $\mathbf{0 . 7 4 8}(0.667)$ & $0.649(0.649)$ & $\mathbf{0 . 6 2 4}(0.535)$ & $\mathbf{0 . 6 3 0}(0.594)$ & $\mathbf{0 . 6 3 2}(0.542)$ & $\mathbf{0 . 6 0 3}(0.431)$ \\
\hline $\begin{array}{c}\text { Maps } \\
\text { and navigation }\end{array}$ & 0.656 (0.699) & $0.628(\mathbf{0 . 6 6 5})$ & $\mathbf{0 . 5 5 9}(0.529)$ & $\mathbf{0 . 7 1 1}(0.679)$ & $\mathbf{0 . 6 9 4}(0.481)$ & $\mathbf{0 . 6 3 1}(0.455)$ \\
\hline Medicine & $0.707(\mathbf{0 . 7 1 1})$ & $0.713(0.600)$ & $\mathbf{0 . 7 1 3}(0.637)$ & $\mathbf{0 . 6 9 1}(0.617)$ & $\mathbf{0 . 6 7 3}(0.591)$ & $\mathbf{0 . 6 5 9}(0.490)$ \\
\hline Finance & $0.708(0.706)$ & 0.659 (0.709) & $0.615(\mathbf{0 . 6 2 6})$ & $\mathbf{0 . 6 4 1}(0.623)$ & $0.622(\mathbf{0 . 7 0 0})$ & $\mathbf{0 . 6 8 2}(0.497)$ \\
\hline Shopping & $\mathbf{0 . 7 4 5}(0.715)$ & $\mathbf{0 . 7 8 8}(0.756)$ & $\mathbf{0 . 6 9 7}(0.647)$ & $0.576(\mathbf{0 . 6 8 5})$ & $\mathbf{0 . 8 4 1}(0.691)$ & $\mathbf{0 . 6 8 9}(0.524)$ \\
\hline Education & $0.746(\mathbf{0 . 7 6 2})$ & $0.695(\mathbf{0 . 7 4 5})$ & $0.586(\mathbf{0 . 6 2 3})$ & $\mathbf{0 . 7 5 7}(0.726)$ & $\mathbf{0 . 8 1 2}(0.702)$ & $\mathbf{0 . 6 8 6}(0.511)$ \\
\hline Video players & $0.677(\mathbf{0 . 6 9 3})$ & $\mathbf{0 . 7 0 7}(0.685)$ & $0.534(\mathbf{0 . 6 4 7})$ & $\mathbf{0 . 6 0 8}(0.531)$ & $0.529(\mathbf{0 . 5 6 5})$ & $\mathbf{0 . 5 7 4}(0.422)$ \\
\hline Avg. & $\mathbf{0 . 7 1 7}(0.707)$ & $\mathbf{0 . 6 9 4}(0.681)$ & $\mathbf{0 . 6 0 9}(0.608)$ & $\mathbf{0 . 6 5 1}(0.640)$ & $\mathbf{0 . 6 7 7}(0.618)$ & $\mathbf{0 . 6 4 8}(0.476)$ \\
\hline
\end{tabular}




\section{Conclusion}

The results of the experiments suggest that the proposed model shows better results when processing user requests in comparison with the baseline. The improvement with respect to the baseline is $2.9 \%$ for span extraction and $36.2 \%$ for span linking. A qualitative analysis of the results indicates that proposed model is suitable for processing user requests during operations and maintenance of software products.

Information extracted from user requests with respect to the proposed classifier can be used by:

a support service for the classifier-guided routing of user requests to specialists with necessary competencies, recognition of the standard requests and the automatic response generation based on standard templates; a software development department to detect and fix critical bugs revealed by user complaints and suggestions analysis, to modify functional and non-functional requirements, to improve GUI and user guides;

\ a marketing department for monitoring negative and positive opinions about both own and competitors' products and for modifying marketing strategy based on this data.

\section{Acknowledgments}

This study was conducted under government order of the Ministry of Science and Education of Russia, project "Methodological and instrumental support for decision making in the tasks of managing socio-economic systems and processes in a heterogeneous information environment."

\section{References}

1. Standartinform (2011) GOST R ISO/IEC 12207-2010. Information technology. Systems and software engineering. Software life cycle processes. Moscow: Standartinform (in Russian).

2. Schach S.R. (2011) Object-oriented and classical software engineering. N.Y.: McGraw-Hill Education.

3. Antoniol G., Ayari K., Di Penta M., Khomh F., Guéhéneuc Y.-G. (2008) Is it a bug or an enhancement? A text-based approach to classify change requests. Proceedings of the 2008 Conference of the Center for Advanced Studies on Collaborative Research: Meeting of Minds, Ontario, Canada, 27-30 October, 2008, pp. 304-318. DOI: $10.1145 / 1463788.1463819$.

4. Pagano D., Maalej W. (2013) User feedback in the appstore: An empirical study. Proceedings of the 21st IEEE International Requirements Engineering Conference. Rio de Janeiro, Brasil, 15-19 July 2013, pp. 125-134. DOI: 10.1109/RE.2013.6636712.

5. Iacob C., Harrison R. (2013) Retrieving and analyzing mobile apps feature requests from online reviews. Proceedings of the 10th Working Conference on Mining Software Repositories (MSR 2013), San Francisco, USA, 18-19 May 2013, pp. 41-44. DOI: 10.1109/MSR.2013.6624001.

6. Sänger M., Leser U., Kemmerer S., Adolphs P., Klinger R. (2016) SCARE - The sentiment corpus of app reviews with fine-grained annotations in German. Proceedings of the 10th International Conference on Language Resources and Evaluation. Portorož, Slovenia, 23-28 May 2016, pp. 1114-1121.

7. Yekhlakov Yu.P., Gribkov E.I. (2018) User opinion extraction model concerning consumer properties of products based on a recurrent neural network. Business Informatics, vol. 46, no 4, pp. 7-16.

DOI: 10.17323/1998-0663.2018.4.7.16.

8. Peregudov F.I., Tarasenko F.P. (1997) Basics of system analysis: guide. Tomsk: NTL (in Russian).

9. Dyer C., Kuncoro A., Ballesteros M., Smith N.A. (2016) Recurrent neural network grammars. Proceedings of the 15th Annual Conference of the North American Chapter of the Association for Computational Linguistics: Human Language Technologies. San Diego, USA, 12-17 June 2016, pp. 199-209.

DOI: $10.18653 / \mathrm{v} 1 / \mathrm{N} 16-1024$. 
10. Kiperwasser E., Goldberg Y. (2016) Simple and accurate dependency parsing using bidirectional LSTM feature representations. Transactions of the Association for Computational Linguistics, vol. 4, pp. 313-327. DOI: 10.1162/tacl_a_00101.

11. Lample G., Ballesteros M., Subramanian S., Kawakami K., Dyer C. (2016) Neural architectures for named entity recognition. Proceedings of the 15th Annual Conference of the North American Chapter of the Association for Computational Linguistics: Human Language Technologies, San Diego, USA, 12-17 June 2016, pp. 260-270. DOI: 10.18653/v1/N16-1030.

12. Kim Y. (2014) Convolutional neural networks for sentence classification. Proceedings of the 2014 Conference on Empirical Methods in Natural Language Processing (EMNLP), Doha, Qatar, 25-29 October 2014, pp. 1746-1751. DOI: 10.3115/v1/D14-1181.

13. Gehring J., Auli M., Grangier D., Yarats D., Dauphin Y.N. (2017) Convolutional sequence to sequence learning. Proceedings of the 34th International Conference on Machine Learning (ICML), Sydney, Australia, 6-11 August 2017, vol. 70, pp. 1243-1252.

14. Kalchbrenner N., Grefenstette E., Blunsom P. (2014) A convolutional neural network for modelling sentences. Proceedings of the 52nd Annual Meeting of the Association for Computational Linguistics, Baltimore, USA, 22-27 June 2014, vol. 1, pp. 655-665. DOI: 10.3115/v1/P14-1062.

15. Huang Z., Xu W., Yu K. (2015) Bidirectional LSTM-CRF models for sequence tagging. arXiv.org. Available at: https://arxiv.org/abs/1508.01991 (accessed 20 January 2020).

16. İrsoy O., Cardie C. (2014) Opinion mining with deep recurrent neural networks. Proceedings of the 2014 Conference on Empirical Methods in Natural Language Processing (EMNLP), Doha, Qatar, 25-29 October 2014, pp. 720-728. DOI: 10.3115/v1/D14-1080.

17. Wang W., Jialin Pan S., Dahlmeier D., Xiao X. (2016) Recursive Neural Conditional Random Fields for Aspect-based Sentiment Analysis. Proceedings of the 2016 Conference on Empirical Methods in Natural Language Processing (EMNLP), Austin, USA, 1-5 November 2016, pp. 616-626.

DOI: $10.18653 / \mathrm{v} 1 / \mathrm{D} 16-1059$.

18. Goodfellow I., Warde-Farley D., Mirza M., Courville A., Bengio Y. (2013) Maxout networks. Proceedings of the 30th International Conference on Machine Learning, Atlanta, USA, 16-21 June 2013, pp. 1319-1327.

19. He K., Zhang X., Ren S., Sun J. (2016) Deep residual learning for image recognition. Proceedings of the 2016 IEEE Conference on Computer Vision and Pattern Recognition, Las Vegas, USA, 26 June - 1 July 2016, pp. 770-778. DOI: 10.1109/CVPR.2016.90.

20. Graves A., Jaitly N., Mohamed A. (2013) Hybrid speech recognition with deep bidirectional LSTM. Proceedings of the 2013 IEEE Workshop on Automatic Speech Recognition and Understanding, Olomouc, Czech Republic, 8-12 December, 2013, pp. 273-278. DOI: 10.1109/ASRU.2013.6707742.

21. Hochreiter S., Schmidhuber J. (1997) Long short-term memory. Neural Computation, vol. 9, no 8, pp. 1735-1780. DOI: 10.1162/neco.1997.9.8.1735.

22. Chiu J. P.C., Nichols E. (2016) Named entity recognition with bidirectional LSTM-CNNs. Transactions of the Association for Computational Linguistics, no 4, pp. 357-370. DOI: 10.1162/tacl_a_00104.

23. Ma X., Hovy E. (2016) End-to-end sequence labeling via bi-directional LSTM-CNNs-CRF. Proceedings of the 54th Annual Meeting of the Association for Computational Linguistics, Berlin, Germany, 7-12 August 2016, pp. 1064-1074. DOI: 10.18653/v1/P16-1101.

24. Wang Y., Huang M., Zhu X., Zhao L. (2016) Attention-based LSTM for aspect-level sentiment classification. Proceedings of the 2016 Conference on Empirical Methods in Natural Language Processing (EMNLP), Austin, USA, 1-5 November 2016, pp. 606-615. DOI: 10.18653/v1/D16-1058.

25. Caruana R. (1993) Multitask learning: A knowledge-based source of inductive bias. Proceedings of the 10th International Conference on International Conference on Machine Learning, Amherst, USA, 27-29 June 1993, pp. 41-48. DOI: 10.1016/b978-1-55860-307-3.50012-5.

26. Hashimoto K., Xiong C., Tsuruoka Y., Socher R. (2017) A joint many-task model: Growing a neural network for multiple NLP tasks. Proceedings of the 2017 Conference on Empirical Methods in Natural Language Processing (EMNLP), Copenhagen, Denmark, 7-11 September 2017, pp. 1923-1933.

DOI: $10.18653 / \mathrm{v} 1 / \mathrm{D} 17-1206$. 
27. Grave E., Bojanowski P., Gupta P., Joulin A., Mikolov T. (2018) Learning word vectors for 157 languages. Proceedings of the 11th International Conference on Language Resources and Evaluation (LREC 2018), Miyazaki, Japan, 7- 12 May 2018, pp. 3483-3487.

28. Jebbara S., Cimiano P. (2016) Aspect-based relational sentiment analysis using a stacked neural network architecture. Proceedings of the 22nd European Conference on Artificial Intelligence, The Hague,

The Netherlands, 29 August -2 September, 2016, pp. 1123-1131. DOI: 10.3233/978-1-61499-672-9-1123.

\section{About the authors}

\section{Egor I. Gribkov}

Doctoral Student, Department of Data Processing Automation, Tomsk State University of Control Systems and Radioelectronics, 40, Prospect Lenina, Tomsk 634050, Russia;

Machine Learning Engineer, TomskSoft LLC, 8, Nahimova Street, Tomsk 634034, Russia;

E-mail: drnemor@gmail.com

\section{Yuri P. Yekhlakov}

Dr. Sci. (Tech.), Professor;

Professor, Department of Data Processing Automation,

Tomsk State University of Control Systems and Radioelectronics, 40, Prospect Lenina, Tomsk 634050, Russia;

E-mail: upe@tusur.ru

ORCID: 0000-0003-1662-4005 


\title{
Clinical pathways analysis of patients in medical institutions based on hard and fuzzy clustering methods
}

Elizaveta S. Prokofyeva ${ }^{a}$

E-mail: prokofyeva.liza@gmail.com

Roman D. Zaytsev ${ }^{\mathrm{b}}$

E-mail: Roman.Zaitsev@fors.ru

${ }^{a}$ National Research University Higher School of Economics

Address: 20, Myasnitskaya Street, Moscow 101000, Russia

${ }^{\mathrm{b}}$ FORS Group

Address: 3, Trifonovskiy Tupik Street, Moscow 129272, Russia

\begin{abstract}
Modeling the processes in a healthcare system plays a large role in understanding its activities and serves as the basis for increasing the efficiency of medical institutions. The tasks of analyzing and modeling large amounts of urban healthcare data using machine learning methods are of particular importance and relevance for the development of industry solutions in the framework of digitalization of the economy, where data is the key factor in production. The problem of automatic analysis and determination of clinical pathways groups of patients based on clustering methods is considered in this research. Existing projects in this area reflect a great interest on the part of the scientific community in such studies; however, there is a need to develop a number of methodological approaches for their further practical application in urban outpatient institutions, taking into account the specifics of the organization being analyzed. The aim of the study is to improve the quality of management and segmentation of patient input flow in urban medical institutions based on cluster analysis methods for the further development of recommendation services. One approach to achieving this goal is the development and implementation of clinical pathways, or patient trajectories. In general, the clinical pathway of a patient might be interpreted as the trajectory when receiving medical services in respective institutions. The approach of developing groups of patient routes by the hierarchical agglomerative algorithm with the Ward method and Additive Regularization of Topic Models (ARTM) is presented in this article. A computational experiment based on public data on the routes of patients with a
\end{abstract}


diagnosis of sepsis is described. One feature of the proposed approach is not just the automation of the determination of similar groups of patient trajectories, but also the consideration of clinical pathways patterns to form recommendations for organizing the resource allocation of a medical institution. The proposed approach to segmenting the input heterogeneous flow of patients in urban medical institutions on the basis of clustering consists of the following steps: 1) preparing the data of the medical institution in the format of an event log; 2) encoding patient routes; 3 ) determination of the upper limit of the clinical pathway length; 4) hierarchical agglomerative clustering; 5) additive regularization of topic models (ARTM); 6) identifying popular patient route patterns. The resulting clusters of routes serve as the foundation for the further development of a simulation model of a medical institution and provide recommendations to patients. In addition, these groups may underlie the development of the robotic process automation system (RPA), which simulates human actions and allows you to automate the interpretation of data to manage the resources of the institution.

Key words: cluster analysis; data; hierarchical clustering; topic modeling; silhouette coefficient; healthcare; clinical pathways; process mining.

Citation: Prokofyeva E.S., Zaytsev R.D. (2020) Clinical pathways analysis of patients in medical institutions based on hard and fuzzy clustering methods. Business Informatics, vol. 14, no 1, pp. 19-31.

DOI: $10.17323 / 2587-814 X .2020 .1 .19 .31$

\section{Introduction}

$\mathrm{T}$ The rapidly evolving data analysis technologies play a huge role in healthcare. The current level of automation of medical care allows you to process large amounts of information and use the accumulated data to solve optimization problems. Medical institutions have data on receptions, but the traditional approach to documenting visits does not allow a complete representation of the main trajectories of patients and its automatic analysis.

An important area of data processing technologies in healthcare is work optimization of medical institutions: an effective schedule for medical personnel, forecasting the patient flow, planning and distribution of resources, reducing queues and other tasks. Modern analytical technologies facilitate the development of decision-making tools based on empirical data. For example, aggregated data on the actual movements of patients between medical institutions and specialists within these institutions allow one to plan the load of resources, ensure a high level of service availability and optimize the organization's work based on the real demand for these services. Based on such data, patient flow management information systems are actively developing [1, 2].

The development and implementation of clinical pathways, or patient paths, is an important tool in healthcare management. In general, the clinical pathway of a patient is a trajectory when receiving services in respective institutions. According to the source [3], clinical pathways have been introduced internationally since the 1980s. This methodology was presented in medical institutions in Sweden in the mid-1990s; and in the United States, according to source [3], approximately $80 \%$ of hospitals used clinical pathways to improve the quality of care.

In the study [4], the authors described the clinical pathway as a plan which reflects the goals for patients and determines the sequence and time of actions necessary to achieve these goals with optimal efficiency.

According to sources [5,6], the developed clinical pathways were integrated into the electronic document management of medical institutions. However, the rapid growth 
of available data and digital images revealed the need for automatic determination of the patient's clinical pathway based on these data. The solution for the automatic identification of a personal clinical pathway was the technology of process mining $[7,8]$, data mining [9], machine learning algorithms [10, $11]$ and others.

In research papers, there are various definitions of a clinical pathway. For example, according to [12], the clinical pathway can be defined as a structured care plan with the indicated main stages and terms of treatment of patients. It is important to note that each trajectory of the patient is unique and corresponds to his or her medical history [12]. The clinical pathways may include a chain of events corresponding to the profile of the medical institution: initial appointment with the therapist, laboratory tests, obtaining advice from a specific specialist, and others. In [13], the authors pointed out that the identification of clinical pathway patterns can potentially complement the information about the intentions and behavior of the patient and can serve as a basis for further analysis of patient movements.

In this article, hard and fuzzy clustering methods are considered to solve the problem of automatic analysis and segmentation of clinical pathways in order to improve standardization of management and further solution of optimization problems as well as development of relevant services for patients.

The article has the following structure. Section 1 presents the existing approaches to modeling the patient's clinical pathways. Section 2 contains formal definitions generally accepted for modeling clinical pathways, and a methodology for their cluster analysis. A computational experiment using the example of open hospital data and its results are described in Section 3. The Conclusion lists the main trends and directions for further work.

\section{Existing approaches to modeling clinical pathways of patients}

There are many papers [14-18] devoted to the research and analysis of clinical pathways based on initial data of a medical institution. Clinical pathways modeling might be developed on the methodological base of probability theory, mathematical statistics, data mining, graph theory, semantic technologies, process mining, etc.

In a study [14], the authors noted the importance of developing an adaptive approach to modeling clinical pathways due to the high variability of patient trajectories and their individual characteristics. Based on proposed graphs of sequences and data mining methods, patterns or patterns of the clinical pathways of stroke patients are distinguished to predict the trajectories of new patients.

The semi-Markov model of individual patient experience in a family practice clinic is presented in [15]. The scheme of the general patient flow in this clinic is represented by an oriented graph, the vertices of which are the rooms and departments of the clinic, and edges correspond to the direction of movement of the analyzed flow. This model allows one to predict the duration of patient care, but such parameters as the waiting time in the queue and the length of the queue are not available for analysis.

Modeling patient trajectories by Markov chains in [16] made it possible to identify typical clinical pathways during disease progression and visualize it. Due to the ability of Markov chains to take into account nested models, in [16] the clinical pathway is presented in the form of four levels of aggregation. According to the authors of [12], the nested design allows one to simplify the clinical pathway model and highlight the most important regularities of the process. However, as the main drawback of the Markov chain for modeling the clinical pathway, the authors of the study highlight a limited number of states to handle. 
The probabilistic topic modeling method, in particular, Latent Dirichlet Allocation (LDA), was adapted to model the clinical pathways of patients in study [13], where the authors suggested that LDA would allow the hidden treatment patterns of patients to be presented as probabilistic combinations of initial events from the event log (Figure 1). The latent Dirichlet distribution is a generative hierarchical probabilistic model described in 2003 in a study [17] and originally developed to characterize text documents. The parameters of this model are generated from the a priori Dirichlet distribution, and the Bayesian approach methods are used to train the model [17]. The document in the LDA model is represented by a distribution of hidden (latent) topics, each of which is characterized by a distribution of words. In the framework of this study, topics of documents correspond to the patterns of clinical pathways obtained.

A special place among the methods for modeling the clinical pathways of patients is taken by the application of process mining. The development of a process model is based on initial data on the real behavior of patients, their routes and the main characteristics that affect the choice of a particular trajectory. The purpose of process mining is to extract new information about processes from event logs. Thus, process mining as a discipline combines machine learning, data mining, and process modeling techniques. The main ideas of this discipline are described in [19-22].

A number of studies are devoted to the development of process analysis algorithms: for example, the eMotivia algorithm for analyzing the movements of nine patients over 25 weeks [23]. A detailed list of algorithms for process mining in healthcare is given in [7], based on a review of 74 studies in this field. It is important to note that the results of the application of process mining allows one to objectively evaluate the past and current movement of patient flow, however, for a detailed study of the system's behavior and the experimental part for its improvement, it is necessary to develop a simulation model [12, 20, 24].

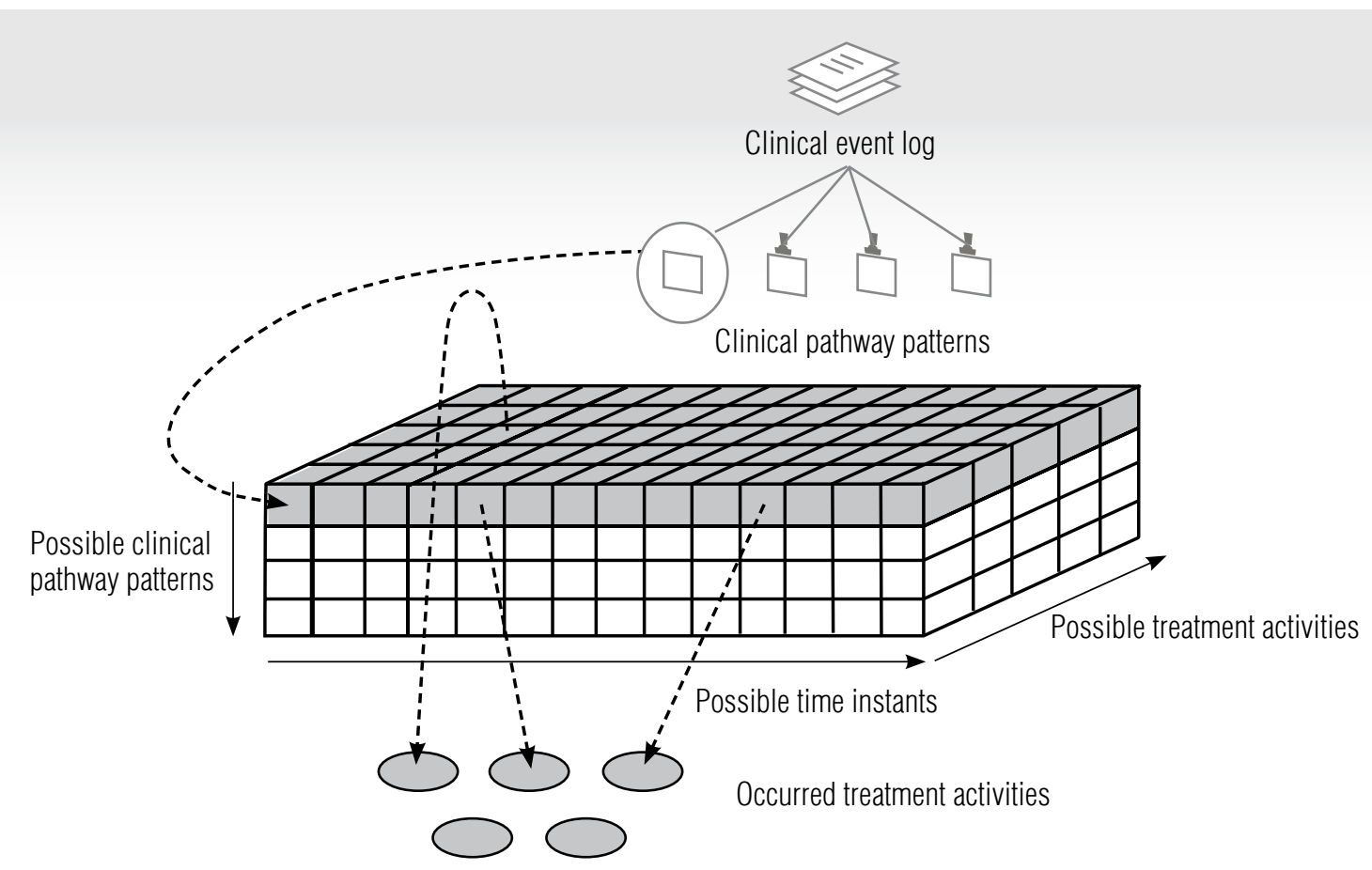

Fig. 1. Study of clinical pathway patterns based on probabilistic topic modeling [13] 


\section{Methods of cluster analysis of clinical pathways of patients}

\subsection{Terms and definitions}

The specific structure of clinical pathways allows us to use cluster analysis of time series. This is due to the fact that the series by which clinical paths are expressed can have both categorical and numerical nature. One of the ways to significantly increase the accuracy of the model so developed is to segment the initial sample into subgroups of objects similar to each other and to construct separate "personalized" models for each of the selected groups in the future. This study aims to identify such groups, or clusters, of clinical pathways based on event logs of medical institutions.

Some formal definitions generally accepted for modeling clinical pathways [12-14]. Let $\mathrm{E}$ be the set of all real events in the study area that occurred during the medical care process: $\mathrm{E} \subseteq \mathrm{A} \times \mathrm{T}$, where $\mathrm{A}$ is the finite set of event identifiers, $\mathrm{T}$ is the set of time attributes. Then the event is a pair $e=(a, t)$, where $a \in \mathrm{A}$ and $t \in \mathrm{T}$. The type of activity and time label of the clinical event is denoted as $e \cdot a$ and $e \cdot t$. It is important to note that when modeling clinical pathways, each event is uniquely determined by a combination of its attributes. Trace $\sigma$ is the event chain of the patient, a nonempty sequence of events of the clinical path: $\sigma=\left\langle e_{1}, e_{2}, \ldots, e_{n}\right\rangle$, where $e i \in \mathrm{E}(1 \leq \mathrm{i} \leq n), n \in \mathrm{N}$ is the length of the patient's route. The set of all routes over $\mathrm{E}$ is denoted by $\mathrm{E}^{*}$. The event $\log$ $\mathrm{L}$ is a non-empty set of patient routes over $\mathrm{E}^{*}$ : $\mathrm{L}=\left\{\sigma_{1}, \ldots, \sigma_{m}\right\}$, where $\sigma_{i} \in \mathrm{E}^{*}(1 \leq i \leq m), m \in \mathrm{N}$

In the framework of process mining terminology adapted for modeling the clinical pathways of patients, the following examples of definitions' correspondence can be given:

$\downarrow$ trace $\sigma_{\mathrm{i}}-$ patient attached to the analyzed clinic;

$\checkmark$ event $e_{i}-$ visit to the therapist for an initial consultation; $\downarrow$ attribute $a_{i}$ - patient characteristic (gender, age, diagnosis, etc.);

$\downarrow$ event $\log \mathrm{L}-$ the source database of the medical institution.

The structure of the event $\log \mathrm{L}$ assumes the presence of the following attributes [22]:

$\checkmark$ identifier (patient_id): stores objects for which sequences of events are built;

^ activity (activity_name): stores actions performed as part of journal events;

$\checkmark$ timestamp: stores the date and time of recording events of the journal, for example, the time of the visit to the therapist;

$\checkmark$ resource: stores the main actors of the events of the journal (those who perform actions within the framework of the events of the journal). In the context of a study, a resource may be provided by a medical professional or research equipment;

$\downarrow$ other data: other data that is potentially useful for modeling the processes of a medical institution.

\subsection{Hard clustering}

There are different patient route encoding systems. For example, in a study [25], the authors use alphanumeric characters to indicate clinical pathway activities (which may include diagnoses, procedures, analyzes, and treatment regimens) according to the Unicode standard. Thus, the authors indicate the ability to encode 65,536 activities of the clinical pathway.

The choice of coding system depends on the maximum number of activities of the event log of a medical institution. In this work, at the initial stage, all patient routes are coded by replacing events with letters of the English alphabet in order, since the initial data set for the experimental part contains 16 types of activities: ER Registration, ER Triage, IV Liquid, IV Antibiotics, CRP, Admission IC, ER Sepsis Triage, Leucocytes, Lactic Acid, Admission NC, 
Release A, Release B, Release C, Release D, Release E, Return ER.

In the context of this study, the upper limit of the length of the pathway was assumed to be 26 events: $Q 50+3 \cdot Q(Q 75-Q 50)$, where $Q 50$ is the median and $Q 75$ corresponds to $75 \%$ quantile. Therefore, pathways containing more than 26 events are considered abnormally long. After analyzing the distribution of the clinical pathways' lengths of the event log, abnormally long paths were excluded from the analysis to improve the quality of clustering.

Two clustering methods were compared: $k$-medoids [26] and the Ward hierarchical agglomerative algorithm [27]. Ward's method is based on analysis of variance methods to estimate distances between groups of objects and, along with the complete linkage method, leads to the formation of small compact clusters. The method is applicable for tasks of more fractional classification of objects with closely spaced clusters [29]. Each sample object in the Ward method is initially considered as a separate cluster [30]. At the next step of the iteration of the algorithm, the closest clusters are combined, the distance between them being measured by the following formula:

$$
\begin{gathered}
\Delta(\mathrm{A}, \mathrm{B})=\sum_{i \in \mathrm{A} \cup \mathrm{B}}\left\|\vec{x}_{i}-\vec{m}_{\mathrm{A} \cup \mathrm{B}}\right\|^{2}-\sum_{i \in \mathrm{A}}\left\|\vec{x}_{i}-\vec{m}_{\mathrm{A}}\right\|^{2}- \\
-\sum_{i \in \mathrm{B}}\left\|\vec{x}_{i}-\vec{m}_{\mathrm{B}}\right\|^{2}=\frac{n_{\mathrm{A}} n_{\mathrm{B}}}{n_{\mathrm{A}}+n_{\mathrm{B}}}\left\|\vec{m}_{\mathrm{A}}-\vec{m}_{\mathrm{B}}\right\|^{2},
\end{gathered}
$$

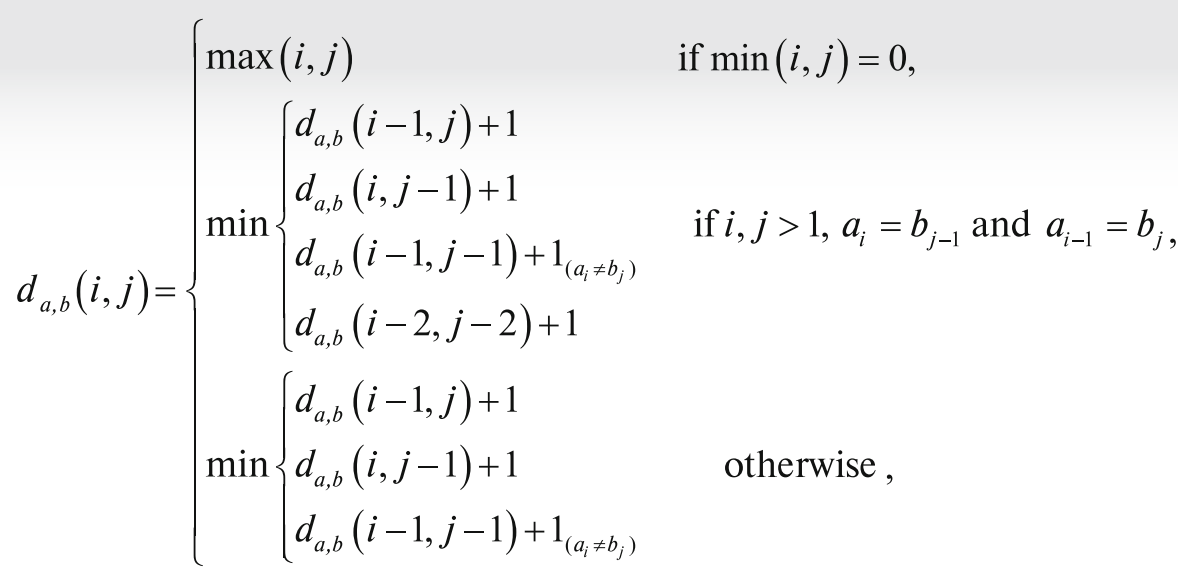


$d_{a, b}(i-1, j-1)+1_{\left(a_{i} \neq b_{j}\right)}$ corresponds to $a$ match or mismatch,

$d_{a, b}(i-2, j-2)+1$ corresponds to $a$ transposition between two successive symbols.

The optimal number of clusters was defined within a silhouette coefficient [32]. This coefficient is based on the idea of determining the proximity of each investigated object to its cluster. Suppose that the distance $d$ on the set to be clustered is given, and using a certain method a clusterization model is obtained. Let for each object of the sample $i$ belonging to the cluster $C_{i}$ the quantity $a(i)$ be equal to the average distance from $i$ to each of the objects $j$ of the same cluster:

$$
a(i)=\frac{1}{\left|c_{i}\right|} \sum_{i \neq j} d(i, j), j \in C_{i} .
$$

This value indirectly indicates how much object $\mathrm{i}$ is similar to its cluster. Further, we define a cluster $C^{\prime}$ from the set of all clusters $C$ adjacent for a point $i$, if:

$$
C^{\prime}=\underset{C_{k} \in C \backslash C_{i}}{\arg \min }\left(\frac{1}{\left|C_{k}\right|} \sum_{j \in C_{k}} d(i, j)\right) .
$$

The average distance from point $i$ to a neighboring cluster defined as $b(i)$ :

$$
b(i)=\frac{1}{\left|C^{\prime}\right|} \sum_{j \in C^{\prime}} d(i, j) .
$$

Then the silhouette coefficient of the object $i$ in the resulting model is determined as follows:

$$
s(i)=\frac{b(i)-a(i)}{\max \{a(i) ; b(i)\}} .
$$

The silhouette coefficient for each object varies in the range $[-1 ; 1]$ and shows how much closer the element is to its cluster than to the nearest neighbor. By averaging the silhouette coefficients of the elements, one can obtain the silhouettes of individual clusters

$$
s\left(C_{k}\right)=\frac{1}{\left|C_{k}\right|} \sum_{j \in C_{k}} s(j) .
$$

and the overall silhouette of the clustering model

$$
s(C)=\frac{1}{|C|} \sum_{C_{k} \in C} s\left(C_{k}\right) .
$$

The largest silhouette coefficient among clustering models obtained using the same distance $d$ can be used as an optimality criterion for choosing the preferred number of clusters $N$ and the preferred clustering algorithm. Since the results of cluster analysis should be well interpreted, it is necessary to choose a model containing clusters with the greatest silhouette. Let $K_{i}=\left\{C_{1}^{i}, C_{2}^{i}, \ldots C_{N_{i}}^{i}\right\}$ be the clustering model dividing the sample into $N i$ clusters, and $C_{\max }^{i}$ the cluster with the largest silhouette among all clusters of the $i$-th clustering model:

$$
C_{\max }^{i}=\operatorname{argmax}_{C_{j}^{i} \in K_{i}}\left(s\left(C_{j}^{i}\right)\right), j \in 1 \ldots N_{i} .
$$

Then there is a need to find model, which contains the cluster with the largest silhouette among all $K$ models:

$$
K_{\text {opt }}=\operatorname{argmax}_{K_{i} \in K}\left(C_{\max }^{i}\right) .
$$

\subsection{Soft clustering}

Probabilistic fuzzy, or overlapping, clustering of patient routes by groups of clinical patterns allows one to develop a more flexible approach when describing the total flow of patients, where each sample object belongs to a cluster with a certain weight or probability. The application of this approach is based on topic modeling, originally developed to determine the topics of a collection of text documents. In terms of topic modeling, the events of the patient during medical care are correlated with the words of the model. The patient's route is represented by a sequence of such events similar to a document with words. Thus, hidden topics discovered by the algorithm are interpreted as patterns of the patient's clinical pathways [13]. 
According to study [13], the application of the LDA method allows us to choose a set of clinical pathway patterns for each patient with different emphasis on the significance of these patterns. Thus, we model a mixture of route patterns as a polynomial probability distribution along a clinical pathway to pattern $z$. Similarly, the importance of each clinical action $a$ with each template is modeled as a polynomial probability distribution $P(a \mid \sigma)$ according to the patient's activities. These two distributions allow us to calculate the probability of a separate clinical activity in a patient:

$$
P(a \mid \sigma)=\sum_{z=1}^{K} P(a \mid z) P(z \mid \sigma) .
$$

In probabilistic generating models (for example, LDA), the available data are considered as the result of the generating process, including hidden variables [33]. In this paper, it is also noted that the generating process determines the joint probability distribution over the observed and hidden random variables. As a result, this joint distribution is used to calculate the conditional probability of hidden variables with observed or posterior probabilities. The choice of a probabilistic approach to modeling is due to the complexity of medical processes and the high variability of patient behavior during treatment.

Application of the LDA method allows each patient to choose a set of clinical pathways patterns with a different emphasis on the significance of these patterns. However, LDA chooses one of the possible solutions, without giving the researcher the opportunity to compare and choose the best solution for a specific task. In connection with this limitation, an alternative approach of Additive Regularization of Topic Models (ARTM) was developed, leading to the modularity of topic modeling technology [34]. In this work, the BigARTM library was used to determine the groups of clinical pathways, based on additive regularization. In this study, the following regularities are applied: $\checkmark$ decorrelation of the distribution of terms in topics in order to increase the diversity of these topics;

$\downarrow$ smoothing the distribution of topics in documents;

$\checkmark$ smoothing the distribution of terms in topics;

$\checkmark$ sparse out the distribution of terms in topics;

$\checkmark$ sparse out the distribution of topics in documents.

To assess the quality of modeling and determine the optimal number of topics, perplexity is used - one of the metrics implemented in the BigARTM library. In the context of this study, perplexity determines the number of basic patient patterns in the $\log$ of a medical institution [13]:

$$
P=\left[\exp -\frac{\sum_{\sigma \in L} \log P\left(e_{\sigma} \mid M\right)}{\sum_{\sigma \in L}|\sigma|}\right],
$$

where $M-$ model;

$e_{\sigma}-$ set of hidden events in the patient's trace $\sigma$.

\section{Computational experiment}

For the experiment of the proposed approach, the public event $\log$ of a Dutch hospital is considered. The event log contains 1,143 patient routes and 150,291 events. The choice of source is due to the fact that the databases contain complete and open information necessary for research tasks in the field of healthcare.

After removing anomalously long pathways, the upper limit of the pathways' length was assumed to be 26 events: $Q 50+3 \cdot(Q 75-Q 50)$, where $Q 50$ is the median and $Q 75$ corresponds to $75 \%$ of the quantile. The programming language $\mathrm{R}$ was chosen for data analysis. This language is well suited to research tasks, because it contains a rich library of packages for various scenarios [28]. The use of the $\mathrm{R}$ language also helps us to visualize data for understanding the general picture of the studied subject area 
[28]. Using the Stringdist package, the distance matrix was constructed using the Osa method (a Damerau-Levenshtein distance measure).

The model with maximum silhouette coefficient in a cluster was discovered by the compared Ward method and $k$-medoids (Figure 2), where the clusters are located along the $\mathrm{X}$ axis, and the silhouette values along the $\mathrm{Y}$ axis.

In accordance with the analysis of the coefficient values, the Ward method was chosen and the trends of the groups obtained were identified (Figure 2). Clusters with a low value were excluded (Figure 3 ), thus, as a result of experiments, clusters 5 and 6 were selected with the highest silhouette coefficient (Table 1).

A free ProcessmapR ${ }^{1}$ package is used to build a map of the processes of the original dataset. However, without preliminary separation of routes into clusters, it is difficult to interpret the resulting clinical pathways.

After determining the optimal number of clusters, process maps for the obtained groups were separately generated. For example, on the process map for cluster 5 (Figure 4), the nodes of the graph indicate the main stages of the clinical pathway for patients diagnosed with sepsis: start, registration in the appropriate unit, taking antibiotics, etc. The edges of the graph represent the transitions of patients at these stages of treatment; the numbers on the edges correspond to the number of people making this transition between nodes. More significant patient paths are marked by wider edges. Thus, the process map allows one to quickly assess the busiest routes of the medical institution. In addition, such maps can be interpreted by medical specialists in the context of comparing them with accepted medical standards to identify overloaded resource units and further reorganize the service process.

The next step was fuzzy, or "soft" clustering of the initial data by topic modeling methods in which the patient's path can refer to several patterns (topic clusters) with different probabilities. Latent Dirichlet allocation (LDA) [17] is used in the definition of clinical path clusters $[13,32]$ and is considered one of the standard

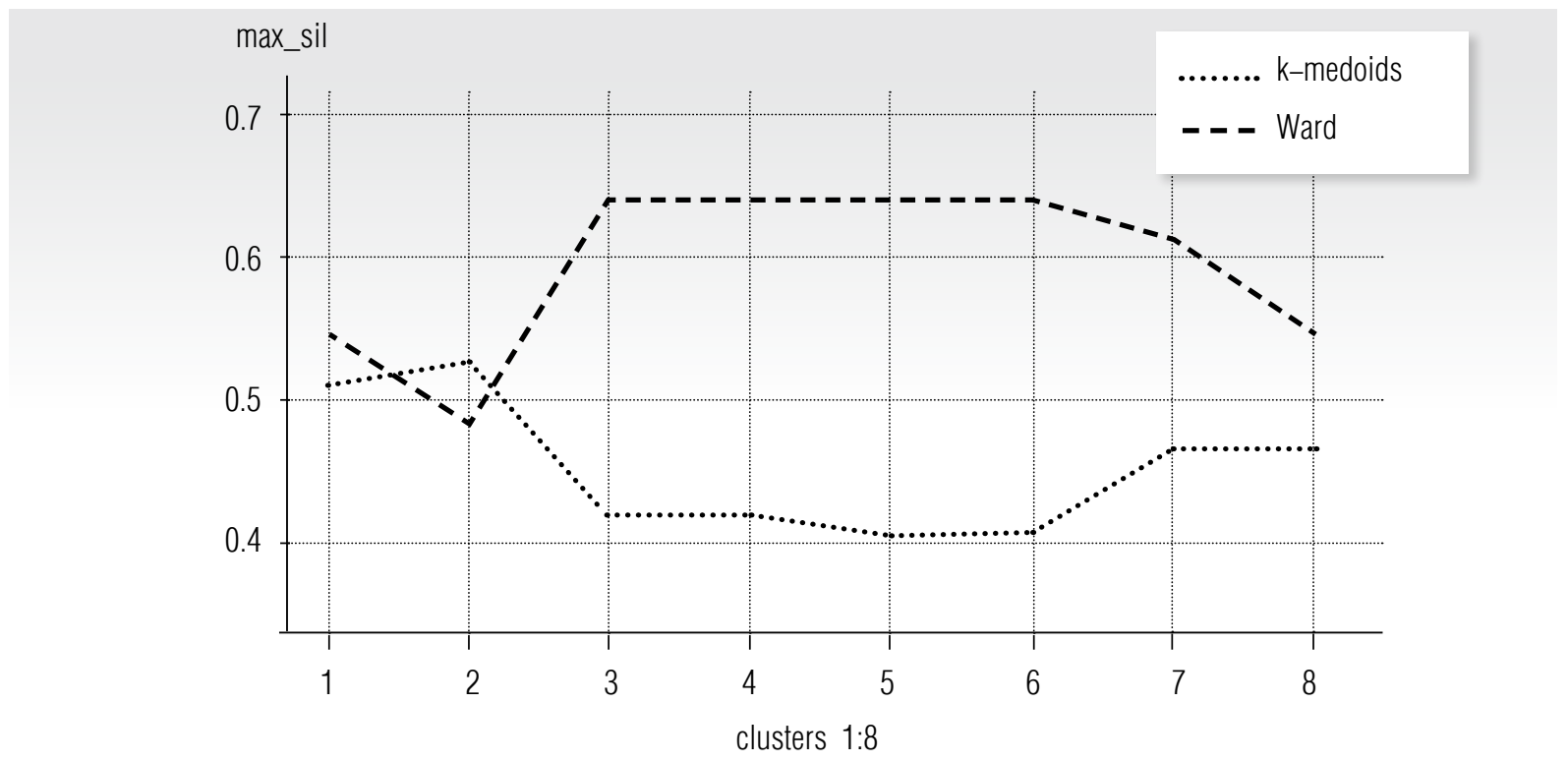

Fig. 2. Dependence of the maximum silhouette coefficient in the model on the number of clusters for k-medoids and Ward methods

\footnotetext{
${ }^{1}$ https://cran.r-project.org/web/packages/processmapR/processmapR.pdf
} 


\section{Cluster Silhouette Values}

\begin{tabular}{c|c|c}
$\begin{array}{c}\text { Cluster } \\
\text { number }\end{array}$ & $\begin{array}{c}\text { Number of } \\
\text { objects }\end{array}$ & $\begin{array}{c}\text { Silhouette } \\
\text { coefficient value }\end{array}$ \\
\hline 1 & 118 & 0.02 \\
\hline 2 & 239 & -0.02 \\
\hline 3 & 193 & 0.002 \\
\hline 4 & 228 & -0.05 \\
\hline 5 & 79 & 0.29 \\
\hline 6 & 118 & 0.64 \\
\hline
\end{tabular}

methods of topic modeling. When constructing such a topic model, an infinite number of solutions arise, leading to instability and poor interpretability of topics [34]. In order to solve such problems with the choice of the best solution, additional regularizations or optimality criteria are specified [34]. Thus, it became necessary to develop a new multicriteria approach - additive regularization of topic models (ARTM), proposed in [34].

The application of this more flexible approach to clustering the clinical pathways of patients has not been previously considered in studies. This article used the BigARTM open source library in Python, which is based on additive regularization. The data was converted to Vowpal Wabbit format, which accepts input in a specific structure: label | A feature1: value1 | B feature2: value2. This format is adapted to be categorized or modal when training a model. The model was created and trained on the initial number of topics $T=300$. Based on the calculated perplexity parameters of 63.97 and sparseness factors $\Theta=0.44$ and $\Theta=0.42$, the optimal number of clusters was chosen, equal to nine.

Each unique patient was assigned a probabilistic assessment of belonging to a par- ticular cluster. For example, for one of the patients in the sample, the distribution according to the clinical path patterns is as follows: $P_{1}=0.017998157, P_{2}=0.059349068$, $\mathrm{P}_{4}=0.5676379, \mathrm{P}_{6}=0.35303143$. Accordingly, the next step of the patient with a probability of about $57 \%$ will correspond to the behavioral pattern 4 of the cluster.

The fuzzy clustering method allows one to add a hierarchical representation of patient routes, displaying the resources of medical institutions. Dedicated clusters will be the starting point for improving the forecast of the flow of the patients, as well as for forming recommendations on the resource equipment of hospitals in the development of services.

\section{Conclusion}

Currently, medical institutions have large amounts of data, however, the traditional approach to documenting processes does not allow a complete picture of all patient trajectories and their automatic analysis in real time, taking into account predicted flow estimates.

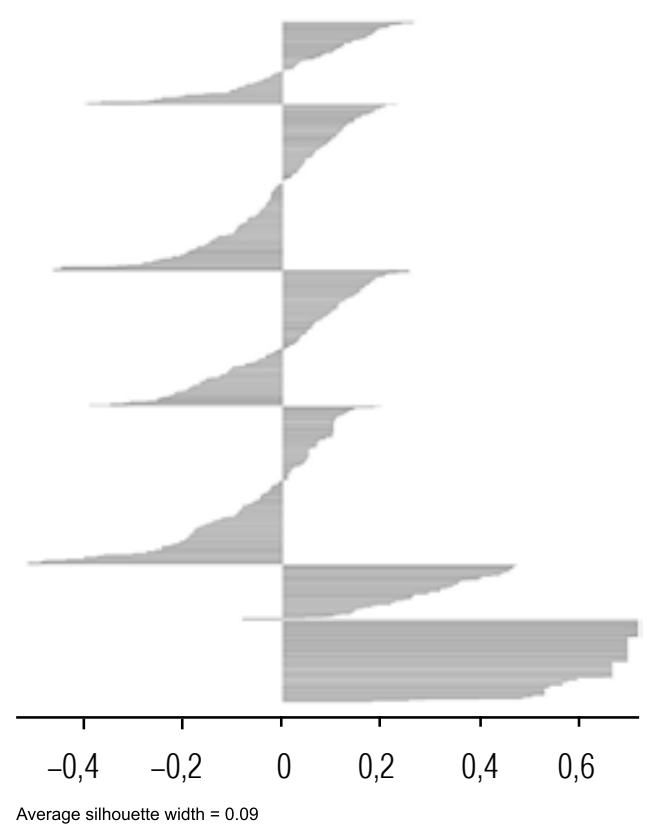

Fig. 3. Silhouette coefficients of the six resulting clusters 


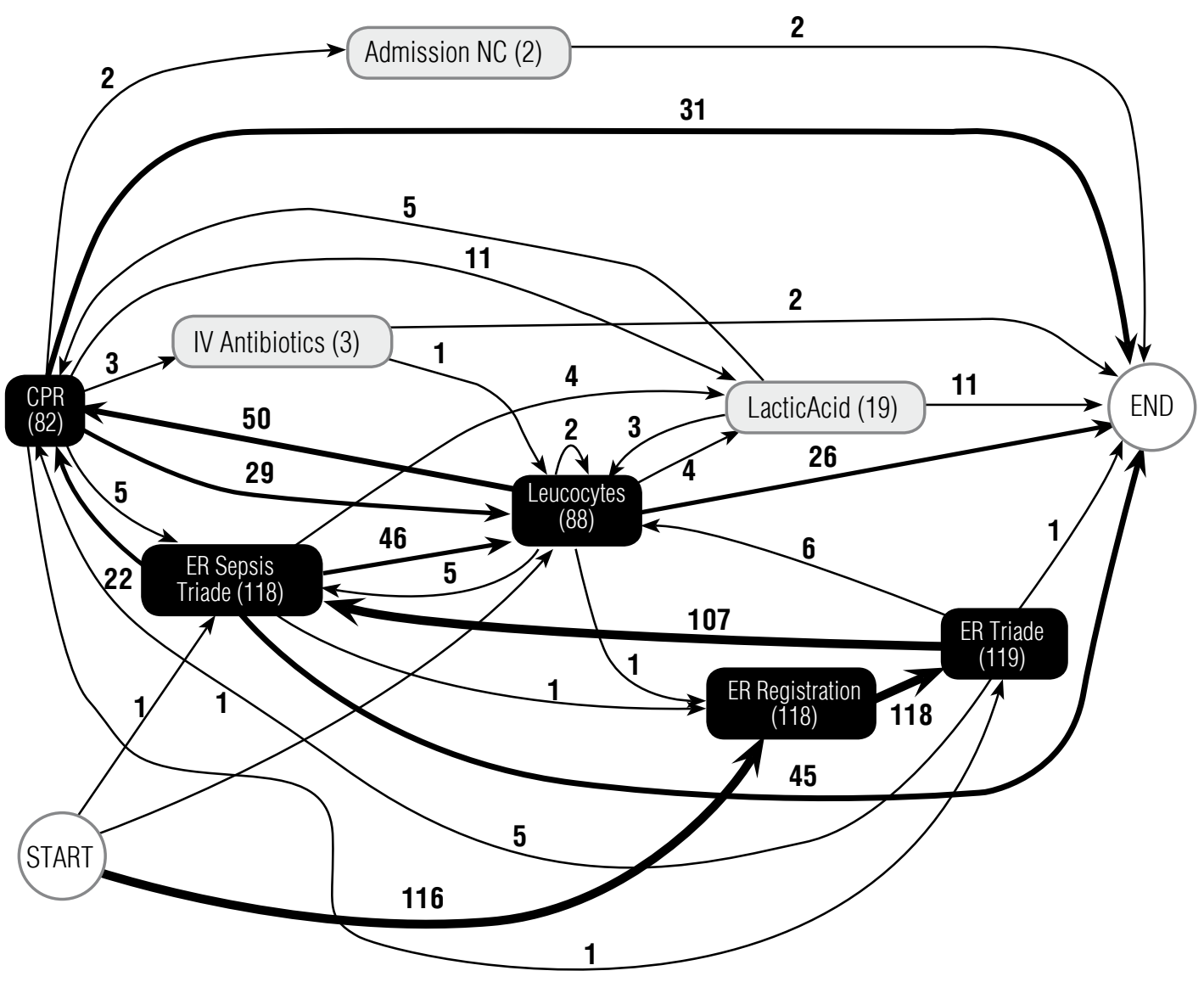

Fig. 4. Process map for cluster 5

In addition, the diverse nature of diseases is reflected in the high variability of routes.

Based on the results of analyzing a number of studies, the main methods for modeling clinical pathways were considered and the limitations of their application were identified. A methodology for the formation of patient route groups by the hierarchical agglomerative algorithm with the Ward connection method is presented. For the first time, Additive Regularization of Topic Models (ARTM) is considered to determine patterns of clinical pathways. A computational experiment based on data on the routes of patients with a diagnosis of sepsis, placed in the public domain.

The results obtained make it possible to conduct a preliminary assessment of the clinical pathways of patients of any event log, to identify bottlenecks in the system and to visualize process maps of the medical institution.

The described approaches to segmentation of the input heterogeneous flow serve as the foundation for the further development of a simulation model of a medical institution and for providing advisory services to patients, for example, chat bots on web pages of a clinic for consulting services.

Medical institutions that are the first to implement these technologies will certainly have a competitive advantage. Consequently, managers and other interested parties will be able to gain access to complete information, which will allow them to make more informed decisions. 


\section{References}

1. Ilyushin G.Ya., Limanskij V.I. (2015) Development of the patient flow management system. Systems and Approaches of Informatics, vol. 25, no 1, pp. 186-197 (in Russian).

2. Azanov V.G. (2016) Structural-functional model of patient flow management. Systems and Approaches of Informatics, vol. 26, no 1, pp. 13-29 (in Russian).

3. Kinsman L., Rotter T., James E., Snow P., Willis J. (2010) What is a clinical pathway? Development of a definition to inform the debate. BMC Medicine, vol. 8, no 31. DOI: 10.1186/1741-7015-8-31.

4. Pearson S.D., Goulart-Fisher D., Lee T.H. (1995) Critical pathways as a strategy for improving care: Problems and potential. Annals of Internal Medicine, vol. 123, no 12, pp. 941-948.

5. Wakamiya S., Yamauchi K. (2009) What are the standard functions of electronic clinical pathways? International Journal of Medical Informatics, vol. 78, no 8, pp. 543-550. DOI: 10.1016/j.jimedinf.2009.03.003.

6. Veselý A., Zvárová J., Peleska J., Buchtela D., Anger Z. (2006) Medical guidelines presentation and comparing with electronic health record. International Journal of Medical Informatics, vol. 75, no 3-4, pp. 240-245. DOI: 10.1016/j.jjmedinf.2005.07.016.

7. Rojas E., Munoz-Gama J., Sepúlveda M., Capurro D. (2016) Process mining in healthcare: A literature review. Journal of Biomedical Informatics, no 61, pp. 224-236. DOI:10.1016/j.jbi.2016.04.007.

8. Huang Z., Lu X., Duan H. (2012) On mining clinical pathway patterns from medical behaviors. Artificial Intelligence in Medicine, vol. 56, no 1, pp. 35-50. DOI: 10.1016/j.artmed.2012.06.002.

9. Rakocevic G., Djukic T., Filipovic N., Milutinović V. (2013) Computational medicine in data mining and modeling. N.Y.: Springer. DOI: 10.1007/978-1-4614-8785-2.

10.Ahmad M. A., Teredesai A., Eckert C. (2018) Interpretable machine learning in healthcare. Proceedings of the 2018 IEEE International Conference on Healthcare Informatics (ICHI), New York, NY, USA, 4-7 June 2018, pp. 447-447. DOI: 10.1109/ICHI.2018.00095.

11.Rotter T., Kinsman L., James E.L., Machotta A., Gothe H., Willis J., Snow P., Kugler J. (2010) Clinical pathways: effects on professional practice, patient outcomes, length of stay and hospital costs: Cochrane database of systematic reviews and meta-analysis. Evaluation \& the Health Professions, vol. 35, no 1, pp. 3-27. DOI: $10.1177 / 0163278711407313$.

12.Prodel M. (2017) Process discovery, analysis and simulation of clinical pathways using health-care data. Université de Lyon. Available at: https://tel.archives-ouvertes.fr/tel-01665163/document (accessed 25 November 2019).

13.Huang Z., Dong W., Ji L., Gan C., Lu X., Duan H. (2014) Discovery of clinical pathway patterns from event logs using probabilistic topic models. Journal of Biomedical Informatics, no 47, pp. 39-57.

DOI: $10.1016 /$ j.jbi.2013.09.003.

14.Lin F., Chou S., Pan S., Chen Y. (2001) Mining time dependency patterns in clinical pathways. International Journal of Medical Informatics, vol. 62, no 1, pp. 11-25. DOI: 10.1016/S1386-5056(01)00126-5.

15.Cote M.J., Stein W.E. (2007) A stochastic model for a visit to the doctor's office. Mathematical and Computer Modelling, vol. 45, no 3-4, pp. 309-323. DOI: 10.1016/j.mcm.2006.03.022.

16.Zhang Y., Padman R., Patel N. (2015) Paving the cowpath: Learning and visualizing clinical pathways from electronic health record data. Journal of Biomedical Informatics, no 58, pp. 186-197.

17.Blei D.M., Ng A.Y. Jordan M.I. (2003) Latent Dirichlet allocation. The Journal of Machine Learning Research, no 3, pp. 993-1022.

18.Fernández-Llatas C., Benedi J.-M., García-Gómez J.M., Traver V. (2013) Process mining for individualized behavior modeling using wireless tracking in nursing homes. Sensors (Basel), vol. 13, no 11, pp. 15434-15451. DOI: $10.3390 / \mathrm{s} 131115434$.

19.van der Aalst W.M.P. (2011) Process mining: Discovery, conformance and enhancement of business processes. Springer. DOI: 10.1007/978-3-642-19345-3.

20.van der Aalst W.M.P. (2018) Process mining and simulation: A match made in heaven! Proceedings of the 50th Computer Simulation Conference (SummerSim 2018). Bordeaux, France, 9-12 July 2018. DOI: 10.22360/summersim.2018.scsc.005.

21.van der Aalst W.M.P. (2016) Process mining: Data science in action. Berlin: Springer-Verlag. 
22.van der Aalst W.M.P. (2011) Process mining manifesto. Business Process Management Workshops. Springer, pp. 169-194. DOI: 10.1007/978-3-642-28108-2_19.

23.Fernández-Llatas C., Meneu T., Benedí J.M., Traver V. (2010) Activity-based process mining for clinical pathways computer aided design. Proceedings of the 2010 Annual International Conference of the IEEE Engineering in Medicine and Biology. Buenos Aires, Argentina, 31 August - 4 September 2010, pp. 6178-6181. DOI: 10.1109/IEMBS.2010.5627760.

24.Kovalchuk S.V., Funkner A.A., Metsker O.G., Yakovlev A.N. (2018) Simulation of patient flow in multiple healthcare units using process and data mining techniques for model identification. Journal of Biomedical Informatics, no 82, pp. 128-142.

25.Williams R., Buchan I., Prosperi M., Ainsworth J. (2014) Using string metrics to identify patient journeys through care pathways. Proceedings of the AMIA Annual Symposium, Washington, DC, USA, 15-19 November 2014, pp. 1208-1217.

26.Kaufmann L., Rousseeuw P. (1987) Clustering by means of medoids. Data analysis based on the L1-norm and related methods, pp. 405-416.

27.Ward J.H. (1963) Hierarchical grouping to optimize an objective function. Journal of the American Statistical Association, vol. 58, no 301, pp. 236-244.

28.Zaitsev R.D., Britkov V.B. (2015) The use of the R language for multidimensional clustering of time series in order to analyze the dynamics of scientific and technological development. Transactions of the Second Youth Scientific Conference "Problems of Modern Computer Science", Moscow, 29-30 October 2015, pp. 92-98.

29.Ferreira L., Hitchcock D. (2009) A comparison of hierarchical methods for clustering functional data. Communications in Statistics - Simulation and Computation, no 38, pp. 1925-1949. DOI: $10.1080 / 03610910903168603$.

30.Konnov I.V., Kashina O.A., Gilmanova E.I. (2019) Solving the clustering problem by optimization methods on graphs. Scientific Letters of the Kazan University, Series Physical and Mathematical Sciences, vol. 161, pp. 423-437 (in Russian). DOI: 10.26907/2541-7746.2019.3.423-437.

31.Boytsov L. (2011) Indexing methods for approximate dictionary searching. Journal of Experimental Algorithmics, vol. 16, no 1, article no 1.1. DOI: 10.1145/1963190.1963191.

32. Rousseeuw P.J. (1987) Silhouettes: A graphical aid to the interpretation and validation of cluster analysis. Journal of Computational and Applied Mathematics, vol. 20, pp. 53-65. DOI: 10.1016/0377-0427(87)90125-7.

33.Huang Z., Lu X., Duan H., Fan W. (2013) Summarizing clinical pathways from event logs. Journal of Biomedical Informatics, vol. 46, no 1, pp. 111-127. DOI: 10.1016/j.jbi.2012.10.001.

34.Vorontsov K.V., Potapenko A.A. (2014) Tutorial on probabilistic topic modeling: Additive regularization for stochastic matrix factorization. AIST'2014, Analysis of Images, Social Networks and Texts. Communications in Computer and Information Science. Springer, pp. 265-267.

\section{About the authors}

\section{Elizaveta S. Prokofyeva}

Doctoral Student, Department of Innovation and Business in Information Technologies,

National Research University Higher School of Economics,

20, Myasnitskaya Street, Moscow 101000, Russia;

E-mail: prokofyeva.liza@gmail.com

ORCID: 0000-0003-1322-2932

\section{Roman D. Zaytsev}

Senior Expert for Data Analysis, FORS Group,

3, Trifonovskiy Tupik Street, 129272 Moscow, Russia;

E-mail: roman.zaitsev@fors.ru

ORCID: 0000-0002-8313-3727 


\title{
Theoretical comparative analysis of cascading, iterative, and hybrid approaches to IT project life cycle management
}

\author{
Dmitry V. Pervoukhin a,b
}

E-mail:dpervuhin@hse.ru

\section{Eugeni A. Isaev ${ }^{\mathrm{a}}$}

E-mail: eisaev@hse.ru

Georgy O. Rytikov ${ }^{\mathrm{c}}$

E-mail: GR-yandex@yandex.ru

\section{Ekaterina K. Filyugina ${ }^{\mathrm{a}}$}

E-mail: ekfilyugina@edu.hse.ru

\section{Diana A. Hayrapetyan ${ }^{a}$}

E-mail: hayrapetyandiana@gmail.com

a National Research University Higher School of Economics

Address: 20, Myasnitskaya Street, Moscow 101000, Russia

${ }^{\mathrm{b}}$ Financial University under the Government of the Russian Federation Address: 49, Leningradsky Prospect, Moscow 125993, Russia

${ }^{\mathrm{c}}$ Moscow Polytechnic University, Higher School of Press and Media Industry

Address: 2A, Pryanishnikov Street, Moscow 127550, Russia

\section{Abstract}

The absence of a common and universal approach to IT project management allows us to formulate a problem to analyze and study when choosing the most efficient project management methodology. The relatively small number of scientific works summarizing practical experience of a theoretical approach allowed us to formulate a generalized mathematical model for a common IT project lifecycle estimation in this work using waterfall, agile or hybrid approaches for the project management. Based on the advantages and disadvantages of existing methodologies that we revealed, it appears that use 
of agile approaches within stages of the cascade methodology approach improves the process of IT project management compared to a pure cascade implementation. Moreover, the recursive application of an iterative approach at certain stages of the project implementation worsens the characteristics of the project life cycle and can be used only to reduce a certain class of project risks. The results of our study allow us to propose a semi-empirical method for project planning estimation accuracy and attainability of the declared project implementation characteristics. All of this should have a positive impact on the effectiveness of the IT project management strategy choice.

Key words: IT project management; iterative methodology; Agile; waterfall; hybrid methodology; model analysis.

Citation: Pervoukhin D.V., Isaev E.A., Rytikov G.O., Filyugina E.K., Hayrapetyan D.A. (2020) Theoretical comparative analysis of cascading, iterative, and hybrid approaches to IT project life cycle management. Business Informatics, vol. 14, no 1, pp. 32-40.

DOI: 10.17323/2587-814X.2020.1.32.40

\section{Introduction}

$\mathrm{D}$ espite their long history [1], the discussions considering advantages and disadvantages of cascade and iterative approaches to IT project life cycle management in general and software development in particular have continued until recently [2, 3]. Starting from 2009, PMI recommends a hybrid version of the project management methodology (PMBOK-4) [4], in which the cascade WaterFall (WF) methodology is used for strategic planning [5], and the main project stages are implemented iteratively (Agile) [6]. In recent years, much attention has been paid to the comparative analysis of risks connected with the use of WF [7] and Agile [8,9] modifications, to the necessity of adapting flexible project management approaches to the characteristics of the subject area (banking, medicine) $[10-12]$, to the optimization of the structural combination of flexible and cascade methodologies [13], etc. In most cases, however, when describing WF shortcomings, the authors of scientific articles, books and reports at conferences rely on numerous accumulated data on project realization or implementation failure using the cascade methodology [14], while the advantages of Agile are mainly demonstrated with the help of successful implementation examples of relevant projects [15-17].

Thus, the "opponents" of a flexible methodology always cite the lack of representative statistics on the Agile projects' implementation, any specific features of the subject area for the successful application of the iterative approach [18] and the lack of a clear system structure and project management processes using iterative approach modifications. The "compromise" outcome is the hybridization of various schemes that combines the elements of the project life cycle management processes clear planning [19] and possibility of relatively effective achievement of the practical results through the use of the iterations at key stages of the project [20, 21]. In this article we consider the question of the existence of an optimal ratio of the discussed management practices application in IT. 


\section{Concept}

According to the general approaches to project management [22], one distinguishes the stages of initialization, planning, implementation and completion of a project (with a cascade approach). Moreover, typical variants of project life cycle models are presented in [23] and can be described, for example, within the framework of a generalized model:

$$
\rho(t)=\rho_{0} \cdot t^{k} \cdot \exp (-\gamma \cdot t),
$$

where $\rho(t)$ is the share of work completed by time $t$;

$\gamma, k$ - parameters that define particular forms of life cycle models;

$\rho_{0}$ - normalization factor ensuring the fulfillment of the condition

$$
\int_{0}^{\infty} \rho(t) d t=1
$$

Representation (1) allows us to describe the dynamics of project $P$ completion degree from time $\tau$ using the expression

$$
P(\tau)=\int_{0}^{\tau} \rho(t) d t=1-\exp (-\gamma \cdot t) \cdot \sum_{n=0}^{k} \frac{\tau^{n} \cdot \gamma^{n}}{n !} .
$$

Consider the individual cases $k=1,2,3,4$ describing typical particular models of the project life cycle:

$$
\begin{aligned}
\rho(t) & =\gamma^{2} \cdot t \cdot \exp (-\gamma \cdot t), \\
\rho(t) & =\frac{\gamma^{3}}{2} \cdot t^{2} \cdot \exp (-\gamma \cdot t), \\
\rho(t) & =\frac{\gamma^{4}}{6} \cdot t^{3} \cdot \exp (-\gamma \cdot t), \\
\rho(t) & =\frac{\gamma^{5}}{24} \cdot t^{4} \cdot \exp (-\gamma \cdot t) .
\end{aligned}
$$

According to (2), they correspond to particular models of the project dynamics:

$$
P(\tau)=1-(\gamma \cdot \tau+1) \cdot \exp (-\gamma \cdot \tau),
$$

$$
\begin{gathered}
P(\tau)=1-\left(\frac{(\gamma \cdot \tau)^{2}}{2}+(\gamma \cdot \tau)+1\right) \cdot \exp (-\gamma \cdot \tau), \\
P(\tau)=1-\left(\frac{(\gamma \cdot \tau)^{3}}{6}+\frac{(\gamma \cdot \tau)^{2}}{2}+\right. \\
+(\gamma \cdot \tau)+1) \cdot \exp (-\gamma \cdot \tau) \\
P(\tau)=1-\left(\frac{(\gamma \cdot \tau)^{4}}{24}+\frac{(\gamma \cdot \tau)^{3}}{6}+\frac{(\gamma \cdot \tau)^{2}}{2}+\right. \\
+(\gamma \cdot \tau)+1) \cdot \exp (-\gamma \cdot \tau) .
\end{gathered}
$$

Figure 1 shows several variants of life cycle models and corresponding models of dynamics of project completion degree.

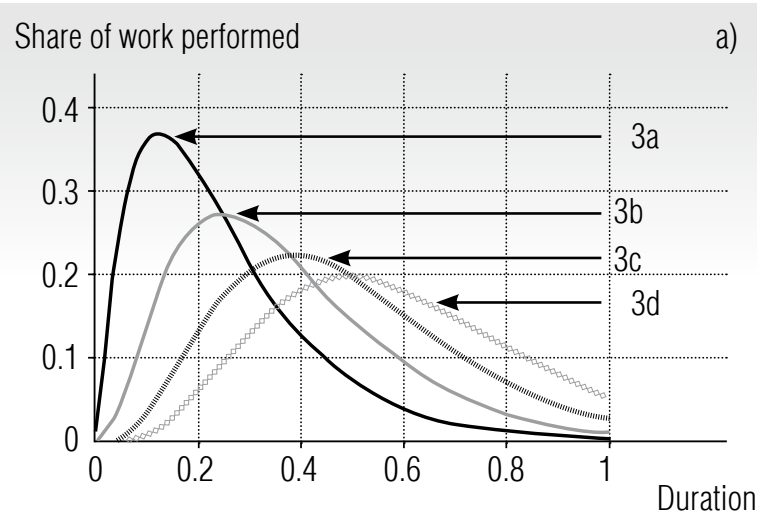

Project implementation degree

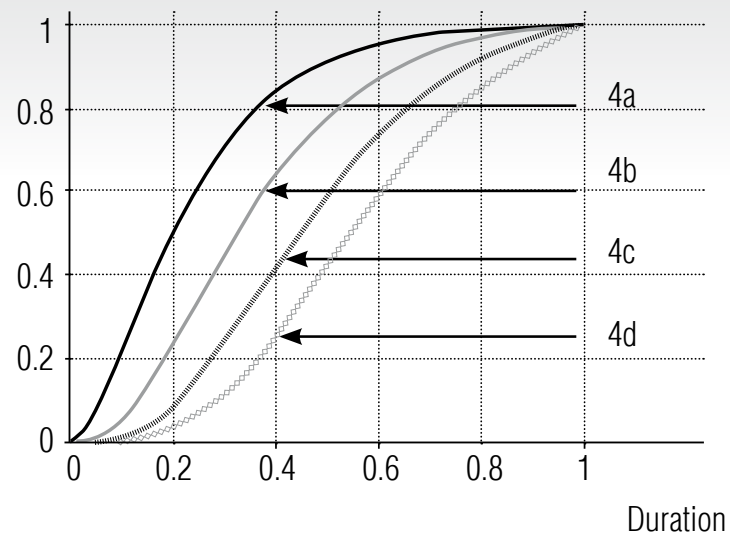

Fig. 1. Variants of life cycle models (a) and dynamics of the project completion degree,

(b) depending on the normalized duration of its implementation (for $\gamma=1$ ) 
To simplify further calculations, we chose a way to represent the model functions in a piecewise linear form (for example, highlighting the stages of the life cycle):

$$
P(\tau) \cong\left\{\begin{array}{l}
a_{1} \cdot \tau+b_{1}, \tau \in\left[0 ; 1,25 \cdot \tau_{1}\right) \\
a_{2} \cdot \tau+b_{2}, \tau \in\left[0,75 \cdot \tau_{1} ; 1,25 \cdot \tau_{2}\right) \\
a_{3} \cdot \tau+b_{3}, \tau \in\left[0,75 \cdot \tau_{2} ; 1,25 \cdot \tau_{3}\right) \\
a_{4} \cdot \tau+b_{4}, \tau \in\left[0,75 \cdot \tau_{3} ; \tau_{4}\right]
\end{array}\right.
$$

where $a_{3}>a_{2}>a_{4}>a_{1}$ with $k=4$, we obtain a simplified model of the project dynamics under the cascade paradigm of planning and management (Figure 2).

\section{Advantages and disadvantages}

According to the cascade paradigm, the end of the previous and the beginning of the subsequent work "overlap" by about $25 \%$. As a result, an advantage is achieved over the relay paradigm, in which the end of the previous work coincides with the beginning of the next one. The "time overlapping" degree of the project implementation neighboring stages determines the difference between cascade and relay planning and also affects the parameters of the lines

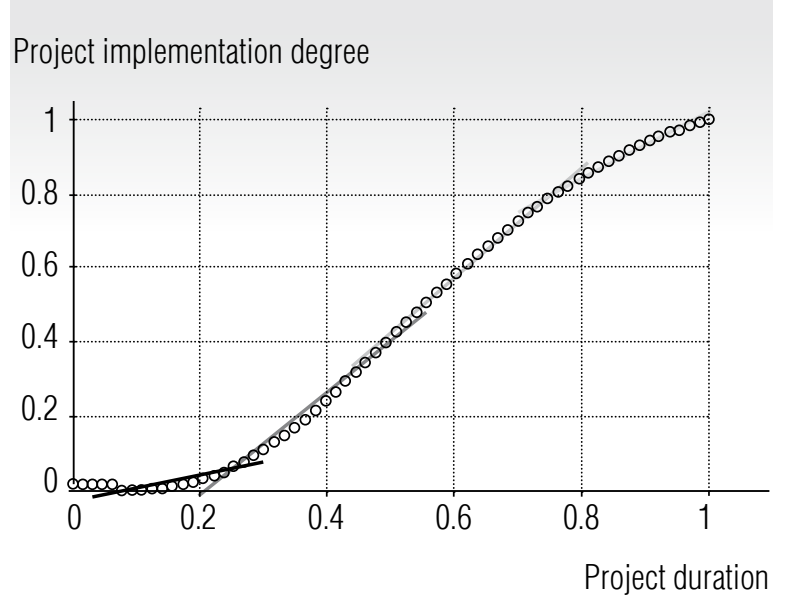

Fig. 2. Dynamics of an abstract project completion degree formed (4d) and the corresponding piecewise-linear model (5) are represented by circles and line segments, respectively equations, the segments of which form a graph of a piecewise-linear function that describes the project realization dynamics. The parameters of linear equations that describe the discussed lines were found by the least squares method [24].

Note that the very emergence of a cascading approach to project management owes its origin to the application of an iterative approach to the relay planning paradigm, because the possibility of actual overlapping in time of the end of the previous and the beginning of the subsequent work is associated with the allocation of the basic and improved versions of the implementation of each stage of the work. As a result, the subsequent work may begin at the end of the basic component execution of the previous work, rather than at the end of all modifications and corrections to the previous work.

A well-known drawback of the cascade (and, especially, relay) approach is the absence of possibility of coordination with the customer about the list of executed works and intermediate results in the course of project performance $[25,26]$. The introduction of elements of iterative approaches to solving certain groups of tasks within the framework of a cascade "strategic plan" of the project is actually a modern standard of project management [27, 28]. To illustrate the advantages of such a hybrid approach, one can, for example, divide a rough piecewise-linear model of project execution dynamics into two/ four successively executed subprojects (since resources are limited, in the model case considered the impossibility of parallel subprojects execution is postulated even with the use of a purely iterative approach to project management). Assuming that in the model case for any abstract project, the Pareto principle is observed $(80 \%$ of the tasks are completed in $20 \%$ of the time, $20 \%$ of the tasks are performed in $80 \%$ of the time), we will estimate distinctions in time of achieving the executed works level of $80 \%$ at division of the project 
into subprojects and redistributing the order of the stages that implement the elements of an iterative approach [29]. Figure 3 shows the corresponding graphs.

It is evident that at simple division of the project into subprojects taken as a basis the cascade approach, the time to reach $80 \%$ of the entire project slightly increases compared to the basic project implementation plan. However, there is an increase in the project implementation speed at the initial stages. Dividing a project into subprojects promotes an increase in average speed at initial stages of a project implementation and, as a whole, is expected to equalize the average speed of the project performance (i.e., effectively reduces the likelihood of schedule disruption). The possibility of parallelizing the work improves the situation radically. However, within the framework of this article, it is assumed that the resources are extremely limited and fixed, so that parallel work is impossible.

Obviously, even with such a model representation, the time to reach the local target indicator of the project initial stages is reduced by $4 \%$ and $14 \%$ by dividing the project into 2 and
4 subprojects. Consequently, the widely used work division into separate tasks and operations is proved to be mathematically justified from the most general assumptions.

\section{The greatest efficiency}

There is a question about "maximum possible utility" of applying an iterative approach for a "cascade" project, the predicted execution dynamics of which are described by a given piecewise-linear functional proportion dependence of successfully completed work share on the project realization duration. Since the main advantage of the iterative approach is the possibility of dynamically reconciling the sequence of stages, we consider the model (5) of the "cascade" project, in which we abandon the requirement to follow the project stages "one after another." Obviously, under the conditions of fixed resources, it is assumed that the speed of each stage cannot be changed. As a result, only the sequence of work can be coordinated with the customer. It is also obvious that, from the customer's point of view, the most effective project plan is one with $80 \%$ a)

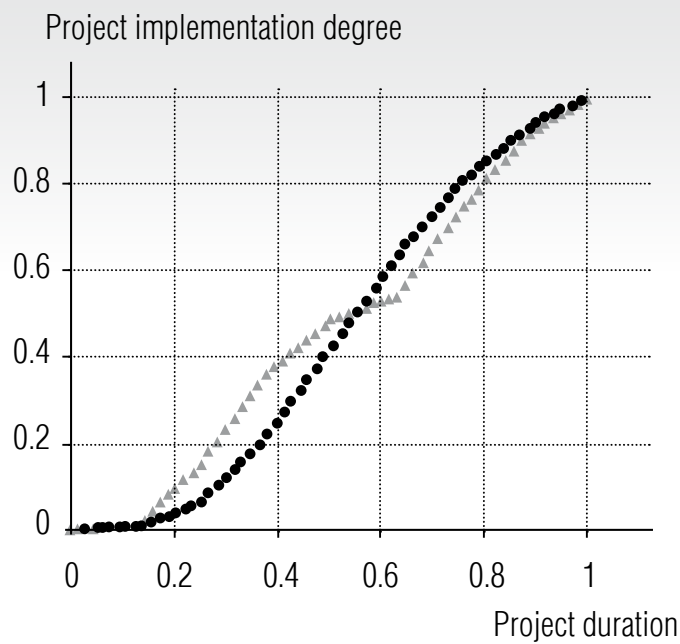

б)

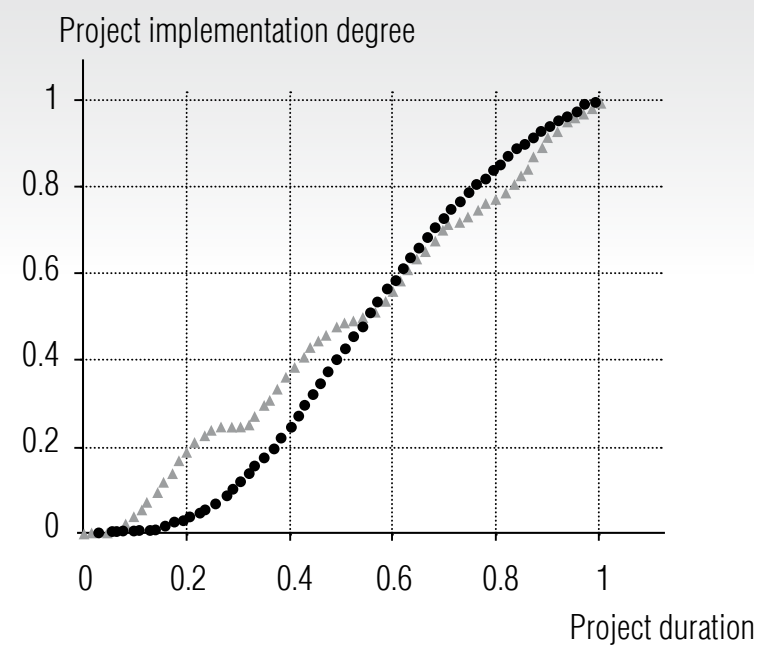

Fig. 3. Dynamics of the project completion degree,

formally divided into two (a) and four (b) subprojects.

The circles represent a theoretical model degree dynamics of the life cycle realization.

Triangles represent the corresponding piecewise-linear models 
of the result achieved as quickly as possible. Thus, the only effective strategy for rearranging work is to transfer the stages characterized by the largest value of the first-order derivative $d P / d \tau$ to the initial positions in the sequence of stages. Taking into account the ratio $a_{3}>a_{2}>a_{4}>a_{1}$ between the model parameters (5) chosen as an example, the considered example of an effective rearrangement of the work sequence will take the following form:

$$
P(\tau) \cong\left\{\begin{array}{l}
a_{3} \cdot \tau+c_{1}, \tau \in\left[0 ; \tau_{1}\right) \\
a_{2} \cdot \tau+c_{2}, \tau \in\left[\tau_{1} ; \tau_{2}\right) \\
a_{4} \cdot \tau+c_{3}, \tau \in\left[\tau_{2} ; \tau_{3}\right) \\
a_{1} \cdot \tau+c_{4}, \tau \in\left[\tau_{3} ; \tau_{4}\right],
\end{array}\right.
$$

where $c_{1}, c_{2}, c_{3}, c_{4}$ are found from the condition that gaps of the first kind are absent.

The iterative approach applied to the planning stage to the cascade model (5) provides the possibility to implement several project execution options. Obviously, considering the fact that the resources are fixed for the

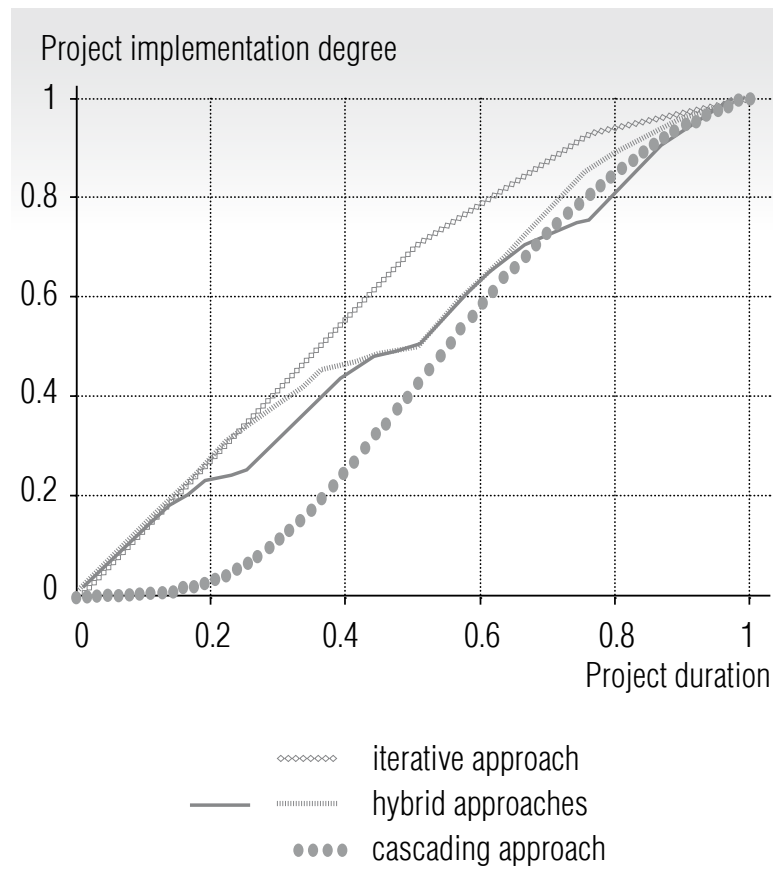

Fig. 4. Dynamics of the project implementation degrees at iterative, hybrid and cascading approaches to project planning and management models, there are no piecewise-linear functions that provide faster achievement of the target indicator of $80 \%$ than the cascading line in Figure 4. To confirm this hypothesis, we will use the technique that was used to demonstrate the differences between the hybrid and cascade approaches. We break down the model project (6) into two/four subprojects, each of which implements an iterative approach. The corresponding dependences are presented in Figure 6. This shows that, from the customer's point of view, $80 \%$ efficiency of the project is achieved for $63 \%$ (using a purely iterative approach), 73\% (splitting into two subprojects with epy rearrangement of the work sequence) and 79\% (splitting into four subprojects with epy rearrangement of the work sequence) of the time designated to achieve the project aim.

Thus, the most effective strategy for achieving the project aim is to apply a purely iterative approach directly to the project, rather than to its individual stages highlighted during the use of the cascading planning paradigm.

\section{Conclusion}

Although purely model tasks have been considered and the iterative approach for the implementation of the conceptual cascade project cannot be fully applied in practice (as, for example, the initialization stage will probably be the last one), significant advantages and disadvantages of iterative, hybrid, and cascade approaches were demonstrated precisely with the help of mathematical models, rather than specific implementations of the corresponding projects.

If we ignore the tough requirements of standards, we would consider works on the content and to structure the project on the basis of "the principle of the greatest derivative." Then the more iterative approach is used, and the more effective it is perceived by the customer for the project implementation plan. 
Finally, there are observations from real-life cases: a large number of successful projects (at least in IT [30]) are implemented according to the following scheme: "first do, then sign an agreement," which matches the model recommendations exactly (6), despite the apparent violation of the project execution process logic.

\section{References}

1. Royce W.W. (1970) Managing the development of large software systems. Technical Papers of Western Electronic Show and Convention (WesCon), Los Angeles, USA, 25-28 August 1970, pp. 328-338.

2. Morien R. (2018) A retrospective on constructing a personal narrative on agile development. Advances in Intelligent Systems and Computing, vol. 685, pp. 290-304. DOI: 10.1007/978-3-319-70019-9_24.

3. Jiang L., Eberlein A. (2008) Towards a framework for understanding the relationships between classical software engineering and agile methodologies. Proceedings of the 2008 International Workshop on Scrutinizing Agile Practices or Shoot-Out at the Agile Corral (APOS' 08), Leipzig, Germany, 10 May 2008, pp. 9-14. DOI: $10.1145 / 1370143.1370146$.

4. Project Management Institute (2008) Project Management Knowledge Base Guide (PMBOK Guide). Philadelphia, USA: PMI.

5. Kamaev V.A. (2008) Cascading technological approaches. Moscow: Higher School (in Russian).

6. Wright C. (2014) Agile governance and audit: An overview for auditors and Agile teams. Cambridgeshire, UK: IT Governance Publishing.

7. Bierwolf R., Frijns P., Van Kemenade P. (2017) Project management in a dynamic environment: Balancing stakeholders. Proceedings of the 2017 IEEE European Technology and Engineering Management Summit (E-TEMS 2017), Munich, Germany, 17-19 October 2017, pp. 1-6.

8. Ramamoorthy B.T., Mayilvahanan P. (2019) Comparative study on agile scrum over traditional waterfall lifecycle projects. Journal of Advanced Research in Dynamical and Control Systems, vol. 11, no 4, pp. 524-529.

9. Pradhan S., Nanniyur V., Melanahalli P., Palla M., Chulani S. (2019) Quality metrics for hybrid software development organizations - A case study. Proceedings of the 19th IEEE International Conference on Software Quality, Reliability and Security (QRS-C 2019), Sofia, Bulgaria, 22-26 July 2019, pp. 505-506.

10. Miloshevich D.Z. (2008) Project management toolkit. Moscow: AjTi; DMK Press (in Russian).

11.Zemlyanaya E.M. (2019) Features of project management in medical organizations. Proceedings of the IX International Scientific and Practical Conference "Economics, Business, Innovations", Penza, Russia, 15 August 2019, pp. 10-13 (in Russian).

12.Hamad R.M.H., Al Fayoumi M. (2018) Scalable agile transformation process (SATP) to convert waterfall project management office into Agile project management office. Proceedings of the 19th International Arab Conference on Information Technology (ACIT 2018), Lebanon, 28-30 November 2018, pp. 1-8.

13. Hiekata K., Mitsuyuki T., Goto T., Moser B. (2016) Design of software development architecture comparison of waterfall and agile using reliability growth model. Advances in Transdisciplinary Engineering, no 4, pp. 471-480.

14.Park K., Kim J., Cho K., Kwon T.T., Choi Y., Pack S. (2013) Waterfall: Video distribution by cascading multiple swarms. IEEE Journal on Selected Areas in Communications, vol. 31, no 9, pp. 165-174.

15. Kniberg H. (2016) Toyota's journey from Waterfall to Lean software development. Available at: https://blog.crisp. se/2010/03/16/henrikkniberg/1268757660000 (accessed 30 November 2019).

16.Serebryakova T.A., Serebryakov V G., Aleksin K.V. (2019) Comparative analysis of Agile and Waterfall methodologies for developing information systems in the banking sector. Colloquium-Journal, no 2-5, pp. 7-9 (in Russian).

17.Götz O., Wai Y., Klein S., Roßmehl M., Basten D. (2018) The (Go)SMART way to agility: Managing a Scrum subproject in a waterfall environment. Journal of Information Technology Teaching Cases, vol. 8, no 2, pp. 149-160.

18. Vlasov A.I., Karpunin A.A., Ganev Yu.M. (2015) A systematic approach to design with a cascading and iterative life cycle model. Proceedings of the International Symposium "Reliability and Quality", Penza, Russia, 25-31 May 2015, vol. 1, pp. 96-100 (in Russian). 
19. Fitsilis P. (2008) Comparing PMBOK and Agile project management software development processes. Advances in Computer and Information Sciences and Engineering. Springer, pp. 378-383. DOI: 10.1007/978-1-4020-8741-7.

20. Mahadevan L., Ketinger W.J., Meservy T.O. (2015) Running on hybrid: Control changes when introducing an agile methodology in a traditional "waterfall" system development environment. Communications of the Association for Information Systems, no 36, pp. 77-103. DOI: 10.17705/1CAIS.03605.

21.Shawky D.M. (2014) Traditional vs Agile development: A comparison using chaos theory. Proceedings of the 9th International Conference on Software Paradigm Trends (ICSOFT-PT 2014), Vienna, Austria, 29-31 August 2014, pp. 109-114.

22.Salahmir V. (2018) Project management methodologies: Waterfall, Agile. Available at: https://salakhmir.ru/проектыметодологии-waterfall-agile/ (accessed 28 November 2019) (in Russian).

23. Voropaev V.I., Gelrud Yan.D. (2013) Mathematical control models for the customer. Upravlenie Proektami i Programmami, no 1, pp. 18-29 (in Russian).

24.Linnik Yu.V. (1958) Least squares method and the fundamentals of the mathematical and statistical theory of observation processing. Moscow: Fizmatlit (in Russian).

25.Karimov R.A., Kachkynbekov N.R. (2018) Some aspects of a flexible software development methodology. Mezhdunarodnyj Zhurnal Gumanitarnyh i Estestvennyh Nauk, no 3, pp. 199-202 (in Russian).

26.Nicula D., Ghimii S.S. (2019) Command and control vs self management. IOP Conference Series: Materials Science and Engineering. 2019. Vol. 514. Product Design, Robotics, Advanced Mechanical and Mechatronic Systems and Innovation Conference (PRASIC), Brasov, Romania, 8-9 November 2018, pp. 1-6. DOI: $10.1088 / 1757-899 X / 514 / 1 / 012039$.

27.Schuh G., Rebentisch E., Riesener M., Diels F., Dölle C., Eich S. (2017) Agile-waterfall hybrid product development in the manufacturing industry - Introducing guidelines for implementation of parallel use of the two models. Proceedings of the 2017 IEEE International Conference on Industrial Engineering and Engineering Management (IEEM), Singapore, 10-13 December 2017, pp. 725-729. DOI: 10.1109/IEEM.2017.8289986.

28.Kuhrmann M., Diebold P., Münch J., Tell P., Garousi V., Felderer M., Trektere K., McCaffery F., Linssen O., Hanser E., Prause C.R. (2017) Hybrid software and system development in practice: Waterfall, scrum, and beyond. Proceedings of the 2017 International Conference on Software and System Process (ICSSP 2017), Paris, France, 15-17 July 2017, pp. 30-39.

29. Chulanova O.L. (2018) Project and project team management technology based on Agile project management methodology. Vestnik Evrazijskoj Nauki, no №4, p. 1-11 (in Russian).

30.Pervoukhin D.V., Isaev E.A., Rytikov G.O., Filyugina E.K., Hayrapetyan D.A. (2019) Analysis of the positive effect of the IT solutions implementation based on risk assessment. Pribory i Sistemy. Upravlenie, kontrol, diagnostika, no 7, pp. 45-54 (in Russian).

\section{About the authors}

\section{Dmitry V. Pervoukhin}

Senior Lecturer, Department of Information Systems Management and Digital Infrastructure Management, School of Business Informatics, Faculty of Business and Management, National Research University Higher School of Economics, 20, Myasnitskaya Street, Moscow 101000, Russia;

Senior Lecturer, Faculty of Applied Mathematics and Information Technologies, Financial University under the Government of the Russian Federation, 49, Leningradsky Prospect, Moscow 125993, Russia;

E-mail: dpervuhin@hse.ru

ORCID: 0000-0001-6500-035X 


\section{Eugeni A. Isaev}

Cand. Sci. (Tech.);

Professor, Department of Information Systems Management and Digital Infrastructure Management, School of Business Informatics, Faculty of Business and Management,

National Research University Higher School of Economics,

20, Myasnitskaya Street, Moscow 101000, Russia;

E-mail: eisaev@hse.ru

ORCID: 0000-0002-3703-447X

\section{Georgy O. Rytikov}

Cand. Sci. (Phys.-Math.);

Associate Professor, Department of Informatics and Information Technologies,

Higher School of Press and Media Industry, Moscow Polytechnic University,

2A, Pryanishnikov Street, Moscow 127550, Russia;

E-mail: GR-yandex@yandex.ru

ORCID: 0000-0001-5521-8662

\section{Ekaterina K. Filyugina}

Student, Business Informatics Educational Program, Faculty of Business and Management, National Research University Higher School of Economics,

20, Myasnitskaya Street, Moscow 101000, Russia;

E-mail: ekfilyugina@edu.hse.ru

\section{Diana A. Hayrapetyan}

Student, Project Management MSc Program, Faculty of Business and Management, National Research University Higher School of Economics,

20, Myasnitskaya Street, Moscow 101000, Russia;

E-mail: hayrapetyandiana@gmail.com 


\title{
Towards a Multi-Channel Service Delivery model in the data-driven public sector
}

\section{Ebenezer Agbozo}

E-mail: eagbozo@urfu.ru

\author{
Alexander N. Medvedev \\ E-mail: a.n.medvedev@urfu.ru \\ Ural Federal University \\ Address: 19, Mira Street, Yekaterinburg 620002, Russia
}

\begin{abstract}
The goal of e-government is to provide public services to end users - be it citizens or residents - of a given nation. Research has shown that there is the susceptibility of governments to check all the boxes so as to present an image of having e-government implementations, yet end users eventually do not benefit from these electronic services. Quality public service delivery is an issue of priority today and, with the increasing availability of modern technological tools and techniques, it is attainable. Datadriven e-government is a necessary ingredient in the modern day public sector due to the widespread availability and rapid production of data (i.e. big data) and it aims at value creation. This study proposes a novel research concept, using the Multi-Channel Service Delivery model as a catalyst to attain the data-driven ecosystem in the public sector. The model was developed based on recommendations from works of previous research to address the changing landscape of the public sector. By integrating the Multi-Channel Service Delivery model into e-government and public sector decision making, governments will be able to bridge the divide and offer services to end users with access to e-services, as well as those who do not. In doing so, the United Nations' Sustainable Development Goals (SDGs) which are aimed at leaving none behind will be arrived at.
\end{abstract}

Key words: Multi-Channel Service Delivery Model; e-government; public sector; value creation; data-driven public sector; user experience; public service optimization.

Citation: Agbozo E., Medvedev A.N. (2020) Towards a Multi-Channel Service Delivery model in the data-driven public sector. Business Informatics, vol. 14, no 1, pp. 41-50.

DOI: 10.17323/2587-814X.2020.1.41.50 


\section{Introduction}

$\mathrm{T}$ he goals of providing public sector services are to meet the needs of citizens and government by providing public goods and services, contribute to the financial sustainability and government effectiveness, and also to improve social effectiveness $[1,2]-$ thereby influencing every facet of a nation's socio-economic ecosystem. An improvement in public service delivery has the potential of enhancing governance and quality of life, as well as alleviating social conflicts [3]. When public services are at their optimal efficiency level, citizens and residents (endusers) are not the only beneficiaries, since service providers (public sector and government), as well as the private sector unanimously benefit from it.

Over the last decade, the digitization of public services - i.e. electronic government - has been adopted by most countries and today countries are at different levels of development in e-government. The United Nations' 2016 e-government survey delves deeply into the development of e-government, points out which countries are improving, stagnant and declining in the e-government sphere, as well as gives reasons why [4]. For e-government to function, certain necessary factors and components are vital. To mention a few, they are perceived usefulness of the system, perceived ease of use, perceived service quality, perceived risk, trust in government and the system, technological infrastructure such as telecommunications, literacy, and many more [5-7].

Modern technological advancement and its ubiquity have created the means for people to access these services via numerous sources. Private sector entities capitalize on digital tools such as self-service terminals, interactive response systems, smartphones, social media, email, video telephony services, web services, and much more as channels for delivering services. These initiatives encourage end-users to envision new forms of interaction with the desire that service providers be as accessible and responsive as modern technology allows [8]. Though governments are aware of such diverse channels for service delivery, many are not fully leveraging the full potential of these Multi-Channel Service Delivery schemes to serve their residents and citizens. This is especially true in developing economies [8]. Coupled with the rise in data creation and availability due to these modern technologies, the public sector is presented with numerous opportunities to take advantage of big data by employing analytical tools to gather insights into citizen engagement and electronic participation (e-participation) of e-government; i.e. the data-driven approach.

A United Nations (UN) report on e-government stated that in an era of rapidly changing technology public officials and policy makers still find it difficult to achieve the right balance between applications and devices and investing wisely on technical platforms when considering the design of multichannel service delivery systems [8]. A Multi-Channel Service Delivery (MCSD) model in the shifting technological climate, a data-driven public sector in this article's case, presents itself as a vital apparatus for more efficient quality service delivery. Without a doubt, e-government has brought about much change in the public sector sphere; by reducing bureaucracy, curbing corruption, and most important of all improving quality of public service delivery, among other benefits. Despite its benefits, research has shown that e-government has the potential of escalating these same issues it promises to solve when not governed appropriately [9]. Since no scholarly work has been done on the convergence of MCSD and data-driven public sector (DDPS), the aim of this study is to explore how the Multi-Channel Service 
Delivery model can be adopted by developing economies as the public sector world shifts towards a data-driven one. The main question posed for this study is: How can the Multi-Channel Service Delivery model be integrated into the data-driven public sector for effective public service delivery?

\section{The data-driven public sector}

E-government traditionally has been termed as delivery of government services and information to the public using electronic means [10] which aims at higher internal efficiency of government agencies and strives for better transactional services. This is then followed by a transition towards e-government 2.0 which creates opportunities for increasing participation of citizens, openness and accountability of governments, and thus enhances democracy; it promotes transparency by promoting the opening and release of public data [11]. E-government 3.0 is built upon the previous e-government versions and is gaining grounds due to an increase in the use of sensors and smart devices which produce big data ranging from human text to sensor data, combined with advanced analytics and modelling, and possibly ubiquitous services (i.e. cloud computing), allowing for smart governance and data-intensive decision making [11]. This is the foundation of the data-driven public sector (DDPS). The DDPS is capable of identifying, collecting and obtaining useful data for policymaking and service delivery within the public sector and for socio-economic development [12]. For example, analytical techniques, semantic methods such as text mining [13] and artificial intelligence methods can be employed in the extraction of knowledge from large corpora of text data from citizen complaints.

Studies have further extended the concept to build a data-driven e-government model which is a collection of digital public services which channels previously stored data back to citizens as solutions, decisions and reforms for accelerated national growth [14]. They further described this model as a paradigm shift that has the potential of steering any country that embraces the concept into digital maturity coupled with socio-economic development which is also capable of aiding in attaining the United Nations' Sustainable Development Goals (SDGs) [15].

While studies on the Data-Driven e-Government (DDeG) and the DDPS are in their elementary phases, recommendations for innovation research in the public sector have been suggested by researchers [16]. The scarcity of agile model research recommendations for the data-driven public sector and public service delivery expresses a cause for novelty. As such, this study aims at integrating an innovative model, the Multi-Channel Service Delivery model, into the data-driven public sector in order to improve upon service delivery, citizen trust and user satisfaction in e-government.

\section{The Multi-Channel Service Delivery model as a data-driven public sector catalyst}

In the world of business and commerce, the Multi-Channel Service Delivery (MCSD) model has been adopted by several corporations. Before further delving into the solution, it is appropriate that the concept of MCSD be explored. Research recommends that in order to further enhance e-services delivery in the public sector, MCSD should be explored [17] and as such, this study aims at fulfilling the recommendations.

Multi-Channel Service Delivery (MCSD) is defined as the provision of public services by various means in an integrated and coordinated way and in doing so end-users are able to select their most suitable channel based on their circumstances [18]. MCSD enables 
organizations to provide the best all-around user experience across multiple communication channels by leveraging the integration of devices such as smartphones, interactive voice response systems, digital television, self-service terminals, and many other modern devices. Despite its benefits, the complexity of integrating it in the public sector increases due to existing bureaucratic culture, outmoded policies and standards, budgetary constraints, inadequate technical know-how and a lack of leadership [8].

Within the context of e-government research, MCSD has been explored by a few researchers. According to [19], a channel is capable of changing users' perception with respect to a service and user interests will always be aligned with the channel that realizes the highest relative value (i.e. high quality, accessibility, flexibility, and cost-efficiency and effectiveness). Their study examined whether new ICTs could enable service providers to re-engineer front and back-offices in order for them to adopt a flexible multi-channel open interoperable architecture which in turn increases service provision sustainability and consequently the end-user's quality of life [19]. The MCSD has been proposed Artificial Intelligence (AI) fuelled social robots as a service channel aimed at providing a richer service experience, somewhat similar to what human agents could offer. Their study pointed out that these social robots are capable of supplementing service providers to improve delivery, possibly replacing certain channels in the future, and creating currently non-existing opportunities [20]. Traditional public service delivery and the consequences of automation prevented and still prevents governments from transitioning to a stable e-government system. Thus, thorough research indicated that MCSD governed by transformational leadership was a necessary factor in reversing the negative attitude towards e-government [21]. The authors furthermore highlighted that
MCSD expands provision of services to the end users of public services in rural areas in China. A systematic review on channel choice with respect to e-service adoption discovered these factors as indicative of end users' choices: channel characteristics (e.g. interactivity, perceived ease of use, perceived usefulness), task characteristics (e.g. task type, problem complexity), personal characteristics (e.g. socio-demographics, experience with channel, habits), situational constraints (price, distance to channels), and satisfaction (e.g. satisfaction with service encounter) [22]. In light of the aforementioned research findings, this study proposes a model where both the MCSD and data-driven public sector interplay and integrate e-government competencies [23] such as legal, managerial, technical, socio-technical and organizational competencies.

Figure 1 illustrates the data-driven public sector where the MCSD model is realized. Here the harmonization of all stakeholders involved in the design process is observable, thereby agreeing with the stakeholder theory [24]. In the concept of co-creation, primarily the multi-stakeholder approach is adopted in this model due to the fact that it provides a robust analytic structure for exploring and evaluating the impact of e-services on both the experience and performance of public service systems with the involvement of all actors necessary $[25,26]$.

The duplex channel concept is introduced into the Multi-Channel Service Delivery model whereby end-users are capable of also communicating with service providers instead of the unreliable unidirectional mode of communication [27]. Thus, the system is made human-centred and balance is enforced since the views and contributions of end-users are welcomed by providers.

In Figure 2, the formal representation of the MCSD from Figure 1 in the data-driven public sector is illustrated in BPMN using 


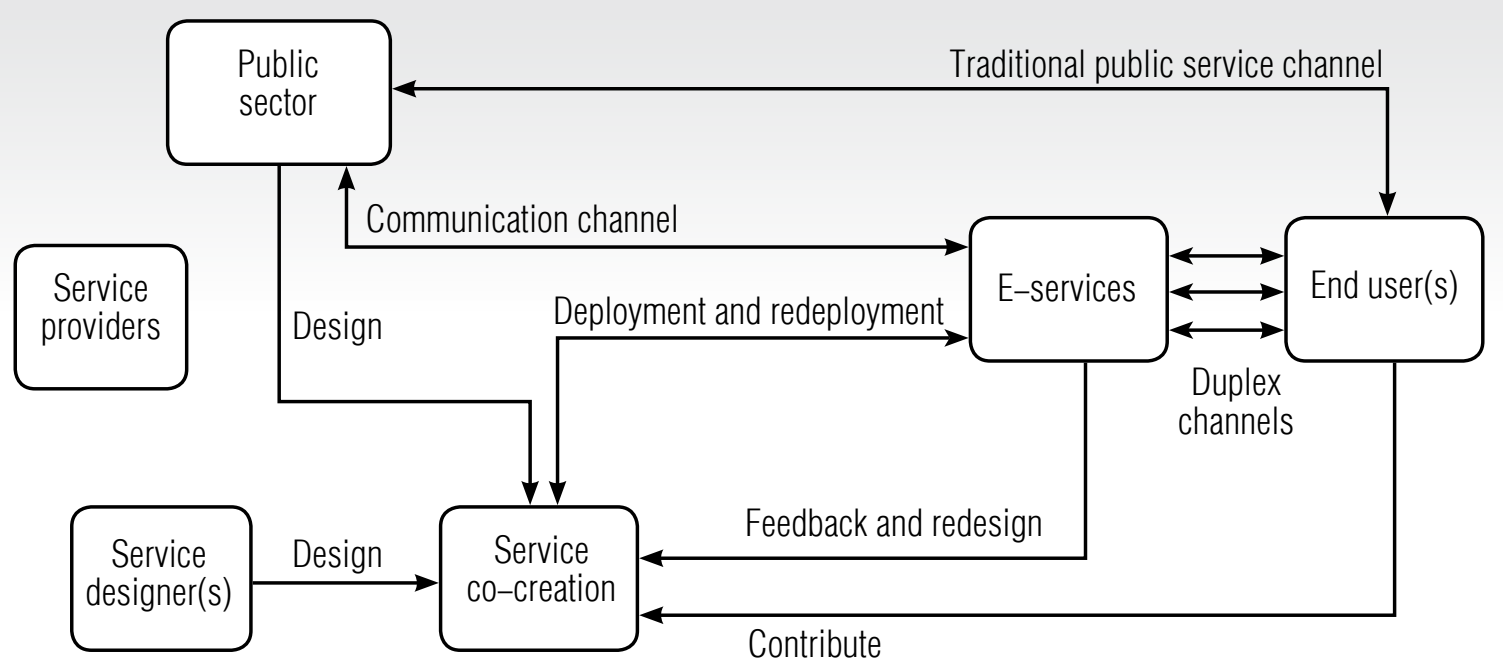

Fig. 1. A Multi-Channel Service Delivery model in the data-driven public sector

the ARIS Express software. In the design and implementation of e-government and digital services for the public sector, design requirement specifications are made and in the case of the model presented, the bottom-up approaches of co-production and co-creation which involve consultation and ideation (design phase); crowdsourcing and co-deliv- ery (execution phase); and service monitoring by means of citizen reporting (monitoring phase) [28] are all integrated. Co-production and co-creation of services are evolving research fields and studies have called for the need to create the appropriate governance structures; linking and integrating the worlds inside government, but also with those outside

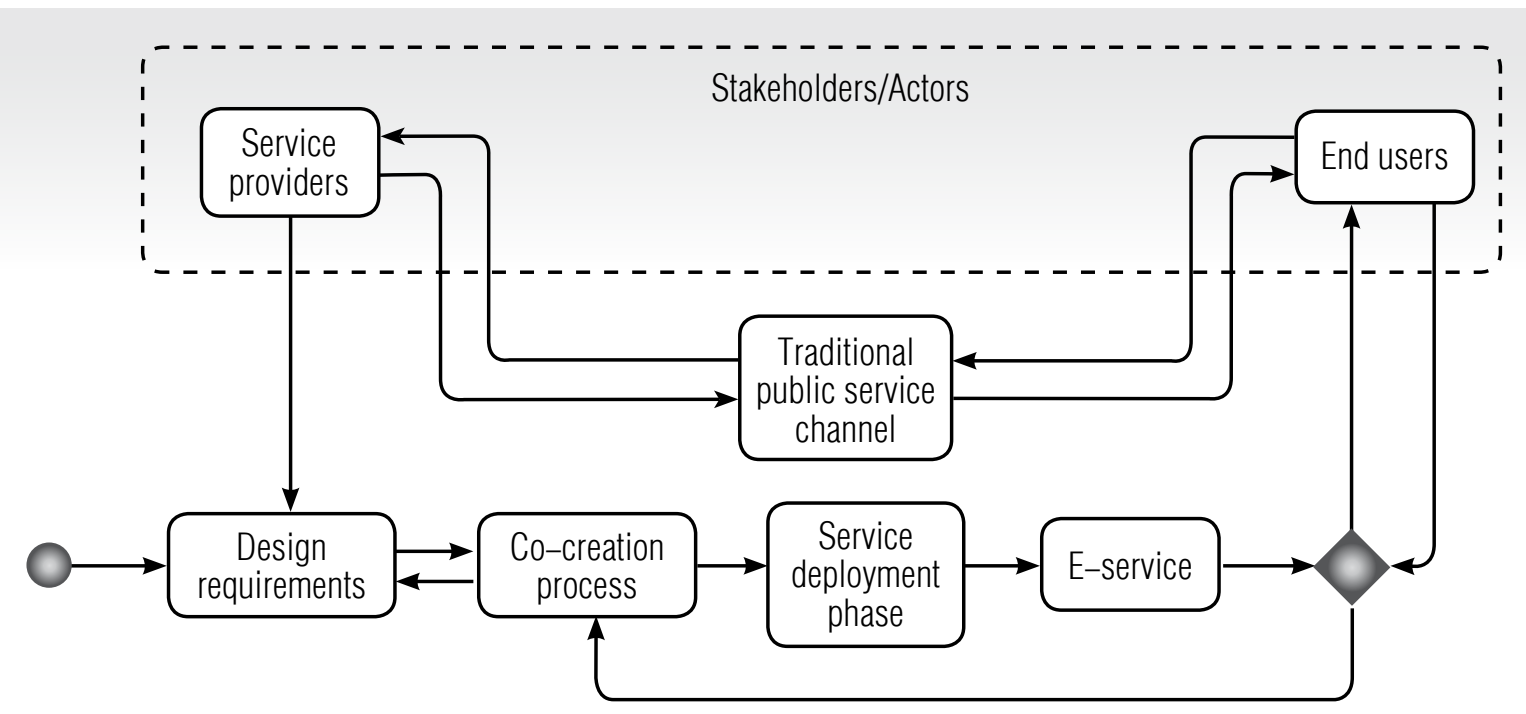

Fig. 2. Business process model and notation (BPMN) representation of proposed model 
government [29]. Thus, this research sought to model the linkage and feasibility of a coproduction model which involves MCSD and data-driven e-government. It adopts the public value theory which not only inquires into what the public sector values but. most importantly, what brings value to the public sector and is defined as value created by government through services, law regulations and other actions addressing issues such as equity, ethos and accountability [30].

Due to the nature of the MCSD model (Figure 2), the data-driven approach is optimized and enabled in the following ways so as to improve upon public service delivery:

Service design, co-creation and deployment phases: Gathering of data from varying sources through qualitative and quantitative means aided by modern technology such as IOT devices and sensors, data streaming tools linked to pre-existing systems (i.e. web platforms). Recommended frameworks based on agile development and continuous improvement can utilize open government data in coproducing services for effective and efficient service delivery [31];

Service engagement: Authorized tracking of non-personal data is fed back to service providers, by virtue of the duplex communication mode in the MCSD model, to create dashboards and reports which will inform decisionmaking at all levels of government. Gamification is also encouraged as a means of boosting e-participation, thereby contributing to building better societies [32];

Decision-making: Data-informed and evidence-based decision-making to support not only design and implementation of e-services but governmental decisions to improve citizen/resident livelihood. Research suggests data/knowledge driven policy-making where a shared platform for policy intelligence is integrated, thereby creating opportunities for multi-stakeholder contribution to decision making [33];
Evaluation and assessment: Public service providers and government, considering the metrics made available from analysed data from the ecosystem, are able to assess the well-being of e-government initiatives, government programs, user satisfaction, engagement, infrastructure efficiency, return on investments and many other deliverables.

As pointed out by studies, a lack of involvement of all stakeholders in the design of e-Government solutions as well as the lack of responsive evaluation and monitoring lead to e-government failure [34]. Another study also indicated that ICT development in developing countries still remains low and authors attribute this to insufficient stakeholder involvement [35]. In an example of co-designing to bridge design-reality gaps for developing citizen-centric projects in Uganda, involvement of public opinion brought to light the benefits economically marginalized citizens could derive should patients be given the freedom to make decisions with regard to online appointment payment [36]. The study indicated that in doing so, quality and improved healthcare delivery will be available to approximately $70 \%$ of poor non-paying citizens.

To engage citizens in the co-design process as well as collecting data, feedback and issues relevant to a city by its citizens, researchers recommended the Gather-Share-Govern (GSG) model and cited examples of e-government initiatives such as ImproveMyCity and the Riyadh Wiki Information and Complaining System (RWICS) in the case of Saudi Arabia [37]. In the RWICS, citizens are involved in the development process rather than the government due to the ease of use. Thus, establishing co-design and in turn promoting trust and transparency.

For these reasons and more, the proposed model is a panacea to the existing ailments in public sector e-service design, implementation and delivery because stakeholder involvement is a core value necessary for the agile e-government development process/cycle. 
At the heart of this model, is the human-centric factor. Thus, user privacy is of great value to governments and all forms of personal data is treated with a high level of caution. The European Union's General Data Protection Regulation (GDPR) is one of such regulations recommended.

Advantages of the amalgamation of the MCSD into the data-driven public sector include: offering services to all groups of individuals and not only the technology-savvy, the continued value and reuse of data, creation of interoperable synergy in the case of highly decentralized public sector systems, enforcing a value co-creation and co-production perspective, and optimization of public service delivery.

\section{Conclusion}

This paper explored the concept of MultiChannel Service Delivery and married it with the data-driven public sector. The MultiChannel Service Delivery approach in the data-driven public sector ecosystem has the potential to achieve the human-centric desire of research in the sphere of public service deliv- ery as well as optimizing public service business processes, end-user engagement with e-services, decision-making at all levels of government, evaluation and assessment of the service sector. The proposed model is hinged on the public value theory and a human-centric core value which aim at delivering quality service, creating value for both service providers and beneficiaries.

With respect to contributions to theory and practice, the model adds to the extant literature on e-government and the public sector transformation studies, as well as new information with regard to the duplex mode of communication in the Multi-Channel Service Delivery approach.

The study presented a general overview of the model and benefits of the model based on the fact that studies have revealed that a lack of stakeholder involvement in e-government design and delivery is detrimental to the development of e-government. For the purpose of future studies, it is recommended that a metric model be developed to ascertain the level to which various countries are utilizing the MultiChannel Service Delivery in the data-driven public sector.

\section{References}

1. Bisogno M., Cuadrado-Ballesteros B. (2019) The role of public sector accounting on financial sustainability and governmental effectiveness. Financial Sustainability of Public Sector Entities. Cham: Palgrave Macmillan, pp. 123-144. DOI: 10.1007/978-3-030-06037-4_7.

2. Zaheer A.N., Rashid A. (2017) Analyzing the role of public sector marketing in improving social effectiveness: a case study from Anhui province, China. International Review on Public and Nonprofit Marketing, vol. 14, no 1, pp. 57-71. DOI: 10.1007/s12208-016-0162-y.

3. Smoke P. (2015) Rethinking decentralization: Assessing challenges to a popular public sector reform. Public Administration and Development, vol. 35, no 2, pp. 97-112. DOI: 10.1002/pad.1703.

4. Peña-López I. (2016) UN e-government survey 2016. E-government in support of sustainable development. United Nations.

5 Mensah I.K., Vera P., Mi J. (2018) Factors determining the use of e-government services: An empirical study on Russian students in China. International Journal of E-Adoption, vol. 10, no 2, pp. 1-19.

DOI: 10.4018/IJEA.2018070101.

6. Joseph B.K. (2017) Determining factors influencing e-government development in the developing world: A case study of Zambia. Journal of e-Government Studies and Best Practices, vol. 2017, Article ID 143795, pp. 1-16. DOI: $10.5171 / 2017.143795$. 
7. Roy M.C., Chartier A., Crête J., Poulin D. (2015) Factors influencing e-government use in non-urban areas. Electronic Commerce Research, vol. 15, no 3, pp. 349-363. DOI: 10.1007/s10660-015-9193-4.

8. UN DESA (2012) E-government survey (2012). E-Government for the people. Department of Economic and Social Affairs, United Nations, New York. Available at: https://publicadministration.un.org/egovkb/ Portals/egovkb/Documents/un/2012-Survey/Chapter-4-Supporting-multichannel-service-delivery.pdf (accessed 20 November 2019).

9. Hasnain Z. (2017) E-bureaucracy: Can digital technologies spur public administration reform? Available at: https://blogs.worldbank.org/governance/e-bureaucracy-can-digital-technologies-spur-publicadministration-reform (accessed 16 September 2019).

10. Jayashree S., Marthandan G. (2010) Government to e-government to e-society. Journal of Applied Sciences (Faisalabad), vol. 10, no 19, pp. 2205-2210. DOI: 10.3923/jas.2010.2205.2210.

11. Lachana Z., Alexopoulos C., Loukis E., Charalabidis Y. (2018) Identifying the different generations of e-government: An analysis framework. Proceedings of the 12th Mediterranean Conference on Information Systems (MCIS), Corfu, Greece, 28-30 September 2018, pp. 1-13.

12. Ubaldi B., Van Ooijen C., Welby B. (2019) A data-driven public sector: Enabling the strategic use of data for productive, inclusive and trustworthy governance. OECD Working Papers on Public Governance, no 33. Paris: OECD Publishing.

13. Karpov N., Babkin E., Demidovskij A. (2016) Evolvable semantic platform for facilitating knowledge exchange. Supplementary Proceedings of the 5th International Conference on Analysis of Images, Social Networks and Texts (AIST-SUP 2016), Yekaterinburg, Russia, 7-9 April 2016, pp. 62-72.

14. Agbozo E., Spassov K. (2018) Establishing efficient governance through data-driven e-government. Proceedings of the 11th International Conference on Theory and Practice of Electronic Governance, Galway, Ireland, 4-6 April 2018, pp. 662-664.

15. Agbozo E. (2018) The role of data-driven e-government in realizing the sustainable development goals in developing economies. Journal of Information Systems \& Operations Management, vol. 12, no 1, pp.70-77.

16. Androutsopoulou A., Karacapilidis N., Loukis E., Charalabidis Y. (2017) Towards an integrated and inclusive platform for open innovation in the public sector. E-democracy - Privacy-preserving, secure, intelligent e-government services: 7th International Conference on e-Democracy, Athens, Greece, 14-15 December 2017, pp. 228-243. DOI: 10.1007/978-3-319-71117-1_16.

17. Voutinioti A. (2013) Determinants of user adoption of e-government services in Greece and the role of citizen service centres. Procedia Technology, no 8, pp. 238-244. DOI: 10.1016/j.protcy.2013.11.033.

18. Ruppel K. (2014) Multi-channel service delivery. Available at: https://blogs.oracle.com/content/multichannel-service-delivery (accessed 16 September 2019).

19. Germanakos P., Samaras G., Christodoulou E. (2005) Multi-channel delivery of services -The road from e-government to m-government: Further technological challenges and implications. Proceedings of the First European Conference on Mobile Government (Euro mGov 2005), Brighton, UK, 10-12 July 2005, pp. 210-220.

20. Pieterson W., Ebbers W., Madsen C.O. (2017) New channels, new possibilities: A typology and classification of social robots and their role in multi-channel public service delivery. Electronic Government, 16th IFIP WG 8.5 International Conference (EGOV 2017), St. Petersburg, Russia, 4- 7 September 2017, pp. 47-58. DOI: 10.1007/978-3-319-64677-0_5.

21. Mahmood K., Nayyar Z., Ahmad H.M. (2018) Switching to electronic government through transformational leadership: Implications of multichannel and digital divide. Journal of Internet Technology and Secured Transactions, vol. 6, no 1, pp. 534-540. DOI: 10.20533/jitst.2046.3723.2018.0066. 
22. Madsen C.O., Kræmmergaard P. (2015) Channel choice: A literature review. Proceedings of the 14th International Conference on Electronic Government (EGOV), Thessaloniki, Greece, 30 August 2 September 2015, pp.3-18. DOI: 10.1007/978-3-319-22479-4_1.

23. Distel B., Ogonek N., Becker J. (2019) eGovernment competences revisited - A literature review on necessary competences in a digitalized public sector. Proceedings of the 14th International Conference on Wirtschaftsinformatik, Siegen, Germany, 24-27 February 2019, pp. 286-300.

24. Jensen M.C. (2010) Value maximization, stakeholder theory, and the corporate objective function. Journal of Applied Corporate Finance, vol. 22, no 1, pp. 32-42. DOI: 10.1111/j.1745-6622.2001.tb00434.x.

25. Osborne S.P., Radnor Z., Strokosch K. (2016) Co-production and the co-creation of value in public services: a suitable case for treatment? Public Management Review, vol. 18, no 5, pp. 639-653. DOI: 10.1080/14719037.2015.1111927.

26. Bryson J., Sancino A., Benington J., Sørensen E. (2017) Towards a multi-actor theory of public value co-creation. Public Management Review, vol. 19, no 5, pp. 640-654. DOI: 10.1080/14719037.2016.1192164.

27. Prem E. (2015) A digital transformation business model for innovation. ISPIM Innovation Symposium (p. 1). The International Society for Professional Innovation Management (ISPIM).

28. Linders D. (2012) From e-government to we-government: Defining a typology for citizen coproduction in the age of social media. Government Information Quarterly, vol. 29, no 4, pp. 446-454. DOI: 10.1016/j.giq.2012.06.003.

29. Halmos A., Misuraca G., Viscusi G. (2019) From public value to social value of digital government: Co-creation and social innovation in European Union initiatives. Proceedings of the 52nd Hawaii International Conference on System Sciences (HICSS 2019), Maui, Hawaii, 8-11 January 2019, pp. 2974-2983. DOI: 10.24251/HICSS.2019.360.

30. Kelly G., Mulgan G., Muers S. (2002) Creating public value: An analytical framework for public service reform. London: Strategy Unit, Cabinet Office.

31. Toots M., McBride K., Kalvet T., Krimmer R., Tambouris E., Panopoulou E., Kalampokis E., Tarabanis K. (2017) A framework for data-driven public service co-production. Proceedings of the 16th International Conference on Electronic Government (EGOV), St. Petersburg, Russia, 4-7 September 2017, pp. 264-275. DOI: 10.1007/978-3-319-64677-0_22.

32. Al-Yafi K., El-Masri M. (2016) Gamification of e-government services: A discussion of potential transformation. Proceedings of the Twenty-second Americas Conference on Information Systems, San Diego, California, US, 11-14 August 2016, pp. 1-9.

33. Misuraca G., Viscusi G. (2015) Shaping public sector innovation theory: an interpretative framework for ICT-enabled governance innovation. Electronic Commerce Research, vol. 15, no 3, pp. 303-322. DOI: $10.1007 / \mathrm{s} 10660-015-9184-5$.

34. Joseph B.K. (2018) Designing effervescent e-government solutions: Lessons from a developing world context. International e-government development. Cham: Palgrave Macmillan, pp. 187-211. DOI: 10.1007/978-3-319-63284-1_8.

35. Boonmee C. (2017) Mail-doc-web: A technique for faster, cheaper and more sustainable digital service development. Proceedings of the 17th European Conference on Digital Government (ECDG 2017), Lisbon, Portugal, 12-13 June 2017, pp. 36-46.

36. Kyakulumbye S., Pather S., Jantjies M. (2019) Towards design of citizen centric e-government projects in developing country context: the design-reality gap in Uganda. International Journal of Information Systems and Project Management, vol. 7, no 4, pp. 55-73. DOI: 10.12821/ijispm070403.

37. Al Helal E., Mokhtar H. (2018) Towards smart Riyadh: Riyadh Wiki information and complaining system. International Journal of Managing Information Technology, vol. 10, no 2, pp. 95-106.

DOI: 10.5121/ijmit.2018.10206. 


\section{About the authors}

\section{Ebenezer Agbozo}

Senior Lecturer, Ural Federal University, 19, Mira Street, Yekaterinburg 620002, Russia;

E-mail: eagbozo@urfu.ru;

ORCID: 0000-0002-2413-3815

\section{Alexander N. Medvedev}

Cand. Sci. (Tech.);

Associate Professor, Ural Federal University, 19, Mira Street, Yekaterinburg 620002, Russia;

E-mail: a.n.medvedev@urfu.ru 


\title{
Practical aspects of project-based learning in the study of the discipline "Developing information systems"
}

\author{
Rimma D. Gutgarts \\ E-mail: gutgarc@gmail.com \\ Irkutsk National Research Technical University \\ Address: 83, Lermontov Street, Irkutsk 664074, Russia
}

\begin{abstract}
Analysis of modern publications dealing with project-based learning at the university has shown that they can be divided into two parts. The first part is devoted to theoretical and methodological issues and its authors are mainly pedagogical specialists. The second part is concrete examples of the application of the indicated teaching technology in various subject areas, including technical specialties. The literature also presents applications on the organizational and technological aspects of introducing project-based learning in the educational process at the university. The authors of the second part are teachers of specialized disciplines in the corresponding field of study (medicine, technology, creativity, economics, etc.). This article provides an example of the use of elements of project-based education as early as in Soviet higher education when teaching students with a specialization in "Information Technology" and their projection on a modern educational platform. The purpose of the study is to consider individual methodological issues and practical recommendations for applying the project method for students of study profiles related to the study of disciplines focused on information systems (IS) design. The result of the study is to focus on the possibility of introducing project-based training within an interdisciplinary nature, in particular, the participation of students studying in economic specialties in projects for the creation of functional IS. Advice is given on the distribution of the roles of students and their functions in a team working on a project.
\end{abstract}

Key words: information systems; project approach to training; competencies; information systems design; examples of project training; participants in project training.

Citation: Gutgarts R.D. (2020) Practical aspects of project-based learning in the study of the discipline "Developing information systems". Business Informatics, vol. 14, no 1, pp. 51-61.

DOI: $10.17323 / 2587-814 X .2020 .1 .51 .61$ 


\section{Introduction}

$\mathrm{O}$ ver the past few years, two terms have come to be actively used in the terminology of the learning process at all levels: "project-based learning" and "competencies." However, project-based training is still perceived as one of the non-traditional pedagogical technologies, although it is promoted for widespread use, especially in the process of higher education [1]. There are a fairly large number of publications on the subject of project-based training. For example, in the Scientific Electronic Library (https:// elibrary.ru) as of 5 January 2020, there were 180,649 of them.

A brief analysis of information sources on the indicated topics as applied to studying at a university has shown that they reflect the following features:

1. The main characteristics and features of project-based training are summarized, for example, in [2-4]

2. The introduction of design technology in the educational process is shown from the point of view of the priority direction of pedagogical activity [5]

3. Project activity is presented as the most popular and effective method of organizing work with students [3]. Moreover, this type of activity is not fundamentally new and in [3] there is a reference to the fact that the idea of project training arose in the United States in the 19 th century

4. The introduction of project training for students is influenced by such external factors as the development of science, technology, economics, and the organization of production [4]

5. The design method is considered as the optimal means of enhancing the motivation to learn among modern youth [6]

6. Training based on the implementation of projects is treated as one of the innovative teaching methods [7-9]

7. Project training is presented as one of the interactive pedagogical technologies aimed at implementing a personality-oriented approach to teaching methods [10]

8. Examples of the application of the design training method are given (for example, in the framework of the bachelor's degree in "Operation of transport-technological machines and complexes" [10], in the bachelor's programs in robotics profile [11], in the discipline "Computer technologies in documentation management "For the specialty" Management (by industry) "[1], in courses on power systems of the Faculty of Electromechanics at the University of Colima in Mexico [12]), as well as the experience and methodological basis for the use of project training (for example, at the Siberian Industrial University [13], in foreign practice [14]). Currently, there is not enough experience in the application of project-based instruction at Russian universities. Nevertheless, in particular, the Urals Federal University already has a certain basis in this matter and shares its methodological and practical achievements through online training

9. Project-based learning is understood as a model that is being introduced into the educational process instead of traditional teaching technology and it is fundamentally changing the process of getting an education [15]

10. Project-based learning embodies the idea of developmental learning [16].

\section{An example of the use of elements of project-based learning in a technical university}

Of the listed features, it is essential to mention the innovative component of project- 
based learning. The term "innovation" at the present stage of economic development in relation to management practice has been used actively relatively recently. However, elements of project-based learning have been used for a long time. One example is the experience of the Irkutsk Polytechnic Institute (now the Irkutsk National Research Technical University), where at the Department of Electronics and Computer Engineering (from the beginning of the 1970s to the beginning of the 1990s) there was a branch research laboratory of automated enterprise management systems (ONIL ASUP), which was engaged in the design, development and implementation of ACS (in the classic sub-systems structure) at seven enterprises in the electrical industry. Moreover, all design decisions were essentially standard and only finalized taking into account the specifics of each enterprise. In modern terminology for the implemented functionality, such an automated control system partially corresponded to the set of tasks of the following types of systems: CAD / $\mathrm{CAM}+\mathrm{MRPII}+\mathrm{CRM}+\mathrm{MES}+\mathrm{HRM}+$ EAM + BI. Almost all students who studied in the specialties "Automated control systems" and "Mechanized processing of economic information" took part in design decisions for all subsystems. The participation of students began from the 3 rd year and continued until the writing and defense of the graduation project. After graduation, some graduates were hired by the laboratory. Employees of ONIL ASUP periodically conducted classes with students. Such classes could be: lectures and practice in academic disciplines or its sections, practical classes, laboratory work. Collaboration was mutually beneficial. On the one hand, students were involved in the implementation of realistically implemented projects, learned to work in a team and even communicate with customers during the internship that took place at the same enterprises for which automated control systems were created. On the other hand, for ONIL ASUP there was an opportunity to attract additional workers and reduce the duration of projects. In addition, almost all teachers of the department also participated in projects. Over the 20-year history, on the basis of the topics of ONIL ASUP, its employees defended 19 candidate dissertations, and subsequently this scientific and practical base became the basis for five doctoral dissertations.

Unfortunately, at the moment, such a practice rarely takes place. Now the presence in universities of specialized units (centers, laboratories), whose activities are focused only on the implementation of business contracts and (or) grants, does not have widespread distribution.

One of the features of the design and development of IS currently consists in the isolation of this type of project activity in an independent direction. Typically they create typed design solutions and adapt them to the conditions of a particular enterprise by adjusting a set of parameters and (or) additional programming (example - 1C:Enterprise). Now standard design solutions for the automation of management activities at the corporate level are offered in the market of functional software (software) in a modular interpretation and can be acquired by any interested user.

Nevertheless, the use of the principles of project training has been preserved at the department until now. Throughout the existence of the department (over 50 years), completely different diploma projects have always been carried out. In fact, most students, starting from the second (or third) year, choose the topic of their future final qualification work (WRC) and, thus, all laboratory works in special disciplines is performed on a specific topic. I will give several topics of WRC in recent years:

- "The system of automated accounting of documents of the archive fund of the Russian Federation in organizations that are the sources of acquisition"

^ "Automated system for student media center IRNITU"

$\downarrow$ "Information system for the school of modern choreography "Steps"

$\checkmark$ "Automated accounting system for the rat- 
ing of cultural and creative activities of students"

"Automated order management system in the dispatching service of the enterprise BETON-STROY”

"Automated workplace of a customer service manager for "1-Megamir"

"Online service for applying for admission to IRNITU".

\section{Aspects of interaction of students of different profiles during project-based learning}

In universities that train specialists in creating information systems and, for example, economists, projects can be joint. The interaction between students of different areas of study contributes to the development of interdisciplinary communication and represents a transdisciplinary approach [4].

Such cooperation will be useful on both sides. On the one hand, developers of economic information systems will gain invaluable experience in communicating with real customers and understanding their functional needs. On the other hand, students of economic specialties who will inevitably use appropriate information systems in their professional activities will be able to learn how to formulate correctly their functional requirements. These can be requirements both for fundamentally new systems, and for already functioning systems in order to develop their functionality (if the project has such an orientation). "Now the creation of an information system is a task not only for programmers with the rare participation of management, but also for economic services included in the development of system modules" [17].

The stage of formation of functional requirements in the design of IS is the initial and extremely important stage. The time of implementation and the cost of the project will depend on the quality of its results. In addition, students of an economic profile will take part in testing the designed IS and critically evaluate the proposed solutions in a practical, professional aspect. This, in turn, allows, firstly, to see the mistakes made at the initial stage of working with requirements. Secondly, to be able to test the implemented requirements in the conditions of the created software product, as well as adjust the requirements as necessary. Thirdly, students of economic specialties can see instructions for users and recommend how to edit them, so that in case of problems when working with the system, some of them can be quickly and independently eliminated. Properly written instructions for the user are an indispensable assistant when working with the information system.

Students of economic specialties can also participate in a joint presentation of the project and present it to the appropriate audience. Thus, the skills of a public thematic report and knowledge of relevant terminology from the field of information technology (IT) will be acquired.

The participation of students of economic specialties in IS projects will reduce the gap between fundamentally different subject areas: IT and economics. It is the different terminology in real projects, especially at the initial stage, that often leads to some problems. According to statistics, about $2 / 3$ of the projects are not completed properly; for example, they stop ahead of schedule due to the fact that their continuation is inappropriate, or they end with a result that the customer does not need.

As projects in the development of the discipline "Designing information systems" can be selected, in particular, the following:

1. Information systems that solve a small 
number of functional tasks that are initiated by third-party clients (for example, systems for accounting, management, analysis, calculations). For such systems, there is no unified design solution in the functional software market. Systems on the market do not take into account the competitive advantages of a particular organization. Initiatively created systems can be designed, for example, to create data warehouses on the economic aspects of the enterprise (organization, company, large structural unit).

2. Information systems for specialized scientific organizations (including scientific departments of universities), if such systems do not include algorithms related to knowhow. This may be systems designed to perform specialized calculations and analysis of the results.

3. Computer programs based on the use of correct algorithms, but implemented on obsolete instrumental base (for example, DBMS, programming language, information storage and presentation technology, interface).

In [18], projects are classified by their nature at the macro level. According to such recommendations, IS projects can be considered as:

$\downarrow$ search (search and analysis of the suitability of similar ready-made design solutions)

$\downarrow$ creative (any design of IS necessarily contains elements of creativity, since in addition to formal algorithms it includes, for example, designing an interface)

$\checkmark$ applied (IS is always created in relation to a specific subject area)

$\checkmark$ role-based (team members in the project must have different specializations and interact with each other, because in the end they should get one software product).

\section{Features of the study of the discipline \\ "Designing information systems" in the context of project-based learning}

When studying the discipline "Designing information systems," students should gain theoretical knowledge on the design process as such, on methodological aspects and on the use of special tools, as well as acquire skills in creating design solutions at all stages of design, taking into account the compilation of the related design documentation. In this case, two fundamental approaches to the study of discipline are possible.

The first approach includes the following:

$\diamond$ to study the theoretical foundations of IS design, stages (steps) of the canonical design process and their content, tools used in the design

to acquire skills in applying the acquired knowledge in practice, i.e. prepare individual information systems design solutions and develop a computer program for them.

The second approach has the following features:

$\rightarrow$ tools used for designing IS, as well as theoretical issues are studied in the framework of special disciplines (for example, "CASE tools," "Web programming," "Information technology," "Object-oriented programming," "Networks and telecommunications," "Technologies for the development of software systems," "Organization of computers and networks," "Data management," "Theoretical foundations of automated control," etc.)

$\diamond$ in practice, perform the design of the IS (on an individual task) using previously studied and mastered tools, including the basic work for each stage, as well as programmatically implement individual design solutions, accompanying the finished program with instructions for its use (for the system pro- 
grammer or administrator) and instruction for the end user.

If you adhere to the first approach, then students studying the discipline "Designing information systems" acquire a combination of different knowledge, abilities and skills in all the main aspects of project activities in relation to the creation of IS. A student receives some "starting capital." However, the depth of development of the material will be clearly insufficient to be ready for independent design work.

Yet, training on the basis of the first approach may be quite appropriate if this discipline is one of the curriculum disciplines in professional areas that are not related to the IT sphere. For example, training in economic specialties does not require deep immersion in the subject of IS design. However, students should have an idea of what needs to be considered when creating IS for economic purposes.

In our opinion, it is advisable to consider the study of the discipline "Designing information Systems" in the framework of the second approach, i.e. pay attention to the study of tools and other specialized issues within the framework of special disciplines which will allow students to gain more in-depth knowledge in the relevant subject areas.

Thus, the study of the discipline "Designing information systems" will be based on the knowledge already acquired by students, as well as their skills and abilities. Then interest will be focused on the design process as such, i.e. on the content of all stages of design, taking into account certain aspects of the compilation of project documentation accompanying each of them.

The result of the education will be a real project of any IS. Moreover, the learning process itself is based on the use of practice-oriented technologies. In such conditions, the students will be able to fully demonstrate their creative abilities and skills in practice, as well as apply the knowledge gained in mastering related disciplines. The role of the teacher is to perform two main functions: 1) to act as the customer of the project and critically analyze its intermediate results and 2) to act as a consultant analyst and edit the project implementation vector in a timely way.

\section{Description of the main participants in the implementation of project-based learning to study the discipline "Designing information systems"}

Let's consider the distribution of roles, functions and responsibilities of project participants using the example of creating an IS of organizational and managerial type. Such projects are always designed to meet the challenges in a particular subject area. It is desirable to form a team of students to carry out such a project in accordance with the specifics of the supporting and functional subsystems.

\subsection{The subsystem of organizational support}

Mentor and tutor: teacher. $\mathrm{He}$ or she substantiates and formalizes the theme of a project which is interesting for students and corresponds to the direction of preparation. Topics can be based on the results of practical training, offered by graduates of a profile direction, already working in their specialty, initiated by municipal services, specific organizations, and other departments of the university. They substantiate the design methodology: canonical or RAD. They concretize the functionality of the project and give recommendations on team building on the basis of general professional training of students to the initial moment of project implementation. The teacher oversees the project and provides advice if necessary. 
An expert, who also can be a customer of the project. An expert may be:

$\downarrow$ a representative of the organization in which the student underwent practical training

$\downarrow$ a graduate working in the specialty profile

$\downarrow$ representative of the municipal service

$\checkmark$ representative of a specific organization or department of the university initiating the project.

The process of studying at the university is very dynamic and attracting experts, tutors and other specialists "from the outside" is very problematic, since these people are employed in the real sector of the economy and can not always attend classes at the scheduled time. Therefore, it is more reasonable to choose for these roles either teachers who are profiled at the faculty or related.

Project manager. Draws up a calendar plan of work for the project, organizes and provides private and general meetings between all project participants, distributes work, keeps track of completed work, monitors compliance with the work plan, records and resolves problems that arise, analyzes the work performed, and regulates the work plan. For the implementation of management processes uses special software for project management.

\subsection{The subsystem of information support}

Students: will specialize in designing a database, reference information, interfaces, forms of input and output documents.

\subsection{Software development subsystem}

Students: will be engaged in the justification and selection of software for the program implementation of design solutions, their programming, as well as debugging and testing of finished programs.

\subsection{The subsystem of mathematical support}

Students: will justify, if necessary, the choice of mathematical and (or) economic and mathematical methods that ensure the implementation of specialized algorithms.

\subsection{The subsystem of technical support}

Students: will be engaged in designing a set of technical means necessary and sufficient for the implementation of the project at the automation object.

\subsection{Functional modules}

Students: will perform analytical work (identification and formalization of functional requirements for the project, preparation of project documentation, preparation of tasks for programmers, preparation of presentations at the end of the project); must use CASE tools in their work for the preparation of project documentation.

In addition, the project team may include:

$\downarrow$ students playing the role of testers (a comprehensive check of the functional operability of the finished software product and the preparation of recommendations for writing instructions for end users and the system programmer or administrator); if necessary, can participate in the compilation of full instructions

$\downarrow$ students acting as technical writers (drawing up instructions for using the developed software and its technological support during the operation of the system at the automation object).

It is advisable that in the process of project implementation the roles among students are periodically redistributed. Thus, students will be able to at least partially master all types of work within each role. Then they will have an 
idea of the specifics of the content of the project as a whole.

\section{The relationship \\ of project training \\ and a competency-based approach}

In [7] it is emphasized that at present such requirements are imposed on employees as the ability to carry out project activities, and this is one of the required competencies. If we talk about university students, then this ability will be formed automatically if the process of studying disciplines in the curriculum is initially based on the technology of project training.

When comparing the qualification and competency-based approaches to education in [19], attention is focused on the fact that the latter is characterized by such features as a creative look at problem solving, the possibility of constructing an individual learning path and interactivity.

The competency-based approach is often opposed to the paradigm of education based on knowledge [19]. The author shows the unreasonableness of this view, since "...the assimilation of knowledge and the formation of competencies are not only mutually complementary, but also closely intertwined" [19].

In [20], it is noted that there are about 400 definitions of competencies. However, it is enough to approach this issue from a formal point of view and turn to dictionaries. Having studied the semantic meaning of the term "competencies" given in [21-24], we can conclude that the term "competency" is a synthesis of a single-valued sequence of the following phases:

1) obtaining a certain set of primary knowledge in a specific subject area

2) the acquisition of initial skills in the use of acquired knowledge to solve problems in the same subject area
3) the application in practice of acquired skills contributing to the acquisition of some skills that improve as time increases in the use of acquired knowledge and the acquisition of experience.

The process of practical application of knowledge, skills and experience in real conditions is associated with the generation of new knowledge that affects the need to adjust existing skills. As a result, a new experience appears. Thus, while a person works in a specialized subject area and positions himself in it as a specialist (or even an expert), his competence develops in a spiral.

Therefore, the presence of a student of a certain professional competence actually consists in acquiring a combination of knowledge, skills and abilities. The level of experience (as the sum of knowledge, skills and abilities) initially cannot be very high due to restrictions of age.

In addition to competencies based on knowledge, students should acquire knowledge, skills and abilities in the field of optimal distribution of time when doing personal work, as well as interacting with other students. This will allow them in the future to quickly adapt to the workforce and solve professional challenges in a timely way $[25,26]$.

\section{Conclusion}

The technology of training at the university, based on the application of the project method, allows us, in particular, to solve the following problems:

1. The ability to respond to rapid changes (the formulation of requirements for the project is iterative in nature and therefore they can be edited throughout the project; to comply with the project deadlines, you need to respond quickly to the adjustment of requirements) 
2. Redistribute, if necessary, roles among project participants

3. To interact among themselves to all project participants (the design and development of one information system inevitably requires this)

4. To show creative abilities (in any project, its intellectual component is an integral part).

In addition, the implementation of one project will certainly contribute to the development of communicative relations between all participants due to the need for continuous cooperation on a variety of issues.

The introduction of project training in the educational process of higher education cannot and should not be understood as another campaign. This process is characterized by complex informational, organizational, and technological components (the relationship between academic disciplines in the same department and the relationship between disciplines in related departments), which will require some editing of curricula and the content of individual disciplines. Changes of this kind, in turn, are very dependent on standards (regulations) from the Ministry of Science and Higher Education. In these standards, for a number of disciplines that are mandatory, the volume of hours for their development is very strictly set. Therefore, universities have significant limitations in the preparation of their curricula.

Thus, the implementation of project-based training in practice will require, firstly, editing the standards by the ministry, secondly, delegating more independence to universities in the preparation of curricula, and thirdly, accounting and exchange of experience already gained on a regular basis.

\section{References}

1. Shapovalova M.S. (2014) Peculiarities of using project-based training in information disciplines within the framework of the Federal State Educational Standards of higher education. Science and Education.

Bauman Moscow State University. Electronic journal, no 10, pp. 413-423. Available at: http://engineering-science. $\mathrm{ru} / \mathrm{doc} / 728379 . \mathrm{html}$ (accessed 19 December 2019) (in Russian).

2. Galchenko A.S., Gabova M.P., Sofyina V.N., Rastorgueva P.A. (2018) Project training of students and managers as a tool for effective training in project management. Modern Education: Content, Technologies, Quality, no 2, pp. 161-163 (in Russian).

3. Gladkova M.N., Vaganova O.I., Smirnova Zh.V. (2018) The technology of project-based learning in professional education. Problems of Modern Pedagogical Education, no 58-3, pp. 80-83 (in Russian).

4. Guzanov B.N., Baranova A.A., Lovcevich T.L. (2019) Project-based training at trans-professional education in a technical university. Professional Education and Labor Market, no 3-38, pp. 44-52 (in Russian). DOI 10.24411/2307-4264-2019-10305.

5. Vyskareva T.A. (2011) Project method of teaching in the system of higher education. Contemporary Higher Education: Innovative Aspects, no 1, pp. 5-12 (in Russian).

6. Kenebaeva D.B., Abdibekova L.M., Bekenova D.B. (2019) Application of the project method of training in the framework of the discipline "Multimedia technologies" for students of higher education institutions. Proceedings of the X International Scientific and Practical Conference "Innovative Technologies in Science and Education”, Penza, Russia, 20 January 2019, pp. 47-49 (in Russian).

7. Kudinova O.S., Skulmovskaya L.G. (2018) Project activity at the university as a basis for innovation. Modern Problems of Science and Education, no 4. Available at: http://science-education.ru/ru/article/ view?id=27928 (accessed 11 December 2019) (in Russian). 
8. Kovrov V.V. (2019) Project activity as an innovative resource in ensuring the quality of professional training of students at the university. Problems of Modern Pedagogical Education, no 62-2, pp. 119-121 (in Russian).

9. Nurmaganbetova M.S. (2017) Project education as one of the innovative methods of training. Proceedings of the VII Russian Scientific and Practical Conference "Youth and the State: Scientific and Methodological, Socio-Pedagogical and Psychological Aspects of the Development of Modern Education. International and Russian Experience”, Tver, Russia, 23-30 October 2017, pp. 80-85 (in Russian).

10.Komarova L.V. (2014) Achievement of quality of training as a result of development of project technologies in profile education. Contemporary Higher Education: Innovative Aspects, no 4, pp. 91-95 (in Russian).

11.Shakhtarin B.I., Veltischev V.V. (2016) Project training in bachelor programs in the field of robotics. Civil Aviation High Technologies, vol. 19, no 05, pp. 54-60 (in Russian).

12.Betancourt R.J., González-López J.M., Espejo E.B., Pérez-González M.A., Laureano E.V., Ledesma J.A. (2018) Virtual instrumentation based learning methodology for teaching power system measurement and protection. Computer Applications in Engineering Education, vol. 27, no 6, pp. 1555-1570. DOI: 10.1002/cae.22170.

13.Protopopov E.V., Feoktistov A.V., Temlyantsev M.V., Gordeeva O.V., Vasilieva M.B. (2017) Project training as a tool for integrating an university's activities into the regional educational space (experience in implementing project training technology at SIBGIU). Bulletin of the Siberian State Industrial University, no 4 (22), pp. 63-69 (in Russian).

14.Souza M., Moreira R., Figueiredo E. (2019) Students perception on the use of project-based learning in software engineering education. Proceedings of the XXXIII Brazilian Symposium on Software Engineering (SBES 2019), Salvador, Bahia, Brazil. 23-27 September 2019, pp. 537-546. DOI: 10.1145/3350768.3352457.

15.Sycheva S.M., Arzumanova R.A. (2019) Project training as a key to preparing a successful specialist. Vestnik Universiteta, no 6, pp. 32-37 (in Russian). DOI 10.26425/1816-4277-2019-6-32-37.

16. Filippov V.M. (2019) Preparation of a dissertation should be difficult, and the defense should be simple and easy. Higher Education Today, no 9, pp. 2-7 (in Russian). DOI: 10.25586/RNU.HET.19.09.P.02.

17.Vinogradova E.Yu. (2018) Current issues of designing and implementing corporate systems for supporting management decision-making at the enterprise. Bulletin of the Far Eastern Federal University. Economics and Management, no 1, pp. 102-111 (in Russian). DOI: https://dx.doi.org/10.24866/2311-2271/2018-1/102-111.

18.Fateeva I.A., Kanatnikova T.N. (2013) Project method as a priority innovative technology in education. Young Scientist, no 1, pp. 376-378 (in Russian).

19.Golovyatenko T.A. (2019) Professional competence of a university teacher as a problem. Higher Education Today, no 10, pp. 15-19 (in Russian). DOI: 10.25586/RNU.HET.19.10.P.15.

20.Korchemny P.A. (2017) The problem of the competence approach from the position of the activity approach as a methodological basis in Russian education. Proceedings of the VIII International Symposium "International Research in Psychology of Security and Their Modern State”, Ekaterinburg, Russia, 2017, pp. 176-188 (in Russian).

21.Lokshina S.M. (1988) Short dictionary of foreign words. Moscow: Russian Language (in Russian).

22.Ozhegov S.I. (2010) Explanatory dictionary of the Russian language: About 100,000 words, terms and phraseological expressions. Moscow: Oniks (in Russian).

23.Brokgauz F.A., Efron I.A. (2004) Encyclopedic dictionary. Society and the state. Rulers and generals. Peoples and countries. Moscow: EKSMO (in Russian).

24.Lapin I.K., ed. (2006) Large encyclopedic dictionary: More than 100,000 articles, more than 4,000 illustrations. Moscow: ACT (in Russian).

25.Chebotarev V.G., Gromov A.I. (2014) Automating the learning process. Business Informatics, no 4, pp. 45-52 (in Russian).

26.Zharov V.K., Taratukhina Yu,V. (2014) Peculiarities of functioning of the information and educational environment of modern higher education. Business Informatics, no 2, pp. 44-50 (in Russian). 


\section{About the author}

\section{Rimma D. Gutgarts}

Dr. Sci. (Econ.), Professor;

Irkutsk National Research Technical University, Institute of Information Technology and Data Analysis, 83, Lermontov Street, Irkutsk 664074, Russia;

E-mail: gutgarc@gmail.com

ORCID 0000-0001-9881-1976 


\title{
Modeling globalization processes taking into account structural changes, using Algeria as an example
}

\author{
Elena D. Kopnova \\ E-mail: ekopnova@hse.ru
}

\author{
Lilia A. Rodionova \\ E-mail: lrodionova@hse.ru
}

National Research University Higher School of Economics Address: 20, Myasnitskaya Street, Moscow 101000, Russia

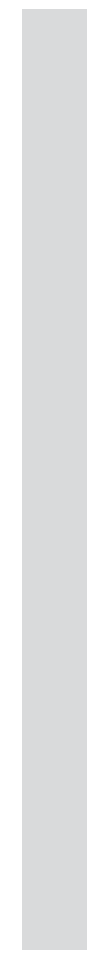

\begin{abstract}
This work is devoted to modeling globalization processes, taking into account the dynamic links between them and structural changes in the trend parameters. Its relevance is due to the fact that most of the work on this topic is devoted to studying the impact of globalization on individual indicators of socio-economic development, and not enough attention is paid to studying the formation of the General trend of globalization, the interaction of its components. The latter is particularly important for developing countries, which are characterized by a strong heterogeneity of these components in the structure of globalization, as well as a marked variability of parameters in their trends. We proposed an approach of cointegration analysis of globalization processes taking into account structural shifts in the trends of these processes. As an example of the implementation of this approach, we consider modeling the dynamics of the components of the KOF globalization index for Algeria during the period 1970-2015. The stationarity of the series was tested using unit root tests with structural breaks: Andrews-Zivot and Perron tests for a series with one structural break, and Clemente-MontanesReyes and Lee Strazicich tests for series with one or two structural breaks. The Johansen test for small samples taking into account exogenous variables was used for cointegration testing. The presence of dynamic relationships was confirmed by comparing forecasts for the vector error correction model and one-dimensional models of processes using the Dibold-Mariano test. Interpretation of models was based on estimates of the impulse response function and the Cholesky decomposition of prediction error. The results show that the formation of the KOF Globalisation Index for Algeria is largely due to the mutual influence of its components. The dynamics of political and economic globalization are formed as a result of mutual changes in the sphere of external economic and political relations. The
\end{abstract}


role of international cooperation in the social sphere for the other two components of globalization in Algeria is small. At the same time, the dynamics of social globalization is determined by its own components. The proposed modeling methodology can be applied to the study of globalization processes in other countries of the world in order to justify political decision-making.

Key words: KOF Globalisation Index; cointegration model; vector error correction model; structural reaks; impulse response functions; Cholesky decomposition.

Citation: Kopnova E.D., Rodionova L.A. Modeling globalization processes taking into account structural changes, using Algeria as an example. Business Informatics, vol. 14, no 1, pp. 62-74.

DOI: $10.17323 / 2587-814 X .2020 .1 .62 .74$

\section{Introduction}

$\mathrm{G}$ lobalization has been developing rapidly since the second half of the 20th century. According to 2018 data, almost a third of the increase in world GDP per capita is due to an increase in the level of globalization [1]. The results of globalization are most noticeable in third world countries, especially in Africa [2], where they are reflected in the context of a new model of economic development that provides for an increased role of such countries in the world economy [3]. According to forecasts, Africa, which currently contributes only $2 \%$ to the gross world product growth, will provide more than $75 \%$ of the world's population growth in the coming two decades, which in the conditions of globalization will be able to supply the world labor market [4]. Globalization processes in African countries, defining new conditions for the interaction of socioeconomic and demographic factors, not only open up opportunities, but also create barriers to the growth of people's well-being, exacerbating social and political risks [5-8]. Making informed decisions in a rapidly and radically changing socio-economic environment requires operational monitoring and objective system analysis.

Current research on this topic is mainly devoted to assessing the impact of globaliza- tion on the socio-economic development of countries. Thus, according to data from Nigeria for the years 1980-2012, the presence of dynamic links between foreign investment, international trade and economic growth is shown [9]. According to Tunisian data for the years 1983-2009 [10], the ambiguous role of economic globalization in the formation of the labor market was shown. The significant role of globalization is demonstrated by the study of the determinants of income inequality according to data from 68 African countries for the years 1990-2010 [11]. The results of the analysis of data from 52 African countries for 1996-2010 [12] indicated a positive impact of international trade and a negative impact of financial integration on the level of human capital.

Despite the available constructive results of statistical data analysis, there are no papers devoted to the analysis of globalization in African countries that study the dynamic relationships between its individual components: economic, political, and social. Not enough attention is paid to forecasting globalization processes. Most of the works deal with economic globalization, while in these countries the role of the other two components, especially the political component, is great. In addition, the research does not pay enough attention to the problems of variability in the trend of globalization processes, which 
can significantly affect the results of statistical analysis [13]. Thus, taking into account the above, it is important to develop a statistical methodology for analyzing globalization processes in African countries using tools that can correctly take into account the interaction of economic, political and social globalization processes and the features of processes in individual countries.

\section{Research information base}

The statistical method of studying the processes of globalization in Africa was used on the example of Algeria according to the time series of sub-indices of the KOF-index of globalization [14] for the years 1970-2015². The dynamics of the selected indicators is shown in Figure 1.

Figure 1 shows that for Algeria, along with a very noticeable predominance of the political component in the structure of the COFindex of globalization, there is a high variability. This indicator was especially unstable in the period 1987-2008, known for the mass riots of 1986-1988, the civil war of 1991-2002 [15] and the subsequent activation of radical Islamists in 2006-2008. The figure shows that all components of the KOF-index of globalization are characterized by structural shifts in the parameters of their development trends, and it is noticeable that the variability of these trends has a similar character.

\section{Research methods}

The research methodology was based on the idea of cointegration analysis of time series using the vector error correction model (VECM) [16], taking into account the presence of structural shifts in the parameters of time series trends. To confirm the conclusions
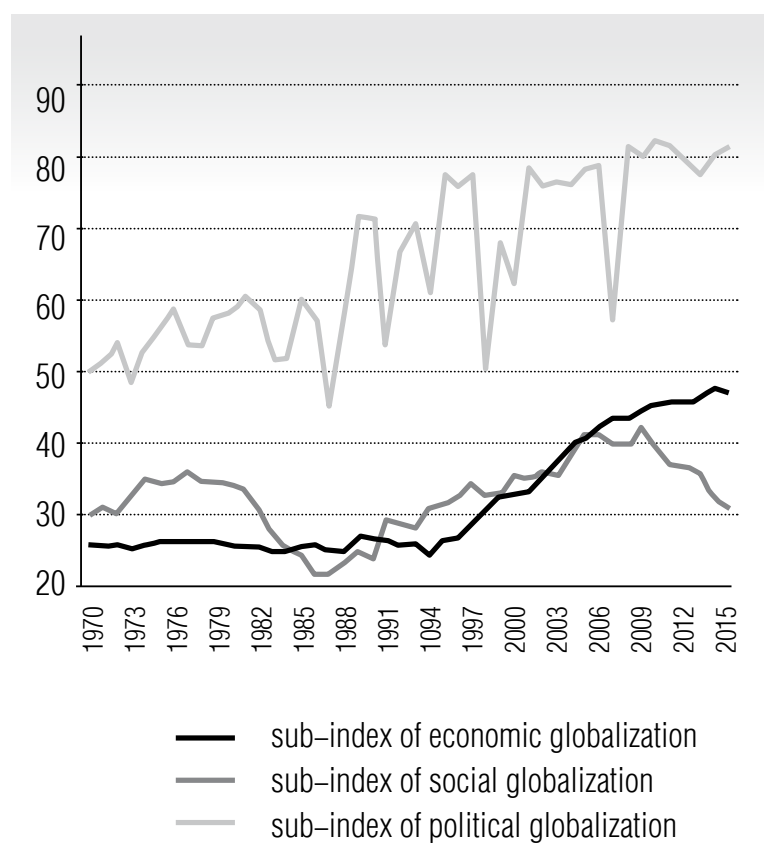

Fig 1. Dynamics of sub-indices of globalization in Algeria, 1970-2015

about the presence or absence of dynamic relationships and the choice of a model for forecasting, the method of comparing forecasts obtained from a multidimensional model and a set of three one-dimensional models was also used. One of these aggregates included integrated autoregressive - moving average (ARIMA) models [16]. Another set was made up of Holt-Winters short-term forecasting models (HWM) [17]. The use of HWM models was justified by the fact that they have a fairly high predictive capacity [18].

Let $\boldsymbol{Y}_{t}(t=1,2, \ldots, T)-$ a random process that generates the time series of sub-indices of economic, political and social globalization on the time interval $[0, T]: \boldsymbol{Y}_{t}=\left(\text { pol }_{t} \text { ec } \text { soc }_{t}\right)^{\prime}$ :

The process is considered in the form of a model:

$$
\boldsymbol{Y}_{t}=\boldsymbol{\mu}_{t} \boldsymbol{\delta}+\boldsymbol{X}_{t}, \boldsymbol{X}_{t}=\left(X_{1 t} X_{2 t} X_{3 t}\right)^{\prime}
$$

${ }^{1}$ KOF (Konjunkturforschungsstelle) Globalisation Index:

https://www.kof.ethz.ch/en/forecasts-and-indicators/indicators/kof-globalisation-index.html 


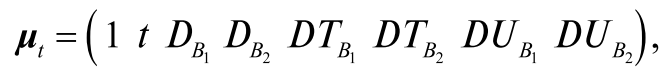

$$
\begin{aligned}
& \boldsymbol{\delta}=\left(\delta_{1} \ldots \delta_{8}\right)^{\prime},
\end{aligned}
$$

$T_{B j}-$ moment of structural shift

$$
\begin{gathered}
D_{B_{j}}=\left\{\begin{array}{l}
1, t \geq T_{B_{j}} \\
0, t<T_{B_{j}}
\end{array}, \quad D T_{B_{j}}=\left\{\begin{array}{ll}
t-T_{B_{j}}, t \geq T_{B_{j}} \\
0, & t<T_{B_{j}}
\end{array},\right.\right. \\
D U_{B_{j}}=\left\{\begin{array}{ll}
1, t=T_{B_{j}} \\
0, t \neq T_{B_{j}}
\end{array}, \quad j=1,2 .\right.
\end{gathered}
$$

The models under consideration differ in the representation of the $X_{t}$ process:

$$
\begin{gathered}
\text { VECM: } \Delta \boldsymbol{X}_{t}=\boldsymbol{\alpha} \boldsymbol{\beta}^{\prime} \boldsymbol{X}_{t-1}+\sum_{j=1}^{p} \Gamma_{j} \Delta \boldsymbol{X}_{t-j}+\boldsymbol{U}_{t} \\
\Delta \boldsymbol{X}_{t}=\boldsymbol{X}_{t}-\boldsymbol{X}_{t-1}, \boldsymbol{\alpha}=\left\|\alpha_{i j}\right\|_{k \times r}, \boldsymbol{\beta}=\left\|\beta_{i j}\right\|_{k \times r}, \\
\Gamma_{j}=\left\|\gamma_{i s}\right\|_{k \times k}, k=3, U_{t}=\left(U_{1 t} U_{2 t} U_{3 t}\right)^{\prime},
\end{gathered}
$$

$r$ - rank of cointegration,

$$
\begin{gathered}
\boldsymbol{U} \sim N\left(\mathbf{0}, \boldsymbol{I}_{T} \otimes \Sigma_{u}\right), \boldsymbol{U}=\left(\boldsymbol{U}_{1} \ldots \boldsymbol{U}_{T}\right)^{\prime}, \\
\boldsymbol{\Sigma}_{u}=\left\|\sigma_{i j}\right\|_{k \times k}, \operatorname{cov}\left[U_{i t}, U_{j s}\right]=\left\{\begin{array}{ll}
\sigma_{i j}, & t=s \\
0, & t \neq S
\end{array} .\right.
\end{gathered}
$$

ARIMA: $\boldsymbol{X}_{t}=\sum_{j=1}^{p} \boldsymbol{\theta}_{j} \boldsymbol{X}_{t-j}+\sum_{j=1}^{q} \boldsymbol{\pi}_{j} \boldsymbol{U}_{t-j}$,

$$
\begin{gathered}
U_{i t} \sim N\left(0, \sigma_{i}^{2}\right), \\
\operatorname{cov}\left[U_{i t}, U_{i s}\right]=\left\{\begin{array}{ll}
\sigma_{i}^{2}, & t=s \\
0, & t \neq s
\end{array} .\right.
\end{gathered}
$$

HWM: $\boldsymbol{Y}_{t}=\boldsymbol{X}_{t}+\boldsymbol{U}_{t}$.

$X_{t}$ contains a deterministic component in the form of a linear trend: $\boldsymbol{\mu}_{t, \tau}=\boldsymbol{\alpha}_{0 t}+\boldsymbol{\alpha}_{1 t} \tau$ :

$$
\begin{gathered}
U_{i t} \sim N\left(0, \sigma_{i}^{2}\right), \\
\operatorname{cov}\left[U_{i t}, U_{i s}\right]=\left\{\begin{array}{ll}
\sigma_{i}^{2}, & t=s \\
0, & t \neq s
\end{array} .\right. \\
E\left[\boldsymbol{Y}_{t+\tau} \mid \boldsymbol{Y}_{t}\right]=\boldsymbol{\mu}_{t, \tau}, \\
\boldsymbol{\alpha}_{0 t}=\lambda_{0} \boldsymbol{Y}_{t}+\left(1-\lambda_{0}\right)\left(\boldsymbol{\alpha}_{0 t-1}+\boldsymbol{\alpha}_{1 t-1}\right), \\
\boldsymbol{\alpha}_{1 t}=\lambda_{1}\left(\boldsymbol{\alpha}_{0 t}-\boldsymbol{\alpha}_{0 t-1}\right)+\left(1-\lambda_{1}\right) \boldsymbol{\alpha}_{1 t-1},
\end{gathered}
$$

$\lambda_{0}, \lambda_{1}-$ vectors containing adaptation parameters.

The stationarity of the processes generating the implementation of a series of sub-indices was pre-tested. Using the Dolado-Jenkinson-Sosvilla-Riviera procedure [19] for each time series, tests for the presence of a single root of the characteristic equation of the corresponding process, taking into account structural shifts, were applied. The tests are based on the augmented Dickey-Fuller test (ADF-test). To account for structural shifts, dummy variables were included. For a series with a single structural shift, Andrews-Zivot tests (AZ-test) [20] and Perron tests (P-test) [21] were used. For a series with one or two structural shifts, Clemente-MontanesReyes tests (CMR test) [22] or Strazicich (Lee, Strazicich) (LS-test) [23, 24] were used. The advantage of P- and LS-tests is that they overcome the disadvantage of AZ- and CMRtests, which often, rejecting the null hypothesis, mistakenly lead to the conclusion of stationarity for a non-stationary process with structural shifts, and thus allow us to obtain an unambiguous result. The advantage of $\mathrm{P}$ and CMR-tests is that they take into account both innovative and additive emissions in the dynamics series, while the LS-test takes into account only additive and A-Z - only innovative emissions. For comparison, classical tests for stationarity without taking into account structural shifts (ADF-, PP-, KPSS-tests [16]) were also used.

To evaluate the parameters of the cointegration equation and the error correction model Johansen's approach [25] was used. By testing for cointegration, we used a modification of the Johansen test for short samples, which provides for the presence of deterministic variables in the model and determines the distribution of test statistics by the bootstrap method [26].

VECM and ARIMA models were evaluated using the maximum likelihood method and 
tested with the inclusion of all dummy variables corresponding to structural shifts. Structural shifts were determined by the results of stationarity tests, as well as by visual analysis of graphs. The optimal model specification was selected based on the Schwartz criterion and the model's compliance with its prerequisites. The residues of models were tested for the absence of autocorrelation and compliance with the normal distribution law (the Breusch-Godfrey LM test, the Jarque-Bera test, and their multidimensional counterparts). Durnik-Hansen orthogonalization was used for the VEC model residues [27]. The short-term prediction algorithm of HWM was implemented using the minimum root mean square error (RMSE) criterion.

The assumption about the exogeneity of the $i$-th $(i=1,2,3)$ sub-index of globalization was tested by testing the significance of the coefficient estimation $\alpha_{i j}$ for the $i$-th correcting variable in VECM, as well as using The Granger causality test [16]. The Granger test, conducted under the VEC model, also took into account structural shifts and a corrective indicator $\boldsymbol{\beta}^{\prime} \boldsymbol{X}_{t-1}$. We took into account the results of analysis of the structure of the Cholesky decomposition of the forecast error variance for each sub-index [28].

Forecast index values were defined as conditional mathematical expectations of model processes with a maximum forecast horizon of five years. By analyzing the predictive ability of models, a recursive calculation scheme was used $[29,30]$. The choice of the optimal model for forecasting was determined using the calculation of intra-sample forecast error indicators [31]. The statistical significance of the difference in forecasts for different models was tested using the Diebold-Mariano method [32]. The results of comparing intrasample forecasts were used to confirm the presence of dynamic links between sub-indices of globalization.

\section{Results}

\subsection{Analysis of stationarity of the sub-indices of globalization, Algeria}

Using ADF, PP, and KPSS tests without taking into account structural shifts for individual processes produced inconsistent results, as expected. For all sub-indexes, the hypothesis of non - stationarity was not rejected by the ADF and PP tests (except for the political one for PP), while the KPSS test did not reject the hypothesis of stationarity (at the significance level of 5\%). Therefore, the results of testing processes for stationarity were taken into account, considering structural shifts. In Table 1 , as an example, some results of this analysis are given, for the sub-index of political globalization, for the case of an additive structural shift only in a constant and inclusion of a trend and a constant in the test regression.

Table 1 shows that the P-, LS-, and CMR tests do not reject the null hypothesis of nonstationarity under the assumption of either one or two structural shifts at the 0.05 significance level, and almost uniquely determine the moments of the shift. In the P-test, the coefficient estimate for the variable that determines the structural shift is statistically insignificant (the t-statistic is 0.198 ), and this corresponds to some discrepancy in determining the moments of the shift. The results of testing the first differences for all sub-indexes showed that they were stationary. Therefore, it was concluded that these series are implementations of firstorder integrated processes with structural shifts in the constant and / or trend.

\subsection{Analysis of dynamic links between Algeria's globalization sub-indices}

Some results of the cointegration analysis are shown in Tables 2 and 3. Table 2 contains the results of cointegration testing for the case of a trend only in the long-term ratio, taking into 


\section{Results of testing for the stationarity of the sub-index of political globalization in Algeria taking into account structural changes}

\begin{tabular}{|c|c|c|c|c|}
\hline $\begin{array}{c}\text { Number } \\
\text { of structural shifts }\end{array}$ & Test indicators & P-test & LS-test & CMR-test \\
\hline \multirow{4}{*}{1} & T-statistics & -2.434 & -2.848 & -1.004 \\
\hline & $5 \%$ critical level & -4.860 & -3.487 & -3.560 \\
\hline & T-statistics for the shift variable & 0.198 & 2.198 & 7.015 \\
\hline & Moment of shift & 2001 & 1996 & 1990 \\
\hline \multirow{5}{*}{2} & T-statistics & - & -2.923 & -3.093 \\
\hline & $5 \%$ critical level & & -3.563 & -5.490 \\
\hline & T-statistics for the first shift variable & - & -2.524 & 3.351 \\
\hline & T-statistics for the second shift variable & - & -3.405 & 2.942 \\
\hline & Moments of shifts & & 1990, 1998 & 1990, 1998 \\
\hline
\end{tabular}

Footnotes: $1 . H_{0}$ : the process is not statiomary in the presence of structural shifts

$H_{0}$ : the process is statiomary in the presence of structural shifts

2. The test equation included 8 lags.

3. In the LS and CMR tests, the sample reduction rate was $10 \%$.

account three lags of sub-indices and exogenous variables that characterize structural shifts in the trends of all series. In this example, two variables were included for the shift in the constant: $\left(D_{1995}\right.$ and $\left.D_{1991}\right)$ one variable for the shift in the slope of the trend $\left(D T_{1987}\right)$ and three variables for the momentary jump ( $D U_{1989}, D U_{1998}$, $\left.D U_{2007}\right)$. The table shows the asymptotic P-values for both Johansen test statistics (MacKin-

Table 1. 
the level of 0.05). Therefore, further exactly one cointegration equation was evaluated.

The estimated VECM corresponded fairly well to the data, since assumptions about the correctness of its specification were not rejected. Thus, the $P$-value for Rao-Fischer statistics for checking the serial correlation of residuals amounted to 0.355 , and the one for statistics for checking of normality was 0.989 .

Table 3 shows parameter estimates and quality indicators for the error correction model presented. Table 4 gives the corresponding results of the Granger causality test. Figure 2 demonstrates graphs of impulse responses of each subindex to shocks in other sub-indexes for 10 years. Figure 3 displays decompositions of the variance of the sub-index forecast error averaged over the first and second five years. The figures are presented in the assumption of the Cholesky superposition, in which the variable that changes after other variables is specified last in their sequence, for example, the following schemes were used for the response and decomposition of the variance of the pol forecast error: $s o c-e c-p o l$.

\section{The results of the evaluation of the error correction model for sub-indices of globalization. Algeria}

\begin{tabular}{|c|c|c|c|}
\hline & $\Delta p o l_{t}$ & $\Delta e c_{t}$ & $\Delta s o c_{t}$ \\
\hline $\boldsymbol{\beta}^{\prime} \boldsymbol{X}_{t-1}$ & $-0.458^{\star * *}$ & $0.197^{\star \star \star}$ & \\
\hline$\Delta p o l_{t-1}$ & $-0.360^{\star \star \star}$ & $-0.076^{\star \star}$ & -0.003 \\
\hline$\Delta p o l_{t-2}$ & -0.119 & $-0.081^{\star \star \star}$ & -0.005 \\
\hline$\Delta e c_{t-1}$ & $1.653^{\star \star \star}$ & -0.061 & 0.063 \\
\hline$\Delta e c_{t-2}$ & $1.602^{\star \star \star}$ & $-0.449^{\star \star \star}$ & $0.123^{\star \star}$ \\
\hline$\Delta s o c_{t-1}$ & -1.240 & 0.214 & -0.025 \\
\hline$\Delta s o c_{t-2}$ & -1.236 & $1.016^{\star \star \star}$ & 0.089 \\
\hline$D_{1991}$ & $-7.359^{\star}$ & $3.255^{\star \star \star}$ & -0.088 \\
\hline$D_{1995}$ & 5.603 & -0.311 & $1.976^{\star \star \star}$ \\
\hline$D U_{1989}$ & $10.888^{\star}$ & $3.173^{*}$ & $2.734^{\star \star \star}$ \\
\hline$D U_{1998}$ & $-27.860^{\star \star \star}$ & $-4.151^{\star \star \star}$ & 0.810 \\
\hline$D U_{2007}$ & $-25.184^{\star \star \star}$ & -1.242 & -0.0564 \\
\hline$D T_{1987}$ & $-0.534^{\star \star}$ & $0.201^{\star \star \star}$ & $-0.047^{\star}$ \\
\hline Const & $15.022^{\star \star \star}$ & $-6.020^{\star \star \star}$ & 0.448 \\
\hline$B I C$ & 6.708 & 4.114 & 2.685 \\
\hline$R-s q$ & 0.850 & 0.721 & 0.706 \\
\hline
\end{tabular}

Footnotes: 1 . The significance level of parameter estimation is specified: * $-10 \%{ }^{* \star}-5 \%$. ${ }^{\star \star \star}-1 \%$

2. Coefficient estimates for $\boldsymbol{\beta}^{\prime} \boldsymbol{X}_{t-1}$ presented for the case of normalization to $p o l$ 
The Granger test results for sub-indices of globalization, Algeria

\begin{tabular}{c|c|c|c} 
& \multicolumn{3}{|c}{$\chi^{2}$ statistics, $P$-value } \\
\cline { 2 - 4 } & to $\Delta p o l$ & to $\Delta e c$ & to $\Delta s o c$ \\
\hline$\Delta p o l$ & - & 0.005 & 0.928 \\
\hline$\Delta e c$ & 0.000 & - & 0.049 \\
\hline$\Delta s o c$ & 0.166 & 0.000 & - \\
\hline
\end{tabular}

Footnote: In the test equations, two lags of the first differences of the sub-indexes were used
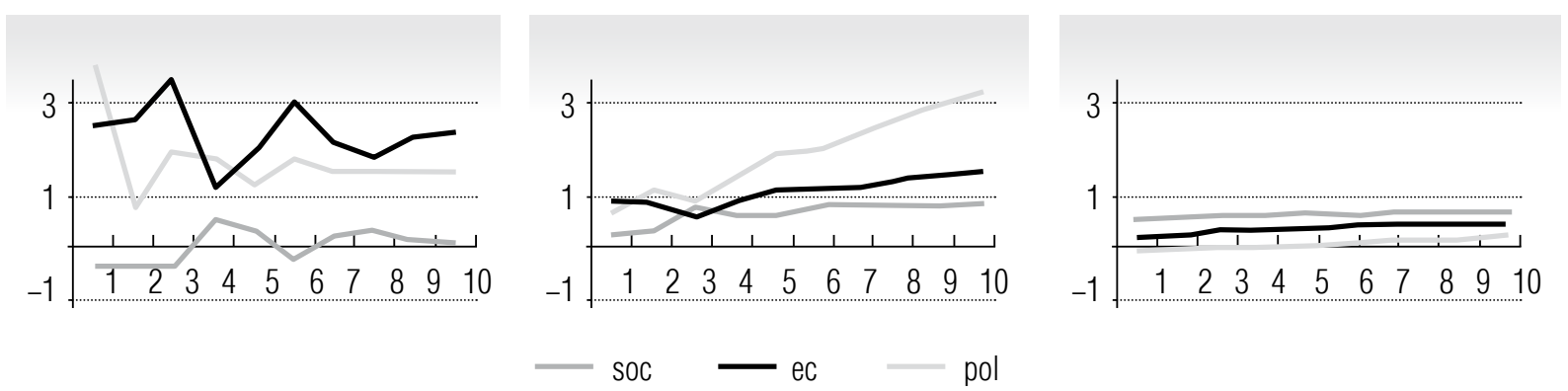

Fig 2. The value functions of impulse responses of the sub-indices of globalization of Algeria to shocks in them

From Table 3, the values of the determination coefficient show that the included variables sufficiently describe the short-term dynamics of all sub-indexes. Coefficient estimates for variables that correspond to structural shifts in sub-index trends are statistically significant ${ }^{2}$, which indicates that they need to be taken into account in the analysis. An insignificant estimate for the correcting term in the error correction model for the social globalization sub-index indicates a weak exogeneity of this variable relative to the VECM parameters, which means that if the system of globalization sub-indexes deviates from the long-term equilibrium, it is not corrected. This variable is not strictly exogenous, since it reveals Granger causality on the part of the sub-index of economic globalization. This corresponds to the statistical significance of the coefficient estimate for in the specified equa- tion. The responses of this sub-index to shocks in economic globalization are significant, although very weak ( 0.7 or less), and about $20 \%$ of the variance of the forecast error of this subindex is due to the dynamics of economic globalization. Responses of the social globalization sub-index to shocks in the political globalization sub-index are statistically insignificant. At the same time, the impact of social globalization shocks on political globalization is statistically insignificant, while the impact on economic globalization, although significant, is small (up to 1.0 ). Therefore, we can talk about the relative independence of social globalization in a country that does not respond well to the variability of external economic and political relations and has little or no impact on their development.

The sub-indexes of political and economic globalization are endogenous variables. Accord-

\footnotetext{
${ }^{2}$ Here and then the significance level of 0.05 was taken into account
} 
a)

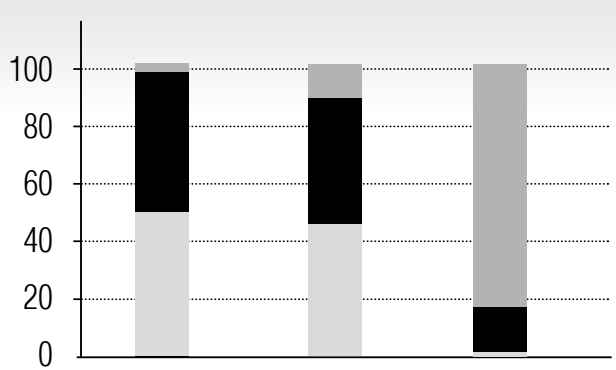

b)

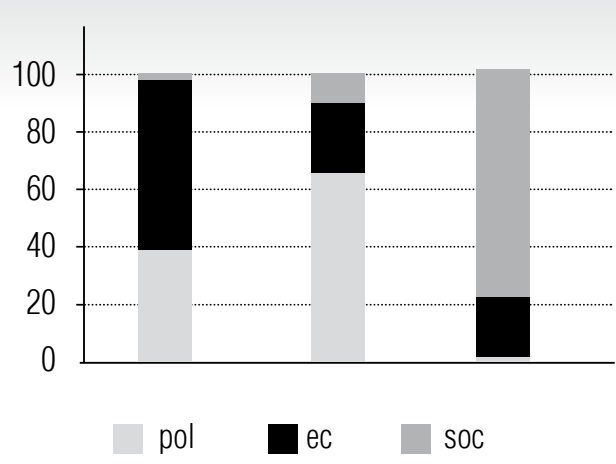

Fig 3. Decomposition of the average (for five years) variance of the forecast error of the globalization sub-indexes, Algeria a) the first five years, b) the last five years

ing to the results of Granger causality testing, they mutually condition each other in the shortterm dynamics. Based on the impulse response charts, it is clear that for the political sub-index, the most significant responses occur in the first half of the ten-year period. The greatest effect is almost instantaneous response from your own shocks. The shocks of economic globalization have a delayed and unstable effect. After the 5-th lag, the indicator of political globalization remains at a new, higher level. This uneven response behavior is also evident in the typical roughness of the political sub-index graph (Figure 1). For the sub-index of economic globalization, the response to the shock in political globalization has been growing almost monotonously throughout the decade, reaching a fairly high level by the end of the decade. This corresponds to the decomposition of the variance of the forecast errors of sub-indexes both of politi- cal and economic globalization and reveals the noticeable redistribution of the share of each component in the structure of the interdependence of political and economic globalization during the transition from the first five-years to the second one. Figure 3 shows that the role of foreign policy events in the formation of international economic relations in Algeria is more noticeable by the end of the decade, which indicates a certain inertia of their impact. This may explain the current downward trend in the level of economic globalization as a result of the sharp drop in the value of political globalization in 2007.

It should be noted that the result of applying the Johansen approach without taking into account structural shifts to the analyzed series did not contradict the above conclusion about the presence of a single cointegration ratio for the same model specification, however, the quality of the estimated model was much worse. Thus, the value of the Schwartz information criterion for such a model was $10 \%$ higher, and the assumptions about uncorrelated residues and normality were not fulfilled.

\subsection{Prediction of sub-indexes of globalization, Algeria}

ARIMA and HWM models were built to confirm the dynamic relationships identified, as well as to predict each sub-index. Tables 5 and 6 show some of the results of their evaluation. Table 5 demonstrates that the moments of structural shifts in the ARIMA models mostly coincide with the moments figuring in the VECM. The results of testing the residues of each model indicate a fairly correct choice of specification.

Table 6 shows the values of optimal smoothing parameters for HWM. Their small values for pol indicate that current information is poorly taken into account in forecasting, which may lead to under-accounting of structural shifts in the trend, especially impulse ones. 
Results of evaluation of ARIMA-models of sub-indexes of globalization. Algeria

Table 5.

\begin{tabular}{c|c|c|c} 
Sub-indexes & $e c$ & $p o l$ & $s O c$ \\
\hline Exogenous variable & $D T_{1987}, D T_{2007}$ & $D U_{1998}$ & $D_{1995}, D T_{2007}, D U_{1989}$ \\
\hline$q$ & 1.3 & 1 & 0 \\
\hline$L M$-test. 2 lags. $P$-value & 0.467 & 0.492 & 0.770 \\
\hline$J B$-test. $P$-value & 0.942 & 0.067 & 0.374 \\
\hline
\end{tabular}

Table 7 shows the results of an intra-sample forecast for one year for the entire sample for three models. It can be seen that for VECM, the root-mean-square error of the forecast for all series is the smallest. The MD test indicates that the difference between forecast errors for VECM and ARIMA is statistically significant for political globalization. Since the response to shocks in the sub-index of political globalization is delayed for economic globalization, it does not appear in the static forecast. At the same time HWM predicts all rows worse. This again suggests that structural shifts should be taken into account correctly, because this model does not explicitly provide for this.

In Table 8 similar results of an out-of-sample forecast calculated using a recursive scheme are presented. Again, as with the intra-election forecast, for political globalization, the forecast is better for the multidimensional model by at least 3 years. Although according to the $p$-values of the Mariano-Diebold test statistics, the difference between RMSE is statistically insignificant. For economic and social globalization, sub-indexes are better predicted using the ARIMA model, and this difference is statistically significant for economic globalization. Perhaps, here again, the effect of political globalization is delayed and begins to be felt only in the second five-year period.

Figure 6 shows a fragment of the series from 2001 to 2015 with a forecast for the period up to 2020. A solid line indicates the forecast for VECM, points - for the ARIMA, and a dotted line-for the HWM algorithm. The forecast for the KOF-index of globalization was calculated as the arithmetic average of the forecasts of individual sub-indices in accordance with the official method of its calculation [14]. The $80 \%$ confidence interval for the forecast of political and economic globalization subindices for VECM is shown in gray. It can be seen that the forecasts for the sub-index of economic globalization for all three models are in this range. Perhaps this is due to the fact that the strong shocks of the sub-index of political globalization which significantly affect its behavior have remained in the past. For polit-

Results of evaluation of HWM

Table 6.

\begin{tabular}{c|c|c|c} 
Smoothing parameters & ec & pol & soc \\
\hline$\lambda_{0}$ & 0.660 & 0.050 & 0.950 \\
\hline$\lambda_{1}$ & 0.610 & 0.090 & 0.290 \\
\hline
\end{tabular}




\section{Results of the intra-sample forecast of globalization sub-indexes,} Algeria (1971-2015), RMSE

\begin{tabular}{|c|c|c|c|}
\hline Model / Sub-indexes & pol & $e c$ & soc \\
\hline VECM & 3.755 & 1.026 & 0.502 \\
\hline ARIMA & 5.662 & 1.180 & 0.542 \\
\hline HWM & 6.928 & 1.891 & 0.828 \\
\hline \multicolumn{4}{|c|}{ MD (for VECM, ARIMA) } \\
\hline$P$-value & 0.009 & 0.219 & 0.117 \\
\hline
\end{tabular}

Results of the out-of-sample recursive forecast

Table 8. of globalization sub-indexes, Algeria (2011-2015)

\begin{tabular}{c|c|c|c|c|c|c|c|c|c}
\multirow{2}{*}{ Horizon } & \multicolumn{3}{|c|}{ eC } & \multicolumn{3}{c|}{ pol } & \multicolumn{3}{c}{ SOC } \\
\cline { 2 - 11 } & ARIMA & VEC & MD & ARIMA & VEC & MD & ARIMA & VEC & MID \\
\hline 1 & 1.208 & 1.934 & 0.138 & 9.766 & 5.807 & 0.313 & 0.730 & 0.822 & 0.413 \\
\hline 2 & 1.605 & 4.205 & 0.012 & 10.435 & 7.855 & 0.328 & 0.862 & 0.909 & 0.441 \\
\hline 3 & 1.787 & 6.508 & 0.000 & 12.508 & 11.349 & 0.386 & 1.328 & 1.444 & 0.112 \\
\hline 4 & 2.746 & 9.855 & 0.000 & 12.411 & 13.412 & 0.962 & 1.925 & 2.062 & 0.298 \\
\hline 5 & 4.030 & 13.938 & 0.000 & 11.440 & 16.393 & 0.489 & 2.634 & 2.903 & 0.211 \\
\hline
\end{tabular}

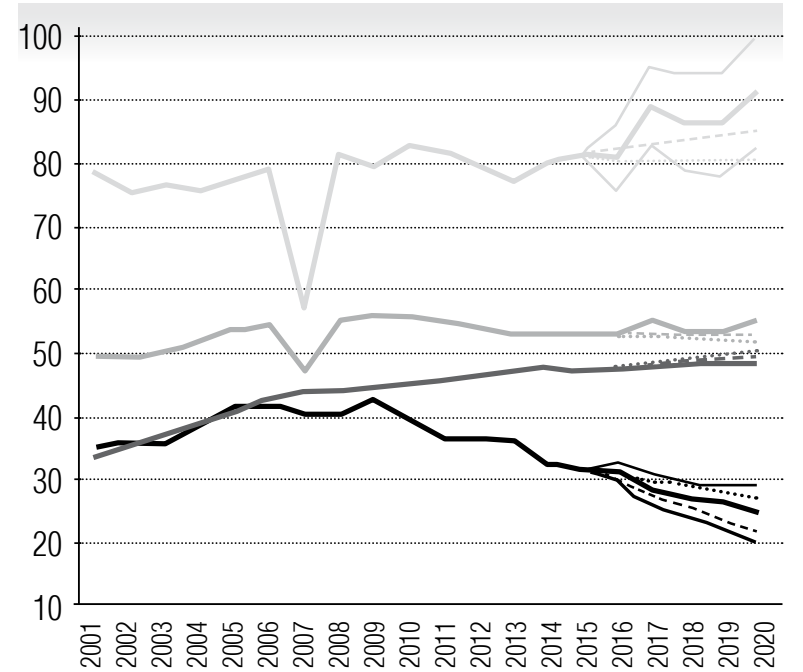

SOC $\quad \mathrm{ec}=\mathrm{pol}=\mathrm{kof}$

Fig 6. Forecast of globalization sub-indexes until 2020, Algeria ical globalization, forecasts for models vary, and do not always fall within the specified confidence interval. Forecasts of the social globalization sub-index for different models are almost identical, which corresponds to its relative independence in the sub-index system. Forecasts for the KOF-index of globalization are also almost identical, however, the graph still indicates a slight overestimation of the forecast for the VECM.

Thus, the formation of the KOF-index of globalization for Algeria is largely due to the mutual influence of its components. The weak growth of the sub-index of political globalization is formed mainly as a result of changes in the sphere of economic and political external relations. Economic globalization has a nega- 
tive trend. The direct impact of political globalization on it which is noticeable in the shortterm dynamics is not able to reverse this trend, perhaps because of the strong variability of the process of political globalization. Stabilization of the overall level of globalization in this country is provided by the positive dynamics of social globalization, which is formed almost self-sufficient, thanks to the rapid development of social networks and mobile communications. However, its role for political and economic integration in Algeria is small.

\section{Conclusion}

Approbation of the research methodology using the tools of cointegration analysis of random processes taking into account structural shifts in the parameters of their trends, as well as comparison of the predictive ability of onedimensional and multi-dimensional models indicated its effectiveness and the possibility of further use in such tasks. This study will contribute to the development of a methodology for predicting globalization indicators in countries where their dynamics are unstable.

\section{References}

1. Weiß J., Sachs A., Weinelt H. (2018) Globalization report 2018. Who benefits most from globalization. Available at: https://www.bertelsmann-stiftung.de/en/publications/publication/did/globalization-report-2018/ (accessed 20 April 2019).

2. Sufian F., Kamarudin F. (2016) The impact of globalization on the performance of banks in South Africa. Review of International Business and Strategy, vol. 26, no 4, pp. 517-542. DOI: 10.1108/ribs-02-2016-0003.

3. Abramova I.O. (2010) Population of Africa in the new global economy. Moscow: Institute of African Studies, Russian Academy of Sciences (in Russian).

4. United Nations Department of Economic and Social Affairs (2009). World population prospects 2009. Washington, pp. 44-48.

5. Kabbaj O. (2003) The challenge of African development. New York: Oxford University Press.

6. Gromoglasova E.S. (2015) Globalization and public protest. International Trends, no 4 (43), pp. 57-73 (in Russian). DOI: 10.17994/IT.2015.13.4.43.4.

7. Vasiliev A.M., ed. (2014) “The Arab crisis” and its international consequences. Moscow: LENAND (in Russian).

8. Malysheva D.B., Rogozhin A.A., eds. (2012) Asia and Africa in the modern world politics. Moscow: IMEMO, Russian Academy of Sciences (in Russian).

9. Nwakanma P.C., Ibe R.C. (2014) Globalization and economic growth. An econometric dimension drawing evidence from Nigeria. International Review of Management and Business Research, vol. 3, no 2, pp. 771-778.

10.Ben Salha O. (2013) Labour market outcomes of economic globalisation in Tunisia: a preliminary assessment. The Journal of North African Studies, vol. 18, no 2, pp. 349-372. DOI: 10.1080/13629387.2012.739822.

11.Atif S.M., Srivastav M., Sauytbekova M., Arachchige U.K. (2012) Globalization and income inequality: A panel data analysis of 68 countries. MPRA Paper No 42385, University of Sydney. Available at: https://mpra.ub.uni-muenchen.de/42385/ (accessed 20 April 2019).

12.Simplice A. (2013) Globalization and Africa: Implications for human development. International Journal of Development Issues, vol. 12, no 3, pp. 213-238. DOI: 10.2139/ssrn.2493238.

13.Maddala G.S., Kim I.-M. (1998) Unit roots, cointegration, and structural change. Cambridge, UK: Cambridge University Press. DOI: 10.1017/CBO9780511751974.

14.Gygli S., Haelg F., Potrafke N., Sturm J.-E. (2019) The KOF Globalisation Index - revisited. Review of International Organizations, no 14, pp. 1-32. DOI: 10.1007/s11558-019-09357-X.

15.Virabov A.G. (2001) Algeria: The crisis of power (the crisis of the social system of Algeria and the prospects for its liberalization). Moscow: IIIBV.

16.Mills T.C., Markellos R.N. (2008) The econometric modeling of financial time series. New York: Cambridge University Press. DOI: 10.1017/CBO9780511817380.

17.Holt C.C. (2004) Forecasting seasonals and trends by exponentially weighted moving averages. International Journal of Forecasting, no 20, pp. 5-10. DOI: 10.1016/j.ijforecast.2003.09.015. 
18.Chatfield C., Yar M. (1988) Holt-Winters forecasting: Some practical issues. The Statistician, no 37, pp. 129-140. DOI: $10.2307 / 2348687$.

19.Dolado H., Jenkinson T., Sosvilla-Rivero S. (1990) Cointegration and unit roots. Journal of Economic Surveys, no 4, pp. 243-273.

20.Zivot E., Andrews D. (1992) Further evidence on the great crash, the oil price shock and the unit root hypothesis. Journal of Business and Economic Statistics, no 10, pp. 251-287.

21.Perron P. (1997) Further evidence from breaking trend functions in macroeconomic variables. Journal of Econometrics, no 80, pp. 355-385. DOI: 10.1016/S0304-4076(97)00049-3.

22.Clemente J., Montanes A., Reyes M. (1998) Testing for a unit root in variables with a double change in the mean. Economics Letters, no 59, pp. 175-182.

23.Lee J., Strazicich M.C. (2003) Minimum Lagrange multiplier unit root test with two structural breaks. The Review of Economics and Statistics, vol. 85, no 4, pp. 1082-1089. DOI: 10.1162/003465303772815961.

24.Lee J., Strazicich M.C. (2013) Minimum LM unit root test with one structural break. Economics Bulletin, vol. 33, no 4, pp. 2483-2492.

25.Johansen S. (1988) Statistical analysis of cointegration vectors. Journal of Economic Dynamics and Control, no 12 , pp. 231-254. DOI: 10.1016/0165-1889(88)90041-3.

26. Trenkler C. (2008) Bootstrapping systems cointegration tests with a prior adjustment for deterministic terms. Computational Statistics, vol. 23, no 1. pp. 19-39. DOI: 10.1017/S0266466608090087.

27.Doornik J.A., Hansen H. (2008) An omnibus test for univariate and multivariate normality. Oxford Bulletin of Economics and Statistics, no 70, pp. 927-939. DOI: 10.1111/j.1468-0084.2008.00537.x.

28.Lütkepohl H. (2007) New introduction to multiple time series analysis. New York: Springer-Verlag. DOI: $10.1017 / \mathrm{S} 0266466606000442$.

29.Schumacher C. (2007) Forecasting German GDP using alternative factor models based on large datasets Journal of Forecasting, no 26, pp. 271-302. DOI: 10.1002/for.1026.

30.Stock J.H., Watson M.W. (2009) Phillips curve inflation forecasts. Understanding inflation and the implications for monetary policy (eds. J. Fuhrer, Y.K. Kodrzycki, J.S. Little, G.P. Olivei). Cambridge: MIT Press, pp. 99-184. DOI: $10.2307 / 23274814$.

31.Turuntseva M. (2011) Evaluation of the quality of forecasts: the simplest methods. Russian Journal of Entrepreneurship, no 8-1, pp. 50-56 (in Russian).

32.Diebold F., Mariano R. (1995) Comparing predictive accuracy. Journal of Business and Economic Statistics, vol. 13, pp. 253-263. DOI: 10.1080/07350015.1995.10524599.

\section{About the authors}

\section{Elena D. Kopnova}

Cand. Sci. (Tech.);

Associate Professor, Department of Statistics and Data Analysis, Faculty of Economic Sciences,

National Research University Higher School of Economics,

20, Myasnitskaya Street, Moscow 101000, Russia;

E-mail: ekopnova@hse.ru

ORCID: 0000-0002-8429-141X

\section{Lilia A. Rodionova}

Cand. Sci. (Econ.);

Associate Professor, Department of Statistics and Data Analysis, Faculty of Economic Sciences, National Research University Higher School of Economics,

20, Myasnitskaya Street, Moscow 101000, Russia;

E-mail: 1rodionova@hse.ru

ORCID: 0000-0002-0310-6359 


\title{
The formation and development of the performance assessment method in the conception of operational management
}

Mikhail B. Zuev ${ }^{\mathrm{a}}$

E-mail:m.zuev25@mail.ru

Boris P. Zuev ${ }^{\text {a }}$

E-mail: zuevboria@yandex.ru

\section{Irina N. Bulgakova ${ }^{\mathrm{b}}$}

E-mail: Bulgakova-IN@yandex.ru

${ }^{a}$ Oil Component Ltd.

Address: 8, Heroes of Hassan Street, Perm 614000, Russia

${ }^{\mathrm{b}}$ Voronezh State University

Address: 1, University Square, Voronezh 394006, Russia

\begin{abstract}
This article is devoted to the integrated performance assessment method - an improved version of the earned value management. It provides a description of the key features and benefits of practical application of the performance assessment method to develop estimates and forecasts of activity. It sets out the authors' opinion about the performance assessment method for execution of key performance indicators in a balanced scorecard. The article touches upon the problems of management due to the unsettled terminology among managers, and various interpretations of the terms: efficiency, effectiveness and economy in management, and proposes a definition to align terminology to uniformity. It provides in a graphical way the vector system: efficiency as the resulting vector of activities obtained from multiplying the vectors of productivity and efficiency, orthogonal to the plane of the multiplied vectors. It gives a conceptual model of the organizational structure of management and cooperation of stakeholders, which opens opportunities for the economic growth of the enterprise, its protection from external or internal risks, both managerial and technological.
\end{abstract}


Key words: performance assessment method; efficiency; effectiveness; economy; management; key performance indicator; performance management system.

Citation: Zuev M.B., Zuev B.P., Bulgakova I.N. (2020) The formation and development of the performance assessment method in the conception of operational management. Business Informatics, vol. 14, no 1, pp. 75-84. DOI: 10.17323/2587-814X.2020.1.75.84

\section{Introduction}

$\mathrm{W}$ hen making management decisions, the object of research (management processes) can be divided into two directions, highlighting the processes of strategic and operational management. Strategic management is intended to direct management's impact on ensuring the future competitive superiority of the organization. The operational management process is aimed, in turn, at ensuring the periodic work of the organization to achieve the main objectives.

To assess the effectiveness of management in Russian practice, we most often use economic performance, production indicators, financial and economic indicators taken separately or in combination with each other.

Among the foreign methods of assessing the effectiveness of management, the most popular are:

DuPont model [1];

$\downarrow$ the French concept of efficiency management Tableau De Bord [2], which has been developed in the works of Eve Cheapello and Michel Lebas [3];

$\downarrow$ Lorenz Meisel's model [4], which focuses on staff development;

$\checkmark$ effective progress and performance measurement (EP2M) model developed by Christopher Adams and Peter Roberts [5];

$\downarrow$ business activity control indicators (key performance indicators, KPI) [6];

balanced scorecard system - strategic planning system by R. Kaplan and D.P. Norton [7].

One of the main reasons for the inefficiency of operational management in various production areas is the use of the most popular method of management today - manual, "on the peephole." Management experts stress that better management requires more attention to be paid to the lack of tools to assess effectiveness and quickly monitor what you are doing $[8,9]$. According to PricewaterhouseCoopers, $61 \%$ of Russian representatives note the need to adjust the set of performance management indicators of the company [10].

The transition to technological system management through targeted change requires addressing the problem of the "nontechnological behavior" of participants, both with mandatory planning and implementation of these plans. In order to raise the technological improvement of management, the success of the tasks and the accuracy of the management decisions taken, it is necessary to have a set of tools that make up a real management system, an integral part of which are not only "levers and pedals" but also the ability to measure performance indicators and deviate from plans, or rather, tools to assess and predict the effectiveness of the process and result of performance, new alternative methods of measuring non-financial indicators. The need for such a measurement is explained by the possibility of achieving only a measurable result. 


\section{Theoretical approaches to determining effectiveness}

The results of the management decisionmaking process are ensured by the experience of managers, their competence and skills in the use of modern methods and tools to achieve the desired goal, as well as a mandatory understanding of the nature of performance indicators, primarily efficiency of activity. Otherwise, purposeful and efficient (effective and cost-effective) management of activities is almost impossible.

It so happened that the popular phrase "efficiency of activity" today does not have a clear, well-established definition, reflecting the meaning and clearly giving an image of efficiency of activity or management of activities. The conclusion is that the image of efficiency is not used in practice which is mathematically accurate and unquestionably accepted by the management community, and the existing terms differ in meaning.

Modern management theory has a wide range of methods for evaluating and analyzing performance. Their use provides an opportunity to study the structure of the organization (from top to bottom), the relationship between structural units, generalization of planning and implementation in the overall management strategy. Existing methodologies can be based on the Six Sigma strategy [11], activity based costing $(\mathrm{ABC})[12,13]$, total quality management (TQM) [14], economic value added (EVA) $[15,16]$, integrated strategic measurement [17] and the theory of constraints (TOC) [18]. These approaches cannot fully meet the enterprise's management needs, as they are mostly theoretical rather than practical, making it difficult to obtain an acceptable result.

However, it is already obvious that the use of a performance indicator (result and pro- cess) is a prerequisite for quality and successful management.

First, let's deal with the term. Efficiency today may mean the following: efficiency, economic efficiency (economy), timeliness, performance, profitability, etc.

For example, ISO 9000:2015 [19] defines efficiency as the ratio between the result achieved and the resources used. What is the effectiveness of this definition? We can assume that we are talking about economic efficiency: economic efficiency - the ratio of the cost of the results of production (products and/or services) and costs (labor and means of production). The semantic similarity of definitions in this case is obvious.

ISO 9000:2015 also gives a rather controversial definition of performance: the degree of implementation of the planned activities and the achievement of the planned results. It is a fairly correct definition, but it is necessary to give a different, we believe, more accurate, definition using the words "relationship" and "result" and take into account the time factor in the definition.

These definitions clearly show the incompleteness and variability of understanding of the terminology used, including in the recommendation documents (state standards). The absence of a single terminology apparatus leads to low controllability of activities, all the more complex. There are no uniform criteria for planning, achieving and evaluating results, nor for processes.

Thus, assessing the success of management is presently used in two entities: economic efficiency (economy) and performance, which are determined with fairly high accuracy, but a single basic integral indicator, taking into account both components, for management purposes is not applied, and it is necessary and simple enough. 


\section{The universal structure of a comprehensive management system}

The basis of any measurement is the method. Management can only be effective when the method of assessing it is appropriate to reality and is used as a real management tool.

Our proposed model of an integrated performance management system provides for such a practical tool based on the performance assessment method, as the variant of the development of the earned value method, which has been repeatedly tested in practice.

Figure 1 presents a conceptual model of the organizational structure of the resulting management structure and the interaction of the participants.

The concept of the organizational structure of an integrated system is based on the following assumptions: $\downarrow$ participants operate in the overall industry;

$\downarrow$ the scope and boundaries of participants' interactions are determined by the overlap of their activities;

$\checkmark$ the resulting efficiency triangle has parameters set in the interaction (content, duration, cost);

$\downarrow$ the quality is determined by the consumer's estimate/price of the result;

$\checkmark$ the resulting efficiency triangle is limited by the risk ring;

$\downarrow$ the risk ring does not go beyond the tops of the interaction triangle;

$\checkmark$ the resource triangle limits the ability to change the parameters of the result (content, duration, cost);

$\downarrow$ activity (process and result) estimates are determined by a comparison of planned and actual values of the parameters of the resulting efficiency triangle.

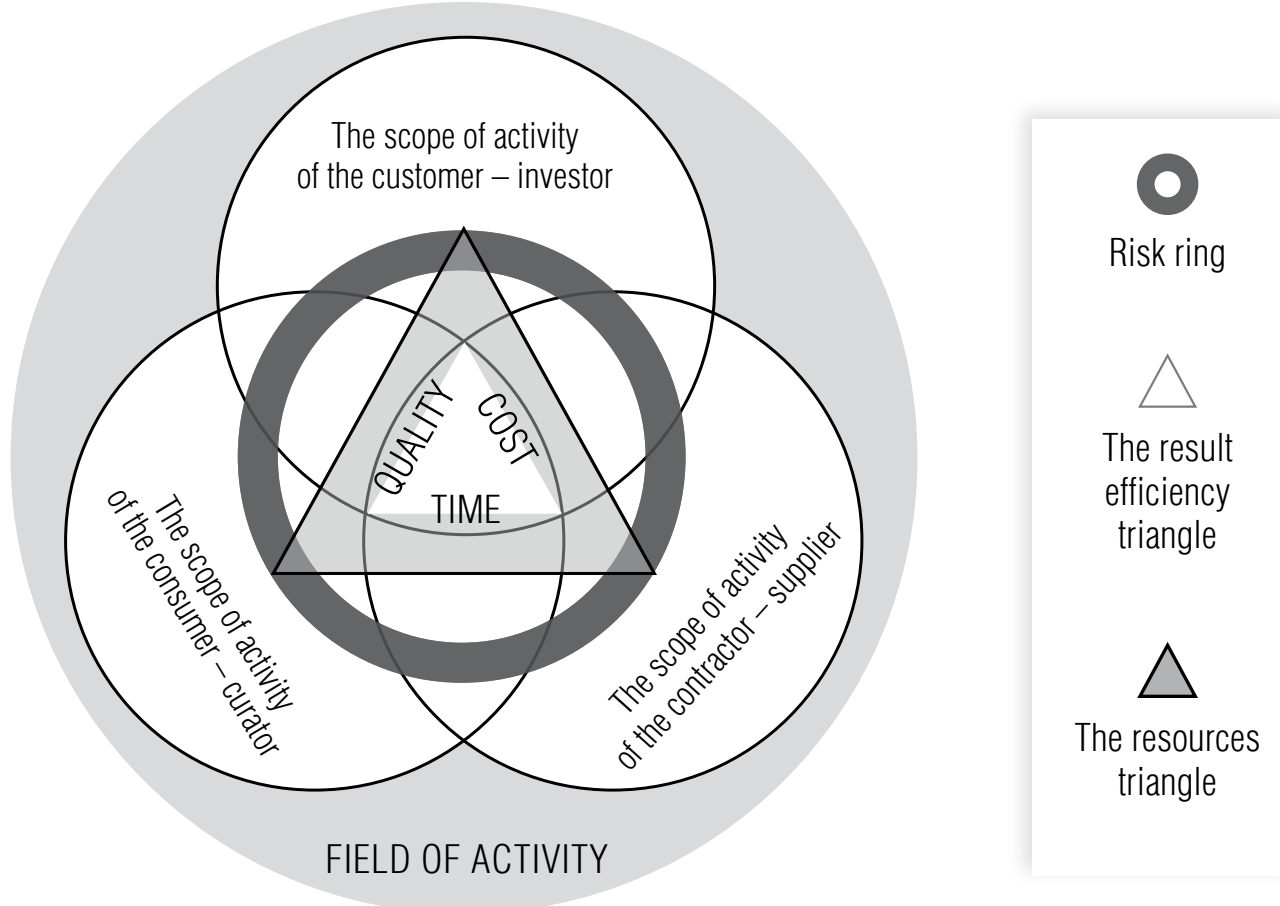

Fig. 1. Conceptual model of the interaction and resulting management structure 


\section{The image of efficiency and its use in a method for assessing the effectiveness of management}

A clear and mathematically defined image of efficiency is used to assess the performance assessment method by calculating performance and predicting performance indicators: Efficiency of activity is productivity based on efficiency (cost-effectiveness).

The performance assessment method, as well as the earned value method, measures $E A$ (efficiency of activity) at any given time in two parameters: $P$ (productivity) and $E$ (economy):

$$
E A=P \times E .
$$

This definition and formula for calculating efficiency allow for an integral assessment of management as a performance (taking into account the time factor) taking into account the resources spent on the actual result.

The performance assessment method allows you to assess the effectiveness of the performance both by result and by process, both employee or unit, and in general the company as a whole. This satisfies the main need of the manager - one numerical value to understand the situation at any implementation level of the task with an almost unlimited score (KPI, efficiency, etc.) and sub-tasks in the hierarchical structure of tasks.

This method makes it possible not only to evaluate the activity on a specific date, but also to predict the dynamics of indicators (efficiency, economy, profitability, timing of performance). Well-known approaches are applied: determining cost-effectiveness, as the ratio of the planned and actual cost of results; determining performance, as the ratio of actual and planned results taking into account the time factor when exceeding planned deadline.

However, despite the usual practice of using the earned value method abroad, in our country it does not find wide practical application in management. One reason is that users do not understand the image and meaning of calculated efficiency and find it difficult to calculate. We believe that the promotion of the performance assessment method (as a variant of the earned value method) will be facilitated by the visualization of the image of the activity and the system of its integral indicators, corresponding to the performance assessment method, if it is clearly presented in the form of an orthogonal system vectors at any given time (Figure 2). The direction of the actual efficiency of the activity vector is determined by the right-hand rule, by the shortest direction of rotation of the productivity vector to the efficiency vector.

Based on the formula and the definition of efficiency, let's present the efforts of doing business (efficiency and cost-effectiveness) as vectors aimed at achieving the result which is economically optimal. Then the efficiency of activity, as a result of the vector work of these vectors, is a vector orthogonal to the plane of the factor vectors (with direction according to the rule of the work of vectors) and numerically equal to the area of the rectangle built on these vectors:

$$
\overrightarrow{E A}=\vec{P} \times \vec{E}
$$

$E A$ (efficiency of activity) is a vector equal to that of two vectors: $P$ (productivity) and $E$ (efficiency). Efficiency can be imagined as an assessment of the usefulness of an activity by the size of the result (selling price, revenue, timeliness, volume of consumption, etc.) and in the direction (plus or minus).

Productivity is a vector (effort, ability, energy, aspiration, etc.) to achieve the planned (expected) result of activity.

Efficiency is a vector (effort, ability, energy, aspiration, etc.) to achieve optimal cost-effectiveness of the result of activity (optimal economic effect of activity).

So Figure 2 presents a way to determine (according to the rules of vector algebra) the 


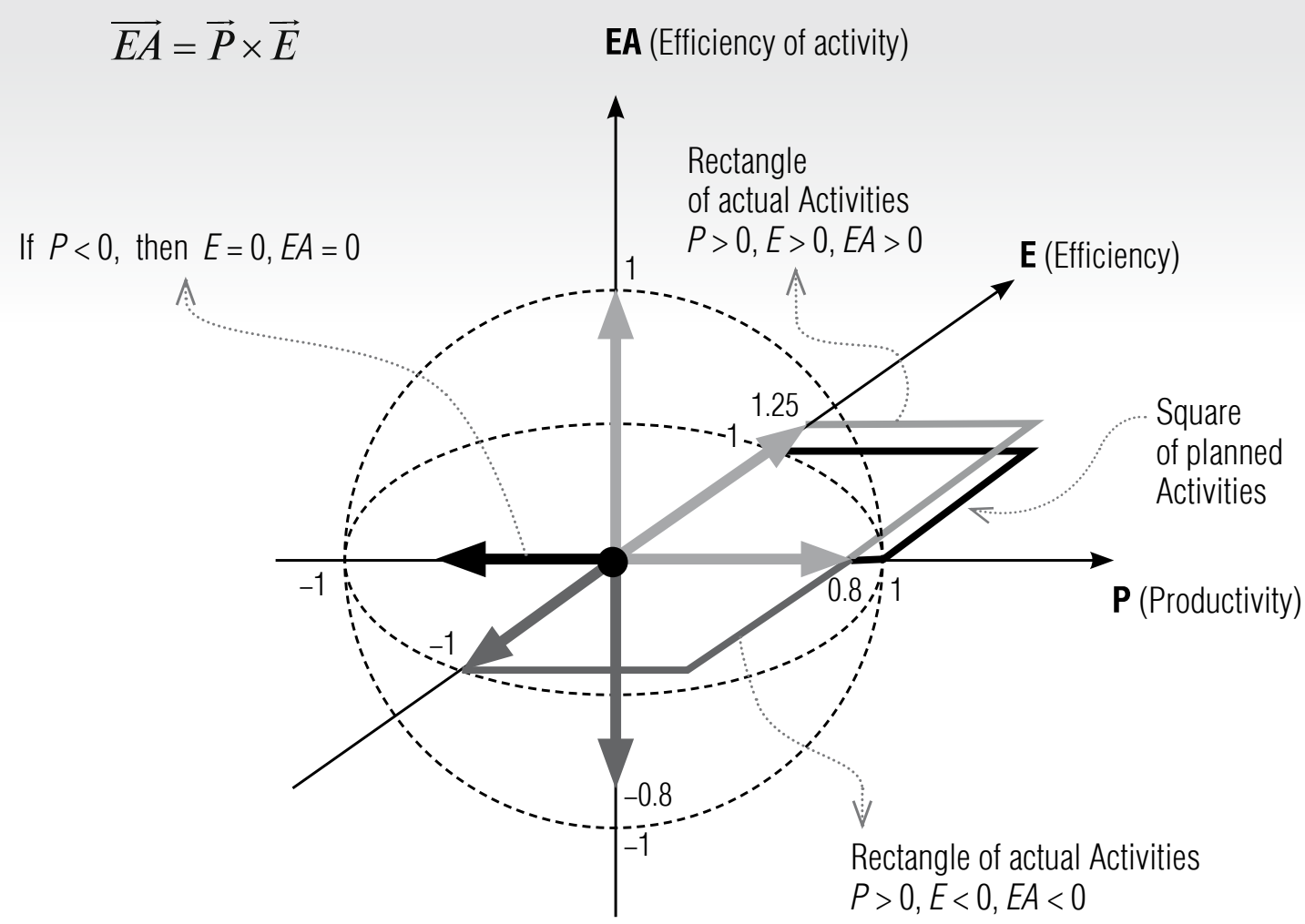

Fig. 2. Vector view of universal performance and management

assessment of the numerical value and direction of the efficiency vector in achieving the goal, as well as the problem of visibility of the image of efficiency and the activity itself and management of the process and result.

In this case, the productivity $(P)$ is calculated by the performance assessment method, as the ratio of the earned value $(E V)$ and the budget cost of the tasks planned for implementation $(P V)$, taking into account the ratio of planned and actual due date (SCT/ACT) according to the formula:

$$
P=\frac{E V}{V P} \times P S P I,
$$

where: $E V$ (Earned Value) is a well-developed volume (the planned cost of actually completed task volume; Budget Cost of Work Performed - BCWP);
$P V$ (Planned Value) is the budget cost of the planned task volume (the planned cost of the tasks planned for the project; Budget Cost of Work Scheduled - BCWS);

PSPI (Project Schedule Performance Index) is the index of project duration:

$$
P S P I=\frac{S C T}{A C T},
$$

where $S C T$ is the planned duration;

$A C T$ is the actual duration of the activity (if $A C T<S C T$, we take $P S P I=1$ for calculations).

Efficiency $(E)$ is calculated by the performance assessment method by comparing the cost of actual costs for the amount earned with the value of the earned value:

$$
E=1+\left(1-\frac{A C}{E V}\right) \times K p r .
$$


Profit Margin $(P M)$ can be calculated for commercial activity (when planning profits) under the efficiency formula.

In the formula (5) we accept:

$A C$ (Actual Cost) is the actual cost of the cost of the volume (Actual Cost of Work Performed, $A C W P$;

$K p r$ (Index Profit) is an index of transition from expense to profit (or specific planned expense for planned profit) that is accepted by an equal unit if profits are not planned. This is simply explained: if the activity is not aimed at making a profit, then the profit is not planned. In this case, both the profit and the expense directed to the profit, tend to zero (to the limit at a minimum).

The earnings transition index is defined as:

$$
K p r=\frac{P V}{P p r},
$$

where $P p r$ (planned profit)is the planned final profit at the end of the business.

The total universal performance formula (result and/or process) on cost-effectiveness or profit:

$$
E=\left[\frac{E V}{P V} \times P S P I\right] \times\left[1+\left(1-\frac{A C}{E V}\right) \times K p r\right] .
$$

In addition to the calculation formulas $(3,5$, 7) it should be noted that if the actual duration $(A C T)$ is less than the planned duration $(S C T)$, we take $P S P I=1$ for calculations; if one does not plan to make a profit, we'll take Kpr=1 for calculations.

\section{Practical application of the performance assessment method}

The performance assessment method is an advanced earned value method, the calculated formulas of which are added to determine corporate, inter-corporate and individual performance indicators: efficiency, efficiency, effi- ciency, profitability, timing, as well as forecasts used for management and motivation of activity.

In developing the performance assessment method, some problems have been solved and the shortcomings of the practical application of the earned value method have been eliminated:

There are many indicators of performance results, the assessments of which do not give accurate and unambiguous estimates and forecasts in general results and process of activity.

Solution: The cost of the earned volume is used as a universal measure of the proportion of each individual indicator (KPI) of a balanced system. The cost of the developed volumes is calculated through KPI in natural units. At the same time, both planned and actual KPIs should be specified in natural units of measurement. The integral volume of the task is equal to the amount of volumes mastered by KPI, which creates the ability to determine an integral assessment of performance (result or process) by one numerical value, including for tasks with multiple KPIs and many sub-tasks.

Estimates (indexes) do not take into account the time it takes to exceed the scheduled deadline.

Solution: The calculated formula includes a duration ratio equal to the planned duration to the actual $(S C T / A C T)$ applied when exceeding the planned period.

Reduce the reactive accuracy of the estimates to complete the task when used in the calculations of planned and actual data from the beginning of the task to the reporting date.

Solution: The calculation can be made at an arbitrary interval.

Formulas of the original earned value method do not allow us to calculate estimates on commercial profits (current and on completion) subject to profit planning.

Solution: the formula uses the unit expense index for profits. 
The management decision should be based on analysis and evaluation of information about the process and the interim result, with forecast of the effectiveness of the final result. Excessive or unstructured information inhibits decision-making, requiring additional time for analysis. Distorted or inaccurate information leads to errors and losses. To work with information, you need to choose the best activity management model to use a convenient performance assessment and forecasting system (results and process) where you can apply a combination of universal measurements to assessments: time and money [2326]. This will certainly give a multiple increase in overall productivity, lower costs (lean production) and increase profitability.

Taking for a specific weight of the result (KPI) the planned costs of its execution, it is easy to calculate the planned volume of the process in monetary units for each indicator at the time of assessment, as well as the planned volume of the result, with direct dependence of these volumes on the size of KPI in natural units of measurement, which, in our opinion, allows us to improve the reliability of information on the performance of these indicators.

This provides an opportunity to determine the volumes for each individual task and the enterprise as a whole, to calculate the performance, as the ratio of actual volume and planning based on the duration of execution, and to reduce to one certain value cost-effectiveness or profitability of the activity, and therefore calculate the efficiency of the activity as efficiency, taking into account economy or profitability.

\section{Conclusion}

Thus, managing the efficiency of the current activities, we get the necessary, planned results, provided that their achievement in force majeure does not go beyond restrictions on material resources and/or time. At the same time, universal, mutually transformable, com- plementary measures - time and money - are necessarily used for evaluations. This approach makes it possible to manage the process and the result purposefully.

Calculating integral indicators, primarily efficiency, is not an end in itself and allows for the use of actual assessments in the system of motivation and stimulation of activity, both personal and collective. In turn, the performance assessment method is used in the activity management system to determine deviations, which also makes it possible to make accurate and timely decisions in the management of process and outcome.

The simplicity and accessibility of the integrated performance assessment indicators at different levels of management enables participants to be involved in the management of different levels of work and perform different functions. This is fully in line with the opinion of the President of the Moscow branch of the Institute of Project Management V. Liberzon: “... an adequate project model (activity) should reflect reality so that it can be used for reliable planning and analysis in decision-making. Showing reality in practice means that:

$\downarrow$ element properties (processes, operations, functions, etc.) of the activity model include all the information that people use in planning and management;

$\downarrow$ information about resources and their assignments includes all the information that people use in planning and management;

$\downarrow$ resources are assigned in the same way as people do;

$\checkmark$ values are assigned in the same way as people do.” [27]

However, stimulating (forced) involvement in the management of joint activities of specific participants is not so much rational as motivational. Employee engagement and motivation is a key factor in the efficiency and management of activities. Motivation is a key task of HR management, for which a socially active 
employee should not be separated from the results of work by his own and his team and company. Thus, we are talking about a mechanism for understandable evaluation of work results, which is an important condition for the success of joint activities.

The practical application of the incentive and motivation system based on the indicators calculated by the performance assessment method [28] creates not only the economic growth of the enterprise, but also allows it to be protected in the event of external and/or internal risks, both managerial and production-technological, by reducing costs.
At the same time, the foregoing is part of a comprehensive business management system, and the performance assessment method can be applied in both corporate and inter-corporate joint management systems of various enterprises with different corporate cultures.

This approach enables purposeful and conscious management of the achievement of performance goals using the Balanced Scorecard system, which is simple enough if the enterprise has a system of planning, budgeting and management accounting of activities, and creates the prerequisites for the formation of intercorporate management systems.

\section{References}

1. Lytnev O.N. (2010) Strategic financial analysis using the DuPont model. Corporate finance management, no 3, pp. 158-171 (in Russian).

2. Redchenko K.I. (2003) Indicative disagreement: Balanced Scorecard and Tableau De Bord. Available at: http://www.e-xecutive.ru/knowledge/announce-ment/339363/?phrase_id=2806776 (accessed 17 March 2020) (in Russian).

3. Chiapello E., Lebas M. (1996) The Tableau de Bord, a French approach to management information. Presented at the 19th Annual Meeting of the European Accounting Association, Bergen, Norway, 2-4 May 1996.

4. Maisel L.S. (1992) Performance measurement. The balanced scorecard approach. Journal of Cost Management, Summer, pp. 45-62.

5. Adams C., Roberts P. (1993) You are what you measure. Manufacturing Europe. London: Sterling Publications, pp. 504-507.

6. Marr B. (2012) Key performance indicators. The 75 measures every manager needs to know. Harlow: Pearson.

7. Kaplan R.S., Norton D.P. (1996) Balanced Scorecard. Translating strategy into action. Harvard Business School Press.

8. Utenin V. (2011) The reasons for low efficiency of Russian companies. Corporate Management. Available at: https://www.cfin.ru/management/controlling/low_eff_reasons.shtml (accessed 17 March 2020) (in Russian).

9. Eskiev M.A., Aslahanova S.A., Beksultanova A.I. (2015) Effectiveness of the organization's management system. The main factors affecting the effectiveness. Young Scientist, no 23, pp. 689-692 (in Russian).

10. Lotakov I. (2019) Out of the shadows into the light flying. Russian business over the past 30 years through the eyes of its "parents" and "children". Available at: https://www.pwc.ru/ru/assets/knowledge-club/doing_business_in_ russia_rus_e-version.pdf (accessed 17 March 2020).

11.Kapterev A.V. (2012) Six Sigma business performance management concept and its application in Russia. Available at: https://gmpua.com/QM/Article/6Sigm/1/6sigma.pdf (accessed 12 January 2020) (in Russian).

12.Atamanov D.Yu. (2003) Cost apportionment using the traditional and activity based approaches. Journal of Marketing in Russia and Abroad, no 3, pp. 121-130 (in Russian).

13.Brimson J.A., Antos J. (1998) Driving value using activity based budgeting. New York: Wiley.

14.Khosrow D., ed. (1989) Quality control, robust design, and the Taguchi method. Pacific Grove, California: Wadsworth \& Brooks/Cole Advanced Books \& Software.

15.Ivashkovskaya I.V. (2004) Value based management: A challenge for Russian managers. Russian Management Journal, no 4, pp. 113-132 (in Russian).

16.Martin J.D., Petti J.W. (2000) Value based management: The corporate response to the shareholder revolution. Harvard Business School Press.

17.Gainullin A.I. (2015) About the specifics of the methodology of strategic enterprise management. Actual Directions of Scientific Research: From Theory to Practice, no 3 (5), pp. 377-380 (in Russian). 
18.Dettmer H.W. (1997) Goldratt's theory of constraints: A system approach to continuous improvement. Milwaukee, WI: ACQ Quality Press.

19.Standardinform (2015) GOST R ISO 9000-2015. Quality management systems. General terms and dictionary. Available at: http://docs.cntd.ru/document/1200124393 (accessed 11 January 2020).

20.Rach D.V. (2011) Method of graphical representation of indicators of the earned value. Project Management and Production Development, no (39), pp. 117-121 (in Russian).

21.Miloshevich D.Z. (2006) Project management toolkit. Moscow: AjTi; DMK Press (in Russian).

22.Levchenko A.Yu., Frei D.A. (2017) Problems of using the earned volume method for managing the cost of complex technological projects. Young Scientist, no 25, pp. 158-160 (in Russian).

23.Zuev B.P. (2014) Performance assessment method for evaluating performance in business management. Perm, PSU (in Russian).

24.Zuev B.P., Bulgakova I.N, Novosadov D.I. (2018) Integrated assessment of the practical effectiveness of management as the difficulty of achieving the goal. Proceedings of the International Scientific-Practical Conference on Methodology of Social and Humanitarian Sciences: Modern Context, Belgorod, 2018, part I, pp. 140-143 (in Russian).

25.Zuev M.B., Zuev B.P., Bulgakova I.N. (2019) The performance assessment method as a convenient tool for evaluating the effectiveness of activities (results and processes) in the field of management. Management in Russia and Abroad, no 5, pp. 11-18 (in Russian).

26.Zuev M.B., Zuev B.P., Bulgakova I.N. (2019) Modified earned value method for integrated efficiency assessment and forecasting of activities results in the field of management. Proceedings of the 1st International Scientific and Practical Conference "Project management: ideas, values, solutions”, Saint Petersburg, 2019, pp. 80-87 (in Russian).

27.Liberzon V. (2001) Project management. Management Today, no 5, pp. 2-8 (in Russian).

28.Zuev B.P. (2015) Performance assessment model. Integrated activity management system (practical model). Perm, PSU (in Russian).

\section{About the authors}

\section{Mikhail B. Zuev}

Adviser of the Director, Oil Component Ltd.

8, Heroes of Hassan Street, Perm 614000, Russia;

E-mail: m.zuev25@mail.ru

\section{Boris P. Zuev}

Technical Director of Performance Assessment Project, Oil Component Ltd., 8, Heroes of Hassan Street, Perm 614000, Russia;

E-mail: zuevboria@yandex.ru

\section{Irina N. Bulgakova}

D. Sci. (Econ.);

Associate Professor, Department of Mathematical Methods of Operations Research, Faculty of Applied Mathematics, Informatics and Mechanics, Voronezh State University, 1, University Square, Voronezh 394018, Russia;

E-mail: Bulgakova-IN@yandex.ru;

ORCID: 0000-0003-1779-5877 